Florida International University

FIU Digital Commons

$11-8-2019$

\title{
Elaborating the Causes and Consequences of Unstructured Socializing with Peers: A Consideration of Mediating, Reciprocal, and Nonlinear Effects
}

Robert Archer

Florida International University, rarch016@fiu.edu

Follow this and additional works at: https://digitalcommons.fiu.edu/etd

Part of the Other Social and Behavioral Sciences Commons

\section{Recommended Citation}

Archer, Robert, "Elaborating the Causes and Consequences of Unstructured Socializing with Peers: A Consideration of Mediating, Reciprocal, and Nonlinear Effects" (2019). FIU Electronic Theses and Dissertations. 4296.

https://digitalcommons.fiu.edu/etd/4296

This work is brought to you for free and open access by the University Graduate School at FIU Digital Commons. It has been accepted for inclusion in FIU Electronic Theses and Dissertations by an authorized administrator of FIU Digital Commons. For more information, please contact dcc@fiu.edu. 


\section{FLORIDA INTERNATIONAL UNIVERSITY}

Miami, Florida

\section{ELABORATING THE CAUSES AND CONSEQUENCES OF UNSTRUCTURED SOCIALIZING WITH PEERS: A CONSIDERATION OF MEDIATING, RECIPROCAL, AND NONLINEAR EFFECTS}

A dissertation submitted in partial fulfillment of the requirements for the degree of DOCTOR OF PHILOSOPHY

in INTERNATIONAL CRIME AND JUSTICE by Robert Joseph Lee Archer 
To: Dean John F. Stack, Jr.

Steven J. Green School of International and Public Affairs

This dissertation, written by Robert Joseph Lee Archer, and entitled Elaborating the Causes and Consequences of Unstructured Socializing with Peers: A Consideration of Mediating, Reciprocal, and Nonlinear Effects, having been approved in respect to style and intellectual content, is referred to you for judgment.

We have read this dissertation and recommend that it be approved.

Stephen F. Pires

Elisa M. Trucco

Jamie L. Flexon, Co-Major Professor

Ryan C. Meldrum, Co-Major Professor

Date of Defense: November 8, 2019

The dissertation of Robert Joseph Lee Archer is approved.

Dean John F. Stack, Jr. Steven J. Green School of International and Public Affairs

Andrés G. Gil

Vice President for Research and Economic Development and Dean of the University Graduate School

Florida International University, 2019 
(C) Copyright 2019 by Robert Joseph Lee Archer

All rights reserved. 


\section{DEDICATION}

I would like to dedicate this dissertation to my loving and supportive family. For one, to my mother, and although he is no longer here with me on earth, to my father. To my supporting wife, and also to my most missed companion, my dog Knight. Without all of your support and love, I would not have made it through the Ph.D. program and this dissertation. 


\section{ACKNOWLEDGMENTS}

Many individuals have played an important role in the completion of this dissertation, and to all of them I am forever grateful. First, I would like to thank Dr. Ryan Meldrum for his continued guidance, mentorship, review of my work, and to the many hours he has spent shaping me into what I am today. Without his continued devotion toward my success, it would not be possible to be where I am now. The change from when I first approached him when entering the doctoral program with no idea about what goes into crafting an academic journal article to where I am today is huge. I would also like to thank my dissertation committee members: Dr. Stephen Pires, Dr. Elisa Trucco, and especially Dr. Jamie Flexon. Without the continued support and replies to several emails sent by me to Dr. Flexon, I would not have been able to complete the methodology portion of this dissertation. I would also like to thank Dr. Rosa Chang for the time we worked together during my doctoral studies at Florida International University.

Next, I would like to express gratitude toward my parents. First, to my mother for her continued support. Next, I am grateful for the constant support my father showed me throughout his entire life and constant hard work to provide a better life for my mother and myself. For that, I am forever grateful. Although he is looking down on me from above, I know that he will be bragging about me in heaven (thanks dad). I am also highly appreciative of my wife Alaiza for her constant love and support. With you by my side, we can conquer the world. In addition, although you are in heaven with my father, I want to thank my dog Knight for all the love he showed me while he was by my side and to my dogs Daisy and Timber as well. 
Last, I want to thank my closest friends for their support and always being there for me through the good times and the hard times. Indeed, Austin, Caleb, Victoria, Monica, Melody, and Talia are my life long best friends. 


\section{ABSTRACT OF THE DISSERTATION \\ ELABORATING THE CAUSES AND CONSEQUENCES OF UNSTRUCTURED \\ SOCIALIZING WITH PEERS: A CONSIDERATION OF MEDIATING, RECIPROCAL, AND NONLINEAR EFFECTS \\ by}

Robert Joseph Lee Archer

Florida International University, 2019

Miami, Florida

Professor Ryan C. Meldrum, Co-Major Professor

Professor Jamie L. Flexon, Co-Major Professor

An abundance of research provides evidence that unstructured socializing with peers (USWP) is positively associated with a wide variety of delinquent acts. What remains less clear is the degree with which proximate and more distal variables affect this association, the reciprocal nature of theoretically important variables implicated in the relationship between USWP and deviance, and whether these mechanisms are nonlinear. This lack of clarity represents significant voids in the research examining USWP and deviancy and gives rise to the purpose of the present work.

While a number of approaches have been used to nest research examining USWP, the routine activity theory of general deviance (Osgood, Wilson, O'Malley, Bachman, \& Johnston, 1996) is particularly well-positioned to provide a foundation for this line of inquiry and will be used to guide the current effort. Indeed, the three essential components of USWP described by Osgood and colleagues (1996) (the presence of peers, lack of structure, and absence of authority figures) are highly conducive to deviance. The 
presence of peers makes deviance easier and more rewarding, a lack of structure leaves greater opportunities for deviance, and an absence of authority figures removes individuals like parents or teachers who would be in a position to prevent deviance or put a stop to deviance when it occurs.

In furtherance of the above objectives, data was collected from students in early adolescence as part of the longitudinal Gang Resistance Education and Training (GREAT) program. The first analysis in this dissertation examined whether the influence of parental knowledge on delinquency operated indirectly through both USWP and peer delinquency. Second, the relationship of USWP and delinquency was investigated over time to determine if this relationship may be reciprocal. Third, the possible nonlinear nature of the relationship between USWP and antisocial behavior was assessed.

Three findings emerged from these analyses. First, the relationship between parental knowledge and delinquency/substance use is mediated by both USWP and peer delinquency/substance use. Second, USWP and property delinquency have reciprocal effects on one another, such that USWP predicts property delinquency, and property delinquency predicts USWP. This pattern of reciprocal effects also emerged when the focus was the relationship between USWP and substance use. Third, the relationship between USWP and property delinquency is nonlinear, with a decelerating effect, meaning the positive effect of USWP on property delinquency weakens at greater amounts of USWP. A similar finding emerged when examining the relationship between USWP and substance use. This dissertation concludes with a discussion of the implications of these findings for policy and theory, study limitations, as well as directions for future research. 


\section{TABLE OF CONTENTS}

CHAPTER

PAGE

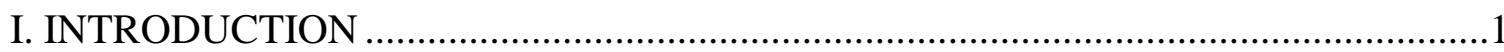

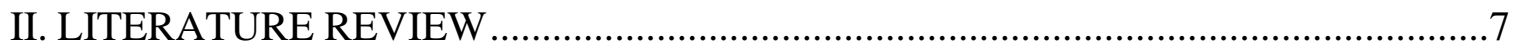

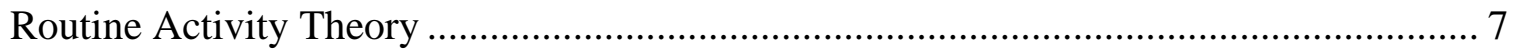

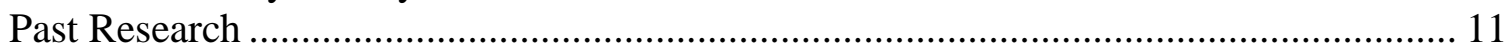

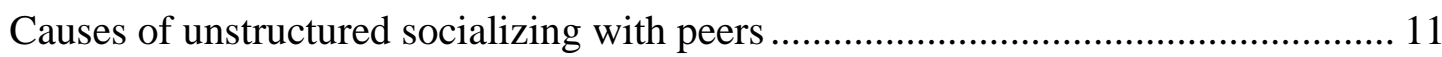

Development of unstructured socializing with peers................................................ 16

Consequences of unstructured socializing with peers. …………………………...... 18

Unstructured socializing with peers and mediating effects. ..................................... 25

Unstructured socializing with peers and reciprocal effects. ....................................... 30

Nonlinear effects of unstructured socializing with peers on antisocial behavior. ...... 32

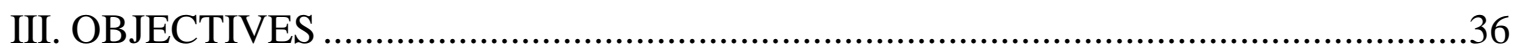

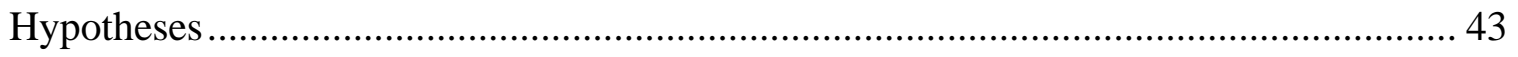

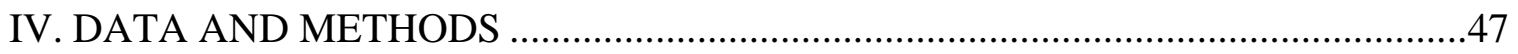

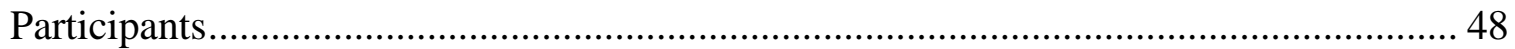

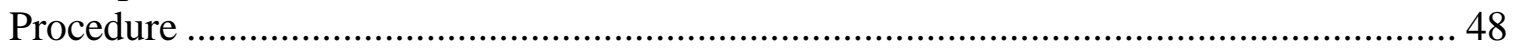

Study 1 (Multiple Mediation) Measures ..................................................................... 49

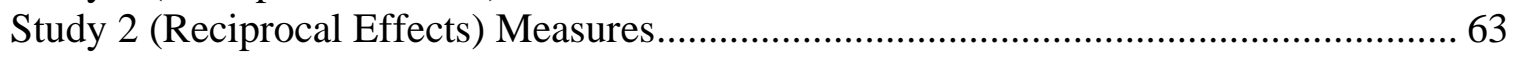

Study 3 (Nonlinear effects) Measures.......................................................................... 72

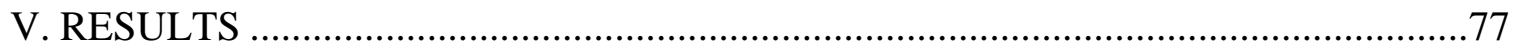

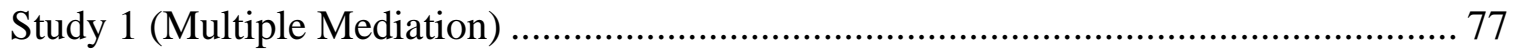

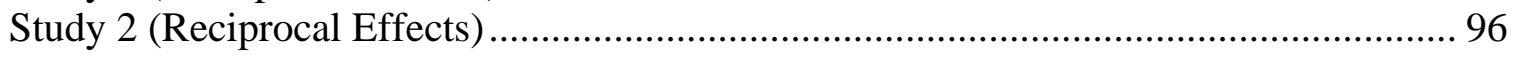

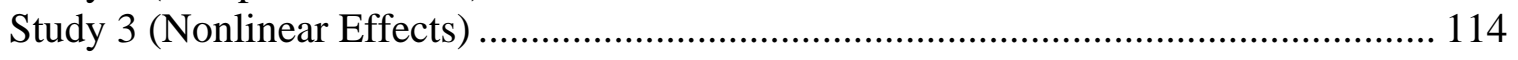

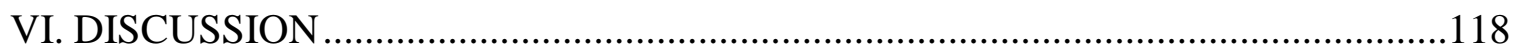

Study 1 (Multiple Mediation) ........................................................................... 118

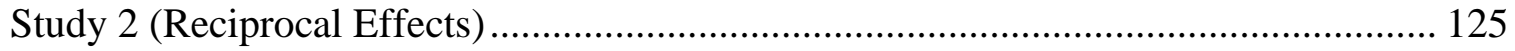

Study 3 (Nonlinear Effects) ……………………………..................................... 132

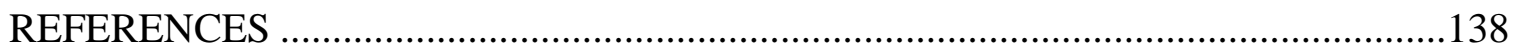

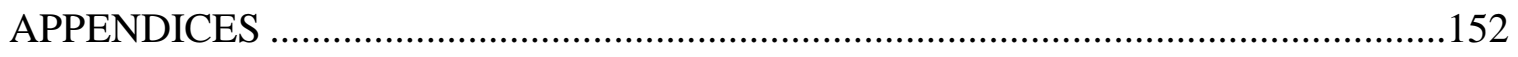

VITA … 


\section{LIST OF TABLES}

TABLE

PAGE

Table 1. Descriptive Statistics of Latent Variables for Mediation Models....................... 54

Table 2. Descriptive Statistics of Variables for Mediation Models ................................ 58

Table 3. Descriptive Statistics of Latent Variables for Reciprocal Effects Models ........ 65

Table 4. Descriptive Statistics of Variables for Reciprocal Effects Models.................... 70

Table 5. Descriptive Statistics for Nonlinear Effects Models...................................... 75

Table 6. Weighted Least Squares with Mean and Variance Adjusted Estimates of

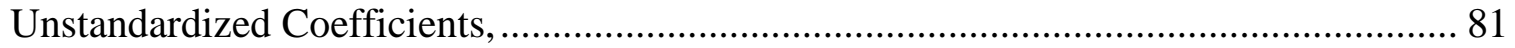

Table 7. Weighted Least Squares with Mean and Variance Adjusted Estimates of Unstandardized Coefficients, Standard Errors, and Standardized Coefficients for Violent Delinquency Mediation Model

Table 8. Weighted Least Squares with Mean and Variance Adjusted Estimates of Unstandardized Coefficients

Table 9. Maximum Likelihood Estimation of Unstandardized Coefficients, Standard Errors, and Standardized Coefficients for Property Delinquency Reciprocal Effects Model

Table 10. Maximum Likelihood Estimation of Unstandardized Coefficients, Standard Errors, and Standardized Coefficients for Violent Delinquency Reciprocal Effects Model

Table 11. Maximum Likelihood Estimation of Unstandardized Coefficients, Standard Errors, and Standardized Coefficients for Substance Use Reciprocal Effects Model .... 111

Table 12. Negative Binomial and Poisson Regressions of Unstructured Socializing on Property Delinquency, Violent Delinquency, and Substance Use 


\section{LIST OF FIGURES}

FIGURE

PAGE

Figure 1. Hypothesized Causal Mediation Models ...................................................... 38

Figure 2. Hypothetical Causal Reciprocal Effects Models ........................................ 40

Figure 3. Hypothesized Model Demonstrating an Accelerating Effect .......................... 42

Figure 4. Hypothesized Model Demonstrating a Decelerating Effect ........................... 43

Figure 5. Property Delinquency Mediation Model with Significant Pathways and

Standardized Coefficients $(\mathrm{N}=1,616)$

Figure 6. Violent Delinquency Mediation Model with Significant Pathways and

Standardized Coefficients $(\mathrm{N}=1,610)$

Figure 7. Substance Use Mediation Model with Significant Pathways and

Standardized Coefficients $(\mathrm{N}=1,604)$ 95

Figure 8. Property Delinquency Reciprocal Effects Model with Significant Pathways and Standardized Coefficients $(\mathrm{N}=1,675)$.

Figure 9. Violent Delinquency Reciprocal Effects Model with Significant Pathways, Standard Errors, and Standardized Coefficients $(\mathrm{N}=1,670)$

Figure 10. Substance Use Reciprocal Effects Model with Significant Pathways,

Standard Errors, and Standardized Coefficients $(\mathrm{N}=1,665)$ 113 


\section{INTRODUCTION}

Situational theories of crime contend that several proximal causes of crime are found in the immediate context of behavior. These situations commonly include where the individuals are, who they are with, and what they are doing. Such approaches have proven to be useful for explaining why some situations lead to crime, others do not, and why the same individual offends in some situations but not others (Pervin, 1978). One such crime-inducive situation is unsupervised peer-oriented social activities during adolescence.

Social control theory (Hirschi, 1969), subcultural theory (Cohen, 1955), and multiple strain theories (Cohen, 1955; Cloward \& Ohlin, 1960; Merton, 1938) have been used to explain the influence of time spent in unsupervised peer-oriented social activities, such as hanging out and riding around in a car, on antisocial behavior (Agnew \& Peterson, 1989). However, the most prominent explanation for why such activities relate to antisocial behavior is the reformulation of routine activities theory (RAT) by Osgood, Wilson, O’Malley, Bachman, and Johnston (1996). This theory, coined the routine activity theory of general deviance, was derived from the basic tenets of RAT (Cohen \& Felson, 1979; Felson, 1998).

Commonly viewed as a theory of victimization, RAT contends crime is dependent upon the circumstances in which offenders carry out predatory criminal acts (Cohen \& Felson, 1979). According to the theory, the convergence of three elements are necessary for a predatory crime to occur: (1) motivated offenders, (2) suitable targets, and (3) an absence of capable guardians. A lack of any one of these elements is sufficient to prevent a crime from happening. Cohen and Felson's (1979) RAT was originally focused to 
explain offending among the individual; however, the perspective was reformulated by Osgood and colleagues (1996) to better explain patterns of situational offending. Osgood et al. (1996) argue that a situation is more conducive to deviance when it lacks structure (e.g., joyriding in a car), when peers are present, and if no authority figure (i.e., someone whose duty in a situation is to exert social control) is present. Thus, unstructured socializing with peers (USWP) describes a situation characterized by these factors.

As the principal test of whether USWP is related to delinquency, Osgood et al. (1996) found that routine activities, such as riding around in a car for fun and recreation, getting together with friends informally, going to parties, and spending evenings out for fun and recreation were each positively associated with within-individual changes (i.e., causes inferred from changes within individuals) for at least three of the five deviant behaviors examined (criminal behavior, heavy alcohol use, marijuana use, other drug use, dangerous driving). Research has since supported Osgood et al.'s (1996) theory using cross-sectional and longitudinal designs, finding that adolescents who spend more time engaging in unstructured socializing have greater involvement in delinquency (Bernburg \& Thorlindsson, 2001; Gerstner \& Oberwittler, 2018; Haynie \& Osgood, 2005; Hoeben \& Weerman, 2016; Maimon \& Browning, 2010; Osgood \& Anderson, 2004). Narrative reviews have also been conducted on this topic and support the same general conclusion (Hoeben, Meldrum, Walker, \& Young, 2016).

Collectively, these studies reveal a distinct relationship between involvement in USWP and delinquency, which has been the primary focus of the literature on USWP. Three issues, however, have been neglected. First, there is a lack of research devoted to considering the multiple indirect pathways linking the causes and consequences of 
USWP. To be clear, some research has examined the processes that mediate the relationship between USWP and antisocial behavior (Bernasco et al., 2013; Greene \& Bamerjee, 2009; Hughes \& Short, 2014; Wong, 2005), and other studies have examined if USWP mediates the association between other factors and antisocial behavior (Bernburg \& Thorlindsson, 2001, 2007; Matsuda et al., 2013; Melde \& Esbensen, 2011; Osgood et al., 1996; Walters, 2017). Few studies, however, has examined these multiple associations together to assess multiple steps of mediation (Hoeben \& Weerman, 2016). Therefore, additional investigation is needed to better understand why adolescents who engage in unstructured socializing are at greater risk for antisocial behavior. Such a study that examines multiple indirect effects would not only speak to the validity of recent studies (e.g., Hoeben \& Weerman, 2016; Walters, 2017), but also provide an additional layer to complexity to the routine activity theory of general deviance proposed by Osgood and colleagues (1996).

Second, even though an abundance of research finds that USWP is positively associated with delinquency (for a review, see Hoeben et al., 2016), recent research suggests that delinquency may influence USWP (Fleming, et al., 2008; McHale, Crouter, \& Tucker, 2001; Melde \& Esbensen, 2011). Despite research linking USWP to antisocial behaviors such as delinquency, as well as recent findings suggesting delinquency may influence USWP, sufficient attention has not been devoted to whether the relationship between USWP and delinquency may be reciprocal. If evidence of this is found, such findings would suggest Osgood et al.'s (1996) theory requires modification to account for the complex interplay between USWP and delinquency. Further, while Osgood and colleagues' (1996) assertions that USWP results in delinquency is clearly supported 
through research, if findings produced from this dissertation support a relationship between delinquency and later USWP, Osgood et al.'s (1996) theory may not be as empirically valid as previously suggested.

Third, what Osgood and colleagues' theory does not specify is the extent to which spending more time in USWP may increase antisocial behavior in a nonlinear manner, either accelerating or decelerating. Findings supportive of a nonlinear effect would suggest that Osgood and colleagues' (1996) theory should be modified to consider more specifically whether spending greater time in USWP reveals an accelerating or decelerating effect on delinquency. Specifically, an accelerating effect would be observed if the more time an individual spends in USWP increases delinquency, particularly at higher amounts of USWP. Conversely, a decelerating (or diminishing) effect would be observed if the more time an individual spends in USWP increases delinquency, particularly at lower amounts of USWP, but the positive effect weakens or levels off at higher amounts of USWP. Such a study would serve to build on the limited prior research that already considers nonlinear effects of USWP on delinquency and substance use (Gage, Overpeck, Nansel and Kogan,2005; Meldrum \& Leimberg, 2018).

Overall, despite numerous studies examining the causes and consequences of USWP (Hoeben et al., 2016), few studies have examined USWP as a mediator of more distal factors influencing delinquency/substance use (Bernburg \& Thorlindsson, 2001, 2007; Matsuda et al., 2013; Melde \& Esbensen, 2011; Osgood et al., 1996; Walters, 2017), and, even fewer studies have examined the factors that mediate the relationship between USWP and delinquency/substance use (Bernasco, Raiter, Bruinsma, Pauwels, \& Weerman, 2013; Greene \& Bamerjee, 2009; Hoeben \& Weerman, 2016; Hughes \& Short, 
2014; Wong, 2005). Likewise, little empirical attention has focused on assessing the cross-lagged or reciprocal association between USWP and antisocial behavior (Fleming et al., 2008; McHale et al., 2001; Vasquez \& Zimmerman, 2014; Ward, Forney, \& Bennett, 2017). Finally, very little research examines the possibility of nonlinear effects of USWP on antisocial behaviors (Gage, et al., 2005; Meldrum \& Leimberg, 2018). This dissertation seeks to address each of these three issues to provide a better understanding of the causes and consequences of USWP.

This dissertation will proceed in the following order. Chapter 2 will be devoted to a review of prior theory and research. This includes the various theories that have been used as frameworks for understanding why USWP is related to antisocial behavior. Research on the causes of USWP, as well as the possible role of antisocial behavior in the etiology of USWP will then be reviewed. Following this, attention will be directed at how USWP may develop over time. Next, discussion will be given to USWP and its various consequences. Thereafter, studies will be reviewed focusing on USWP as a mediating variable between various distal factors and outcomes including antisocial behaviors, and the extent to which certain factors mediate the association between USWP and antisocial behavior. The chapter concludes by directing attention to studies suggesting the potential for reciprocal effects between USWP and delinquency and the possible nonlinear effects of USWP on delinquency and substance use.

Chapter 3 will discuss the objectives of the dissertation that includes greater detail as to how the studies presented in this dissertation will improve three areas of research relating to USWP. The specific hypotheses for each study will also be given. Thereafter, Chapter 4 will provide the methodology of the dissertation. This section will provide 
details of the data used to conduct each study and descriptions of the measures necessary to probe each hypothesis. The analytic plans and how missing data were dealt with will also be discussed.

Chapter 5 provides the results for the studies of the dissertation. The findings for the study that examines mediation will be first discussed, followed by results of the reciprocal effects studies, and finally, findings of the study which examined nonlinear effects. Figures of these findings will also be provided in studies one and two. In Chapter 6 discussion of the results pertaining to each study are given. Specifically, this section will review the results of each study and how these findings offer implications for theory and policy. Last, attention will be given to the limitations of each study and directions for future research. The remaining chapters of this dissertation will include a list of references, appendices, and vita. 


\section{LITERATURE REVIEW}

\section{Routine Activity Theory}

Essential to the theoretical framework of USWP is routine activity theory (RAT), established by Cohen and Felson (1979) as one of the most important advancements in criminological theory (Osgood et al., 1996). The underlining premise of RAT is that changes in people's routine activities may influence behavioral patterns. Routine activities are defined as "any recurrent and prevalent activities which provide for basic population and individual needs, whatever their biological or cultural origins" (Cohen \& Felson, 1979, p. 593). According to RAT, the structural nature of routine activities may influence trends in direct contact predatory violations, defined as illegal acts wherein "someone definitely and intentionally takes or damages the person or property of another" (Glaser, 1971, p. 4).

According to Cohen and Felson's (1979) routine activity perspective, environmental changes in routine activity patterns can influence crime rates due to the convergence in time and space of three key things: motivated offenders, suitable targets, and an absence of capable guardians. As a theory of opportunity, RAT contends that daily activities can increase the risk of criminal victimization while providing would be offenders with opportunities for engagement in delinquent and criminal behavior. Specifically, when a motivated offender establishes contact with a suitable target (e.g., an individual, motor vehicle, empty house, etc.), in the absence of a capable guardian (e.g., a household resident, security guard), antisocial behavior should be more likely to occur.

Even though RAT was initially developed to explain patterns of victimization and aggregate crime rates (Birbeck \& LaFree, 1993; Cohen, Cantor, \& Kluegel, 1981; 
Kennedy \& Forde, 1990; Messner \& Tardiff, 1985), the theory has since been reformulated to explain patterns of offending by individuals in particular settings (Osgood et al., 1996). The key assumption underlying the reformulation put forth by Osgood et al. (1996) replaces the element of motivated offenders found in RAT with the notion that "motivation resides in the deviant behavior itself" (p. 639). In other words, focus is given to motivation based on situational factors, rather than the offender's characteristics. In the context of USWP, such situational factors are implicit in unstructured activities, which leave more time available for individuals to engage in deviance than structured activities (e.g., employment, afterschool sporting activities).

Osgood and colleagues (1996) also departed from the original formulation of RAT by replacing the element of suitable targets with situations are more conducive to deviance, as they also made clear that the presence of friends makes deviant behavior both easier and more rewarding. The authors argued that peers can serve as useful resources, both as lookouts to increase the success of theft and as a source of protection if challenging a rival to a fight (Osgood et al., 1996). Therefore, spending more time with peers generates situations conducive to delinquency (Osgood et al., 1996). The likelihood of delinquency is further increased if authority figures (e.g., parents or guardians) are absent.

When revising RAT, rather than emphasizing an absence of capable guardians, Osgood et al. (1996) focused on contexts wherein situations that lack social control are more conducive to deviance than those where an authority figure is present. In doing so, they borrowed from Gibb's (1981) conceptual analysis of social control arguing that it is particularly useful for explaining why deviance is more likely in situations such as 
USWP, which lack social control. Gibbs (1981) defined social control as "the use of social means to manipulate the behavior of others" (p. 78). As absence of authority figures reduces social control, and therefore time spent in unstructured and unsupervised activities should increase the likelihood of delinquency (Osgood et al., 1996).

According to these preceding arguments, USWP is characterized by 1)

adolescents spend time with their friends, 2) in the absence of authority figures, and 3) without a specific agenda (Osgood et al., 1996). Under such conditions, there are greater opportunities for delinquent behavior. Given that three specific conditions are required for delinquency to occur, it is necessary to elucidate whether the reformulation of RAT can be applied to identify situational factors conducive to delinquency. One of the key tenets of RAT is that motivated offenders are a necessary element for predatory crime to occur (Cohen \& Felson, 1979). On the other hand, Osgood and colleagues (1996) posited that motivation derived from specific situational factors is the driver of delinquency. Thus, rather than focusing on individual characteristics, attention should be given to the potential role of these factors in USWP. The ideas noted above are not novel, as scholars have proposed similar explanations for some time. For one, Briar and Piliavin (1965) claim delinquency is "prompted by short-term situationally induced desires experienced by all boys to obtain valued goods" and to portray courage or be loyal while in the presence of peers (p. 36). Matza (1964) similarly noted that delinquency arises from "drift," or a state of openness to deviant values but not a rejection of conventional values. Concurring with these authors, Gold (1970) argued that delinquency can be viewed as a "pickup game" of basketball wherein deviance is often viewed as casual and spontaneous. 
Although not every situation gives rise to deviant behaviors, prior theories have helped pave the way for the routine activity theory of general deviance (Osgood et al., 1996). In Gottfredson and Hirschi's (1990) general theory of crime, the motivation for crime is posited to be "inherent in or limited to immediate gains provided by the act itself" (p. 256). The authors further purported that self-control in association with situational opportunities is responsible for virtually any kind of criminal behavior. However, according to Cornish and Clarke's (1986) rational choice theory, offending is based upon a self-interested appraisal of the costs and benefits of alternative methods of action, in which the action with the greatest perceived utility is taken, thus emphasizing the role of opportunity. This is in line with Osgood and colleagues (1996) routine activity theory of general deviance, which also focuses on opportunities for deviance.

With recognition to the above theoretical advancements, several lines of research have evolved examining USWP that focus on: 1) the causes of USWP (e.g., parenting practices), 2) the development of USWP over time, and 3) outcomes associated with USWP (e.g., non-violent, violent, and substance use behaviors as well as other behaviors). These different lines of research are instructive as they inform the three different sets of analyses that serve as the foci of later chapters of this dissertation. The different methodological approaches used in this prior work also inform the current study and call attention to the need to consider multiple mediation pathways, reciprocal effects, and nonlinear effects. The work by others in this area, then, is laudable and also shows that further exploration is clearly needed. The following sections review these areas of research and serve to couch the current approach. 


\section{Past Research}

Causes of unstructured socializing with peers. Osgood and colleagues' (1996) reformulation of RAT paved the way for research into the various causes of USWP. As part of this line of research, individual and contextual variables as sources of USWP have been examined (Bernburg \& Thorlindsson, 2001, 2007; Janssen, Bruinsma, Deković, \& Eichelsheim, 2016; Janssen, Deković, \& Bruinsma, 2014; Osgood \& Anderson, 2004), including adolescent autonomy (i.e., freedom from parental control) (Bernburg \& Thorlindsson, 2001; Goldstein, Davis-Kean, \& Eccles, 2005; Meldrum \& Piquero, 2017), gang involvement (Melde \& Esbensen, 2011; Taylor, Peterson, Esbensen, \& Freng, 2007), employment (Staff, Osgood, Schulenberg, Bachmanm \& Messersmith, 2010), and gang involvement Among these studies, the role of parenting practices was prominently featured as a precursor to USWP and therefore warrants further elaboration.

Adolescence is a stage in life when children spend greater time with peers away from their parents (Janssen et al., 2014). Parenting practices are crucial in this period as some children may not be able to set proper boundaries when seeking greater autonomy (Smetana, Campione-Barr, \& Metzger, 2006). In this respect, it is essential for parents to exert a level of control over adolescents' activities, while offering support to ensure open communication (Dishion \& Patterson, 2006). Given these assertions, past research has been conducted examining such factors. For example, in following work by Wikstrom and Butterworth (2006), Janssen et al. (2014) used data from the Peterborough Youth Study and found that greater parental oversight, stricter rules, and better parent-to-child relationship quality were associated with less USWP. An extension of that work demonstrated that more parental monitoring, greater rule-setting, and positive parent-to- 
child relationship quality operate indirectly through self-control to influence USWP (Janssen et al., 2016). Hence, low self-control is a more proximate factor associated with USWP than parenting practices. Results also indicate that the aforementioned parenting measures operate indirectly through delinquent attitudes to influence USWP, and tolerance to delinquency appears to be more proximately associated with USWP. Taken together, these findings suggest that an adolescent's ability to self-regulate behavior is a more proximate factor than parenting practices in determining adolescent propensity for USWP.

Work further examining the link between parenting practices and USWP reported that greater parental knowledge of children's socialization practices was associated with less adolescent involvement in USWP (Osgood \& Anderson, 2004). Their analyses revealed that attending schools with peers whose parents are more involved in their social lives reduces the likelihood of engagement in USWP. Such findings are in concert with similar work in this area that found that contextual effects (i.e., embeddedness in social ties) were significantly associated with less engagement in unsupervised peer activities (Bernburg \& Thorlindsson, 2007). In this manner, social ties are viewed as parental awareness of who are their child's friends and whether parents know the parents of their child's friends (Bernburg \& Thorlindsson, 2007). Given this, social ties link parents and their children while exerting social control on the adolescent (Coleman, 1988). Subsequently, Hoeve et al. (2009) argued that parental support during a time where adolescents are seeking autonomy promotes better parent-to-child-relationships, which would in turn make it less likely for teenagers to engage in delinquency when socializing away from home. 
Given the importance of adolescence in the formation of one's personality and inconsistent findings regarding the role of parental monitoring and knowledge of adolescents in situations like USWP, Stattin and Kerr (2000), along with Kerr and Stattin (2000), examined these issues further. Based on their findings, Stattin and Kerr (2000) claimed that parental knowledge, which is often used synonymously with parental monitoring, may not be an effective means of adolescent control and surveillance. Instead, the scholars asserted that parents should strive to gain information on how their child spends his or her time and with whom via 1) voluntary child disclosure, 2) asking their children and their children's friends for information (parental solicitation), and 3) imposing rules and limits on their children's activities and with whom they associate toward restraining children's freedom to do things without seeking parental approval (parental control). Although all aforementioned strategies were advocated, Stattin and Kerr (2000) concluded that greater child disclosure was most predictive of less normbreaking behavior. Similarly, Kerr and Stattin (2000) found that both boys and girls who had better relationships with their parents were more adjusted (i.e., exhibited less delinquency, less school problems, better teacher relationships, among others). Related work has also demonstrated that parent-to-child communication was effective in reducing substance use, while control and surveillance were not (Cohen \& Rice,1995).

In a more recent study focusing on rural youth, Lippold, Greenberg, Graham, and Feinberg (2014) found that parenting efforts to monitor youth and voluntary child disclosure were more effective than parental control efforts at reducing problem behaviors such as delinquency and substance use. Fletcher, Steinberg, and Williams- 
Wheeler (2004), however, claimed that all three of these measures were useful in reducing adolescent involvement in substance use.

In an attempt to explicate the causes of USWP, Goldstein et al. (2005) examined the influence of autonomy on unstructured, unsupervised leisure time with friends of adolescents in 7 th and 8 th grade and demonstrated that having greater autonomy during the seventh grade predicted greater engagement in unstructured, unsupervised leisure time with friends in the eighth grade. More recently, Staff et al. (2010) used the same data as Osgood and colleagues (1996) to examine the role of employment (as a means of gaining greater financial autonomy) in USWP. These authors found that youth were more likely to spend greater time engaging in USWP if they had their own income. These findings suggest that employment may provide youth with financial resources, as well as respect from parents. Such circumstances may in turn reduce parental supervision resulting in more autonomy and opportunities for USWP. In sum, employment may play a causal role in unstructured socializing during adolescence and early adulthood.

\section{Other factors that contribute to unstructured socializing with peers. As}

previously discussed, Osgood and Anderson (2004) examined a range of factors other than just parenting practices that are likely to contribute to greater involvement in USWP. They concluded that living in a single-parent household, limited educational opportunities, inadequate school commitment, being male, being Black and Hispanic, as

well as propensity for risk-seeking behaviors were associated with greater involvement in USWP.

Beyond the study by Osgood and Anderson (2004), Bernburg and Thorlindsson (2007) found that weak attachment to social norms, as well as living in an urban area, 
was also associated with greater involvement in unsupervised peer activities. This finding is consistent with the postulates of Shaw and McKay's (1942) social disorganization theory suggesting that communities characterized by high levels of residential mobility and family disruption, which is typically the case for urban, but not rural communities, would provide adolescents more opportunities to engage in delinquency.

Adolescent attachment to conventional social agents (e.g., school bonding) and unstructured peer activities in the absence of authority figures has also been examined with results revealing that the more tied an adolescent is to school and family, the less likely he/she would be to spend time in unstructured peer activities (Bernburg \& Thorlindsson, 2001) .

Other factors leading to USWP have been examined by Taylor et al. (2007) who assessed the influence of gang and non-gang youth membership on USWP. Their analyses revealed that both victims of crime and gang members tend to report greater exposure to USWP than do non-victims/non-gang members. Further, gang members who are victims are at the greatest risk to spend time in USWP. Similarly, Melde and Esbensen (2011) concluded from their work that an adolescent's involvement in gangs was associated with greater USWP. Taken together, these findings highlight the importance of understanding deviant lifestyles among adolescents' leading to USWP.

Summarily, research has focused on the role of parenting practices, autonomy, and several other factors that may cause an individual to spend greater time engaging in USWP. Understanding how USWP may develop over time, however, is also necessary for understanding why spending time in such a situation may be more common among adolescents. It is to this literature that attention is now directed. 
Development of unstructured socializing with peers. Osgood et al. (1996) contended that USWP reflects situations of relative opportunity (i.e., the amount of time an individual spends in situations that are conducive to deviance), and that the theory accounts for the continuation of delinquent behavior (Higgins \& Jennings, 2010). Considering adolescents spend the greatest amount of time with their peers, view their peers as important, and are most strongly influenced by their peers during this time than any other time during the life course (Brown, 1990), understanding how USWP may develop over time is of particular importance.

Framing their study in the routine activity theory of general deviance (Osgood et al., 1996), Higgins and Jennings (2010) sought to examine the extent to which USWP is a dynamic process that may follow distinct developmental trajectories during adolescence. Their investigation focused on a specific cohort of adolescents aged 12-16 years, aiming to elucidate factors that may result in different trajectories of USWP. Drawing on data from the GREAT program (Esbensen, 2002), the authors identified three developmental trajectories of unstructured socializing, which were denoted as G1-G3. Although the authors established that the propensity for USWP increases from age 12 to 16 across all trajectories, certain differences emerged. Specifically, $21 \%$ of the sample that reported no involvement in unstructured socializing at age 12 increased engagement in USWP to one hour per week by the age of 16 (G1 trajectory). Similarly, 63\% of the sample began by spending about one hour of their daily free time engaged in unstructured socializing, which gradually increased to two hours by the time they turned 16 (G2 trajectory). However, $15.5 \%$ of the sample that reported spending little over three hours per day in unstructured socializing at the age of 12 continued to spend increasing amounts of time 
with their peers until the age of 15, after which a slight decline was reported (G3 trajectory).

Higgins and Jennings (2010) further established that adolescents that are prone to risk taking were more likely to follow the G2 or G3 trajectory. However, being female was found to marginally decrease an adolescent's odds of following the G2 trajectory, suggesting that adolescent females may be more closely monitored than their male counterparts. Similarly, the likelihood of adolescents following the G3 trajectory decreased under greater parental supervision. These findings suggest that the development of USWP is not only dependent on age, but also other factors.

To pursue this line of research further, Osgood, Anderson, and Shaffer (2005) sought to examine how age was associated with USWP on weekends, weekday afternoons, and weekday evenings. Their analysis of data drawn from the National Youth Survey indicated that most adolescents engage in USWP on weekends, as they have more free time and less parental supervision on non-school days. Moreover, with the exception of weekday afternoons, as youth aged in the study, they tended to spend more time in USWP, likely because they became more independent and were granted greater autonomy by their parents.

Similar to Higgins and Jennings (2010) discussed above, Wong (2005) attempted to establish the link between adolescents' age and time spent in USWP finding that respondents in grades $5-6,7-8,9-10$, and $11-12$ respectively, spent an average of 13.4 , 14.7, 15.4, and 17.6 hours per week engaging in USWP. These results confirm a temporal trajectory to USWP and suggest that interventions during youths' developmental stages must be put in place early to reduce the potential for delinquent behaviors as adolescents 
mature. Parents should be increasingly vigilant in this sensitive developmental period, given that USWP can lead to a wide range of negative consequences, many of which are described in the section below.

Consequences of unstructured socializing with peers. Given that adolescence is a time of exploration during which increased engagement in USWP occurs, an extensive body of research has been dedicated to the consequences of USWP, such as non-violent crimes (Barnes, Hoffman, Welte, Farell, \& Dintcheff, 2007; Bernburg \& Thorlindsson, 2001; Haynie \& Osgood, 2005; Higgins \& Jennings, 2010; Hughes \& Short, 2014; Hundleby, 1987; Melde \& Esbensen, 2011; Meldrum, Young, \& Weerman, 2009; Osgood \& Anderson, 2004; Wong, 2005). Research has also examined violent crimes (Agnew \& Peterson, 1989; Bernasco et al., 2013; Bernburg \& Thorlindsson, 2001; Haynie \& Osgood, 2005; Maimon \& Browning, 2010; Wong, 2005), drug use (Barnes et al., 2007; Bernasco et al., 2013; Green \& Banerjee, 2009; Hawdon, 1996), and victimization (Taylor et al., 2007). Each of these research streams is discussed in greater detail below.

Unstructured socializing with peers and non-violent behavior. According to Osgood and colleagues (1996), involvement in USWP presents greater opportunities for deviance to occur. In support of this argument, research shows that adolescents who spend more time engaging in USWP are more likely to commit delinquency (Osgood et al., 1996). Given this early supportive evidence, it is not surprising that a link between USWP and minor forms of anti-social behavior among adolescents has been established in several studies. Indeed, more than half a century ago, Briar and Piliavin (1965) suggested that unstructured activities may prompt adolescents to break social norms. 
More recently, Barnes et al. (2007) used data on 606 adolescents who took part in a sixwave longitudinal study to examine whether adolescents who spend more time with peers were more likely to engage in various forms of delinquency, such as truancy and arguing with one's parents. The findings of the study indicated that spending more time in USWP increased the likelihood of delinquent behavior.

In an earlier study, Bernburg and Thorlindsson (2001) sought to examine the relationship between USWP and property offending. Measures used to assess the severity of such offenses included stealing something worth more than $\$ 50$, breaking into a building or a car with the intent to steal something, and ruining something that did not belong to them. The results indicated that time spent in USWP was positively associated with engaging in property offending within the last 12 months. Using longitudinal data, Haynie and Osgood (2005) examined whether spending time with peers was associated with delinquency. However, the authors were unable to measure whether adults were present during unstructured socializing activities - a key element in the conceptualization of USWP by Osgood and colleagues (1996). To gather data for the study, the authors developed a questionnaire probing respondents' delinquency within the last 12 months, including property damage, painting graffiti, shoplifting, stealing something worth less/more than $\$ 50$. Results showed that spending time while hanging out with peers is positively associated with delinquency.

As previously discussed, Higgins and Jennings (2010) examined whether there is a possible overlap between the USWP and delinquency trajectories among adolescents aged 12 to 16 years. For this purpose, the authors adopted 14 items from the GREAT survey to measure delinquency, focusing on less serious offenses, such as skipping school 
without an excuse and attempting to steal something worth more than $\$ 50$ (see Esbensen, Osgood, Taylor, Peterson, \& Freng, 2001 for a full list of delinquency items). The authors found a positive link between greater engagement in USWP and delinquency.

More recently, Hughes and Short (2014) analyzed cross-sectional data from the Group Process and Gang Delinquency Project (Short \& Strodtbeck, 1965), establishing a significant positive link between USWP and delinquency (e.g., gambling, drinking, illegal money making). Support for the link between delinquency and time spent with peers was also offered over thirty years ago by a cross-sectional study conducted by Hundleby (1987) who analyzed data obtained from over 2,000 boys and girls attending ninth grade in Ontario. Considering the emphasis provided by Osgood et al. (1996) that lack-of authority figures are a necessary element for activities like USWP to lead to delinquency, it is particularly interesting that Hundleby (1987) found that routine activities like boating and camping, which one might think would include authority figures like parents, were positively associated with property delinquency (e.g., destroying property just for the fun of it). Although the authors did not specify whether such activities were supervised, their findings suggest that the likelihood of delinquent behaviors increases in the presence of peers. Melde and Esbensen (2011) similarly sought to examine the extent of the relationship between USWP and a variety of delinquent acts. By analyzing three waves of panel data from more than 1,400 youth (sixth to ninth graders) across the United States, the authors found that youth who spend greater time in USWP are more likely to engage in delinquency.

The influence of the amount of time spent with peers on delinquency was also the topic of Meldrum et al.'s (2009) study based on data drawn from the Netherlands-based 
NSCR School Project focusing on peer network formation, personal development, and school interventions aimed at behavior and delinquency prevention. The authors found a positive link between time spent in USWP and prior delinquency, as well as self-reported delinquency one year later. Similarly, through use of the GREAT data (Esbensen 2002), Osgood and Anderson (2004) examined acts of delinquency resulting from time spent in USWP like status offending (e.g., truancy), drug sales, and minor forms of offending. The authors established that individuals who engage in more USWP are more likely to engage in delinquency, especially if in a social environment supportive of such acts.

Wong (2005) also drew a link between routine activities, such as dating and spending time with friends (without specifying the extent if parents were around), and various outcomes, such as property crime, trivial offenses (e.g., truancy, cheating during an exam, and public disorder, among others) and other delinquent acts (e.g., skipping class, cheating, assault, and robbery, among others) within the last 12 months. Results indicated that spending more time with friends is positively associated with property crime, trivial offenses, and other delinquent acts. In turn, these effects weakened social bonds, thus increasing delinquency. In sum, extant studies indicate that unstructured socializing with peers is conducive to non-violent behaviors like damage to property, theft, academic cheating, truancy, among others. Considering the association between USWP and non-violent behavior has been provided, what still warrants discussion is how USWP may lead to more serious antisocial behaviors.

Unstructured socializing with peers and violent behavior. The growing body of evidence indicating that USWP is associated with non-violent behaviors has prompted some researchers to examine its link with violent offending. More recently, Maimon and 
Browning (2010) demonstrated that spending greater time in USWP provides opportunities for conflicts to occur among peer group members. Hence, it is not surprising that such internal conflict may be extended to outward violence (Osgood et al., 1996), necessitating that the link between USWP and violent behavior be investigated further.

Agnew and Peterson (1989) were among the first to examine the association between unsupervised social activities with peers and violent behavior. While their study was theoretically focused on social control (Hirschi, 1969), subcultural theory (Cohen, 1955), and strain theory theories (Cohen, 1955; Cloward \& Ohlin, 1960; Merton, 1938) the authors adopted measures of delinquent behavior that included whether the respondent had hurt someone badly, set fire to property, and trespassed, reporting positive associations between USWP and deviant behavior. Bernburg and Thorlindsson (2001) analyzed cross-sectional data pertaining to Icelandic adolescents aiming to elucidate the relationship between unstructured peer interactions in the absence of authority figures and violent behavior (defined as punching, kicking, or seriously hurting someone with a weapon within the past 12 months). The results obtained after controlling for gender and parents' education revealed that unstructured peer interaction in the absence of authority figures has a significant and positive effect on violent behavior.

Drawing on three waves of data from the Project on Human Development in Chicago Neighborhoods (PHDCN) Community Survey and Longitudinal Cohort Study, Maimon and Browning (2010) adopted a multi-item measure to examine the strength of the link between unstructured socializing and violent offending. Once again, findings indicated that USWP was positively related to violent offending. While the relationship 
between USWP and violent behavior has been discussed, and that the seminal work of Osgood and collogues (1996) found USWP leads to substance use, attention is now warranted towards this research area.

Unstructured socializing with peers and substance use. The strong links between USWP and a wide variety of antisocial behaviors suggest that adolescents involved in such acts would also be more likely to engage in substance use. Given that Osgood et al. (1996) claimed that friends are a frequent source of illegal drugs, spending time in USWP is bound to increase the likelihood of substance abuse. Moreover, USWP creates greater opportunities for substance use, thus warranting further investigation of the nature of this relationship.

Barnes et al. (2007) provided a valuable contribution to this research topic by examining whether USWP leads to substance use. The authors analyzed data collected as part of a six-wave longitudinal study and reported that USWP was positively associated with heavy drinking, cigarette smoking, and illicit drug use. Similarly, in their study based on the space-time budget data from The Hague, Netherlands, Bernasco and colleagues (2013) found that USWP was linked to both alcohol and cannabis use. These findings concur with the results obtained by Greene and Banerjee (2009), who, after administering a cross-sectional survey to 248 middle-school students from two schools in the northeastern United States, reported that USWP was positively associated with adolescent cigarette smoking.

In an earlier study, Hawdon (1996) examined the relationship between adherence to routine behavioral patterns and marijuana use. Though commonly deemed a mild act of deviance, marijuana use is highly correlated with the use of other drugs and with the 
performance of other delinquent behaviors (Akers, 1992; Goode, 1989; Inciardi, 1992;

McBroom, 1994). After analyzing data collected as part of the Monitoring the Future Study, Hawdon (1996) reported that routine patterns such as getting together with friends informally and going to parties or other social gatherings were significantly and positively related to marijuana use. These findings also support Hundleby's (1987) research results, suggesting that even recreational activities like boating and camping can lead to substance use (e.g., tobacco, marijuana, and alcohol).

Other outcomes associated with USWP. Given the growing body of evidence linking USWP with deviance (including offending, drug use, among others), some authors posited that it may also lead to other adverse outcomes such as victimization (Taylor et al., 2007). Taylor et al. (2007) examined the associations between USWP and both general and serious violent victimization among gang and non-gang members, where victimization was defined as being hit by someone (i.e., simple assault), being attacked by someone with a weapon (i.e., aggravated assault), or being a victim of armed robbery. The authors found that spending greater time in USWP was significantly and positively associated with general violent victimization, but not with serious violent victimization.

Summarily, research has examined a wide variety of outcomes resulting from USWP. Such outcomes include non-violent behaviors like skipping school, arguing with one's parents, property delinquency such as theft, simple assault, among others. More violent outcomes resulting from USWP have also been found such as aggravated assault, setting fire to property, and other forms of violent offenses. To date, a wide variety of substance use like marijuana, alcohol, cigarettes, and other illicit drugs has also received 
copious amounts of attention from research on USWP. Given attention has been devoted to the various causes and consequences of USWP, further consideration is still needed to mechanisms which appear as more proximate or distal factors of USWP and anti-social behavior.

Unstructured socializing with peers and mediating effects. While the various causes and consequences of USWP have received considerable attention in extant research, there is a paucity of studies aiming to ascertain whether USWP may mediate the association between various causal mechanisms and antisocial behavior (Bernburg \& Thorlindsson, 2001, 2007; Matsuda et al., 2013; Melde \& Esbensen, 2011; Osgood et al., 1996; Walters, 2017). Similarly, little is presently known about factors that may mediate the association between USWP and antisocial behavior (Bernasco et al., 2013; Greene \& Bamerjee, 2009; Hoeben \& Weerman, 2016; Hughes \& Short, 2014; Wong, 2005). The research that has been done indicates that USWP does play an important mediational role when seeking to explain antisocial outcomes. Given these considerations, further attention is needed to this line of research.

\section{Unstructured socializing with peers as a mediator between various causal}

factors and antisocial behavior. In their landmark study of USWP, Osgood et al. (1996) examined whether USWP (e.g., riding around in a car for fun and getting together with friends informally) mediated the relationship between certain sociodemographic variables (age, gender, and socioeconomic status) and deviant behaviors (heavy alcohol use, marijuana use, use of other drugs, and dangerous driving). Findings revealed that USWP mediates nearly $100 \%$ of the relationship between gender and drug use. Moreover, the authors found that nearly $50 \%$ of the relationship between school grades and deviant 
behavior (with the exception of dangerous driving) was explained by USWP. Further, USWP mediated $73 \%$ of the relationship between parental education and deviance, while $87 \%$ of the effect of parental education on heavy alcohol use was mediated by USWP.

Further research supports the idea that USWP is an important mediator in models seeking to explain youth antisocial behaviors. USWP has been found to mediate the association between differential social relations (e.g., school bonding, family commitment) and deviant behavior (Bernburg \& Thorlindsson, 2001). While the evidence in support of these associations was very weak, it was argued that school attachment would reduce propensity for delinquency, which would be more likely to occur if adolescents predominantly socialized with delinquent peers. Along these lines, USWP has been found to partially mediate the relationship between gang membership (as a form of delinquent peer affiliation) and violent delinquency (Matsuda et al., 2013; see also Melde \& Esbensen, 2011).

Other work has also examined the role of USWP as a mediator. Research has evaluated the degree to which unsupervised peer activity mediated the relationship between community structure and delinquency finding that participation in USWP did not mediate the relationship between community structure and delinquency, and that greater social ties have a significant negative effect on unsupervised peer activity.

In a more recent study focusing on the effect of parental knowledge of adolescents' socialization practices on delinquency operating through USWP, Walters (2018) examined data collected as a part of the longitudinal Pathways to Desistance Study. Results showed significant support for the indirect negative influence of parental knowledge on delinquency operating through USWP. In sum, these results indicated that 
lack of parental knowledge leads to greater USWP, which in turn gives rise to greater delinquency.

Research examining how USWP may mediate the relationship between various factors such as gender, school grades, parental education, school bonding, family commitment, parental knowledge, among others and antisocial behavior has been discussed so far. Research has also gone on to examine the role of various factors which have appeared as mediators between USWP and antisocial behavior, which are discussed next.

\section{Proximate factors as mediating mechanisms in the relationship between}

unstructured socializing with peers and antisocial behavior. A number of scholars have examined various mediators between USWP and antisocial behaviors that offers some guidance here. The potential role of alcohol as a mediator between unstructured socializing (i.e., presence of peers, absence of adult handlers, public space, and unstructured activities) and offending has been evaluated, with results demonstrating that, although alcohol use more than doubles the odds of offending, it does not mediate the association between USWP and offending (Bernasco et al. 2013). However, another study reported that the association between USWP and adolescent smoking was partially mediated by having delinquent peers, social expectancies about cigarette smoking, and cigarette offers from peers (Greene \& Bamerjee, 2009). A more recent study also reported that exposure to opportunities (i.e., perceived temptations), tolerance for offending and substance use, and peer delinquency each separately mediated the association between USWP and delinquency (Hoeben \& Weerman (2016). Support was also found for two sequential indirect relationships, namely 1) USWP influenced 
propensity for associating with delinquent peers, which in turn influenced tolerance for substance use and offending, ultimately influencing involvement in delinquency; and 2) USWP exposes adolescents to delinquent peers, which in turn affects their perceived temptations, thus influencing their involvement in delinquent behavior. On the other hand, Hoeben and Weerman (2016) found that exposure to group pressure did not mediate the association between USWP and delinquency. The authors further reported that, based on their analyses of sequential mediating effects, exposure to group pressure and tolerance for delinquency, irrespective of the order in which they occurred, failed to mediate the relationship between USWP and delinquency.

Other work has demonstrated that the more time boys spent hanging out in the streets or attending parties, the more likely they were to signify (i.e., testing status boundaries and self-presentations in the streets), which would in turn make them more likely to engage in fights. Hughes \& Short, 2014). used cross-sectional data gathered as a part of the Short and Strodtbeck's (1965) study of Black and White gang and non-gang males to assess whether signifying mediated the relationship between USWP and fighting. Their analyses revealed that the more time boys spent hanging out in the streets or attending parties, the more likely they were to signify, which in turn made them more likely to engage in fights. Specifically, signifying mediated $34.9 \%$ of the effect of hanging around in the streets on fighting. In addition, signifying mediated $14.1 \%$ of the effect of between time spent attending parties and fighting. Yet, signifying did not mediate the relationship between time spent riding around in a car for fun and fighting (Hughes \& Short, 2014). 
Wong (2005) sought to establish whether delinquent peer associations and social bonds mediated the relationship between spending time with friends and delinquency in the past 12 months. Results showed that delinquent peer associations partially (36\%) mediated the relationship between spending time with friends and delinquency, while to a lesser degree social bonds partially mediated the relationship of spending time with friends and delinquency ( $21 \%$ mediation).

Taken together, the above demonstrates that factors like delinquent peers, social expectations about cigarette smoking, cigarette offers from peers, signifying, exposure to opportunities for delinquency, tolerance for offending, substance use, and peer delinquency, and also attachment to things like school, peers, and parents each mediated the association between USWP and antisocial behavior.

In this section, the ways that USWP operated as a mediating variable were examined, demonstrating that the association between certain factors (e.g., differential social relations, community structure, gang membership, age, sex, socioeconomic status, and parental knowledge of adolescent's socialization habits) and delinquency is partially mediated by USWP. Additionally, attention was given to prior research examining whether there are more proximate factors (e.g., exposure to opportunities for delinquency, tolerance for offending, substance use, peer delinquency, signifying, and social bonds) that mediate the effect of USWP on delinquency and other adverse outcomes. While research has examined the role of USWP in mediation, there is a dearth of research examining whether there is a reciprocal relationship between USWP and deviance. The following section discusses the few studies that have devoted attention to this topic. 
Unstructured socializing with peers and reciprocal effects. The reciprocal effects between USWP and antisocial behavior have rarely been examined in research (Fleming, et al., 2008; McHale et al., 2001; Vasquez \& Zimmerman, 2014; Ward et al., 2017). Given this lack of attention, greater consideration is needed to better understand the continuity of USWP and for a more rigorous understanding of the USWP and delinquency relationship. By better understanding the USWP and delinquency relationship, the legitimacy of Osgood and colleagues (1996) routine activity theory of general deviance can be further probed to better explain adolescent deviant behavior.

Of the studies that have examined these relationships, findings lead toward the idea that USWP and deviance are reciprocally related. For example, Fleming (2008) examined the effect of activities similar to USWP (such as hanging out in a mall, shopping center, or arcade, and hanging out in one's neighborhood) on delinquency (e.g., fighting, school misbehavior among 6th to 8th graders). After controlling for relevant factors such as prior antisocial behavior, results showed that greater involvement in unstructured activities in seventh grade was associated with teacher reports of greater misbehavior and delinquency in eighth grade. Additionally, misbehavior in school during sixth grade was associated with involvement in unstructured activities in seventh grade.

Other research also points toward the potential of reciprocal causation. Using data from Wave 1 and 3 of a non-representative survey on family influences assessing gender development during middle childhood and early adolescence, McHale et al. (2001) examined the relationship between hanging out with friends (unsupervised) and conduct problems, such as fighting and lying. Results showed that adolescents who spend more time in USWP at age 10 have greater conduct problems at ages 10 and 12. In addition, 
having conduct problems at age 10 predicted spending greater time in USWP at age 12 . Based on these findings, the authors posited that the processes linking activities in childhood and adjustment in adolescence may influence one another over time.

Considering delinquency is an inherently social event involving peers (Felson, 2003; Reiss, 1986; Warr, 2002), and that research tracing back to the early 1900's has demonstrated that $90 \%$ of juvenile court cases involve two or more peers (Shaw \& Myers, 1929), it is plausible that delinquents would spend time in a social setting such as USWP. Additionally, Elliot and Menard (1986) found that the majority of adolescents at age 17 reported moderate to high levels of delinquent peers. Given this finding, antisocial behavior is an attractor of peers during adolescence where these individuals are seeking out activities associated with mature status like drinking and smoking, which are common outcomes of USWP (Meldrum \& Leimburg, 2018).

Rebellon (2006) and Riley (1987) offer further insight as to why delinquency may influence USWP. For instance, deviant peers are viewed as being more fun and entertaining than their normative counterparts. This then offers opportunities for deviant youth to become the cool and more popular kids. This assertion is in concert with the notions of Osgood and colleagues (1996) that spending time among peers can increase status among those peers. It is also consistent with the argument made by Gold (1970) that deviance is a performance where the presence of peers can provide an appreciative audience.

Vasquez and Zimmerman (2014) drew upon the data collected during Wave 3 (1978) and Wave 4 (1979) of the National Youth Survey to examine whether delinquency (such as substance use, property offending, and violent acts) is positively associated with 
an increase in time spent with peers. The authors reported that engagement in drugrelated, property-related, and violent-related delinquency was associated with an increase in time spent with peers. These findings suggest that delinquents are more likely to seek peer groups with whom they can commit such acts, which would in turn exacerbate their antisocial behavior.

Most recently, at the American Society of Criminology annual meeting, Ward et al. (2017) presented cross-lagged associations (i.e., one mechanism influencing the other over time in a reciprocal fashion) between USWP and delinquency using data collected as part of the Pathway to Desistance study. In this presentation, USWP was measured with three items, such as how often the respondent got together with friends informally; twenty items were used to measure delinquency. Results showed that USWP predicts delinquency but delinquency did not influence USWP. Considering that the reciprocal effects between USWP and delinquency have rarely been studied, exploring the crosslagged effects between USWP and antisocial behavior is needed to better understand the dynamics of this relationship. While the majority of research on USWP has focused on how USWP may cause antisocial behavior (Hoeben et al., 2016), the research above offers evidence that this relationship may in fact be reciprocal.

\section{Nonlinear effects of unstructured socializing with peers on antisocial}

behavior. Given the paucity of studies on the reciprocal effects between USWP and antisocial behavior, it is not surprising to find that the potential for nonlinear effects of USWP on various forms of antisocial behavior has also been understudied. Thus far, only two such studies have been conducted (Gage et al., 2005; Meldrum \& Leimberg, 2018). Therefore, a detailed description of these two studies and what they found is warranted. 
Gage et al. (2005) analyzed data obtained through the Health Behaviors of School-aged Children Survey, a nationally representative cross-sectional survey of youth in grades 6-10. Their aim was to explore the association between the number of evenings per week spent out with friends, aggressive behaviors (e.g., physical fights, bullying, carrying a weapon), and substance use (drinking and smoking tobacco). Bivariate analysis results revealed that both male and female students who reported spending 5-7 evenings out with friends per week were more likely than those spending $0-1$ and $2-4$ to be involved in frequent fighting, frequent bullying, carrying weapons, consuming alcohol, and smoking tobacco.

Multivariate analyses were also performed as a part of this study, revealing that boys who spend 5-7 evenings per week out with friends were over four times more likely to be involved in physical fighting, over three times more likely to report frequent bullying, weapon carrying, consume alcohol and smoke tobacco than those spending 0-1 evenings out with friends each week with friends. Moreover, for girls who spent 5-7 evenings out per week, the risk of fighting was similar to that reported for boys. However, they were five times more likely than boys to carry a weapon, and four times more likely to engage in bullying than those spending $0-1$ evenings out a week with friends. The findings yielded by this study suggest that students who report spending at least five evenings per week out with friends are most likely to exhibit problem behaviors, providing support for the contention that the relationship between time spent in USWP and problem behaviors is nonlinear and is particularly pronounced among adolescents who spend most of their evenings out with friends. 
In a more recent study, Meldrum and Leimberg (2018) utilized data collected as part of the 2017 Florida Youth Substance Abuse Survey to examine whether the association between USWP—-measured in hours per week socializing with friends, not doing anything in particular where adults are not present and substance use is nonlinear. The study participants reported whether they had used a wide variety of substances within the past 30 days, including cigarettes, e-cigarettes, alcohol, and marijuana. Results showed that increase in the risk of cigarette use was only significant for adolescents who spend 20 or more hours per week in USWP relative to those who spend zero hours per week. Risk for e-cigarette use, however, begins at 6-10 hours per week, and gradually increases, peaking for adolescents who report spending more than 20 hours per week in USWP. The risk of alcohol use begins at 3-5 hours per week, but levels off at 6-10 hours per week, suggesting a saturation point. Regarding the effect of USWP on marijuana use, risk also begins at 3-5 hours per week (relative to 0 hours) and gradually increases until reaching a maximum for those reporting spending more than 20 hours in USWP.

When focused on a variety index composed of the aforementioned items measuring substance use, Meldrum and Leimberg (2018) further reported that adolescents who spend 1-2 hours per week in USWP were $30 \%$ more likely to engage in substance use compared to those that did not engage in any USWP ( 0 hours per week). Thereafter, the risk of using a variety of substances increases as time spent in USWP increases until 6-10 hours and remains constant thereafter, indicating a saturation point. Supplementary analyses using a squared term (which enables the researcher to assess whether an effect may be decelerating or accelerating) for USWP indicated that the 
relationship between USWP and drinking, marijuana use, and the variety index of substance use is a decelerating one. 


\section{OBJECTIVES}

A review of the literature on USWP indicates there are at least three areas of research that are underdeveloped, which call attention to the research objectives of this dissertation. First, some studies examining USWP in models of mediation did so with USWP as the mediating variable of various factors on anti-social behavior (Bernburg \& Thorlindsson, 2001, 2007; Matsuda et al., 2013; Melde \& Esbensen, 2011; Osgood et al., 1996; Walters, 2017). Likewise, other studies have examined various factors that may mediate the relationship between USWP and anti-social behavior (Bernasco et al., 2013; Greene \& Bamerjee, 2009; Hoeben \& Weerman, 2016; Hughes \& Short, 2014; Wong, 2005). Yet, almost no attention has been directed at examining the role of multiple indirect effects by joining together these two strands of research. Such a model would expand on work such as that by Walters (2018), who examined and supported a model of mediation involving: Parental Knowledge $\rightarrow$ USWP $\rightarrow$ Delinquency, and additionally the work of Hoeben and Weerman (2016), who examined and supported a model of

mediation involving: USWP $\rightarrow$ Peer Delinquency $\rightarrow$ Delinquency. A study which includes multiple indirect effects would not only expand on past research by Walters (2018) along with Hoeben and Weerman (2016), it would provide a more rigorous explanation of the various ways in which USWP leads to anti-social behavior.

Summarily, Walters (2018) makes clear that parenting precedes peer influence when it comes to predicting delinquency. Thus, parental knowledge would have an effect on USWP, which would then impact peer delinquency and in turn delinquency/substance use. Considering that USWP is a situation that is conducive to deviance (Osgood et al., 1996), further support consistent with Hoeben and Weerman (2016) may be found that 
USWP contributes to associating with delinquent peers, and then, individual delinquency and substance use. The model to be tested in this dissertation extends these recent studies by examining multiple indirect effects on the outcomes of delinquency/substance use as presented in Figure 1.

In order to investigate these associations, structural equation modeling (SEM) will be utilized to estimate the following hypothesized effects: 1) the direct effect of parental knowledge on USWP (negative effect), 2) the direct effect of USWP on peer property delinquency (positive effect), and 3) the direct effect of peer property delinquency on property delinquency (positive effect). The next process to be estimated is the indirect effect of parental knowledge on peer property delinquency operating through USWP (negative effect). Thereafter, the indirect effect between USWP and property delinquency operating through peer property delinquency will be estimated (positive effect). Last, the estimation of the indirect effect of parental knowledge on property delinquency operating through both USWP and peer property delinquency will be conducted (negative effect). These processes will then be repeated separately for violent delinquency and substance use models (Model 2 and Model 3 in Figure 1). 

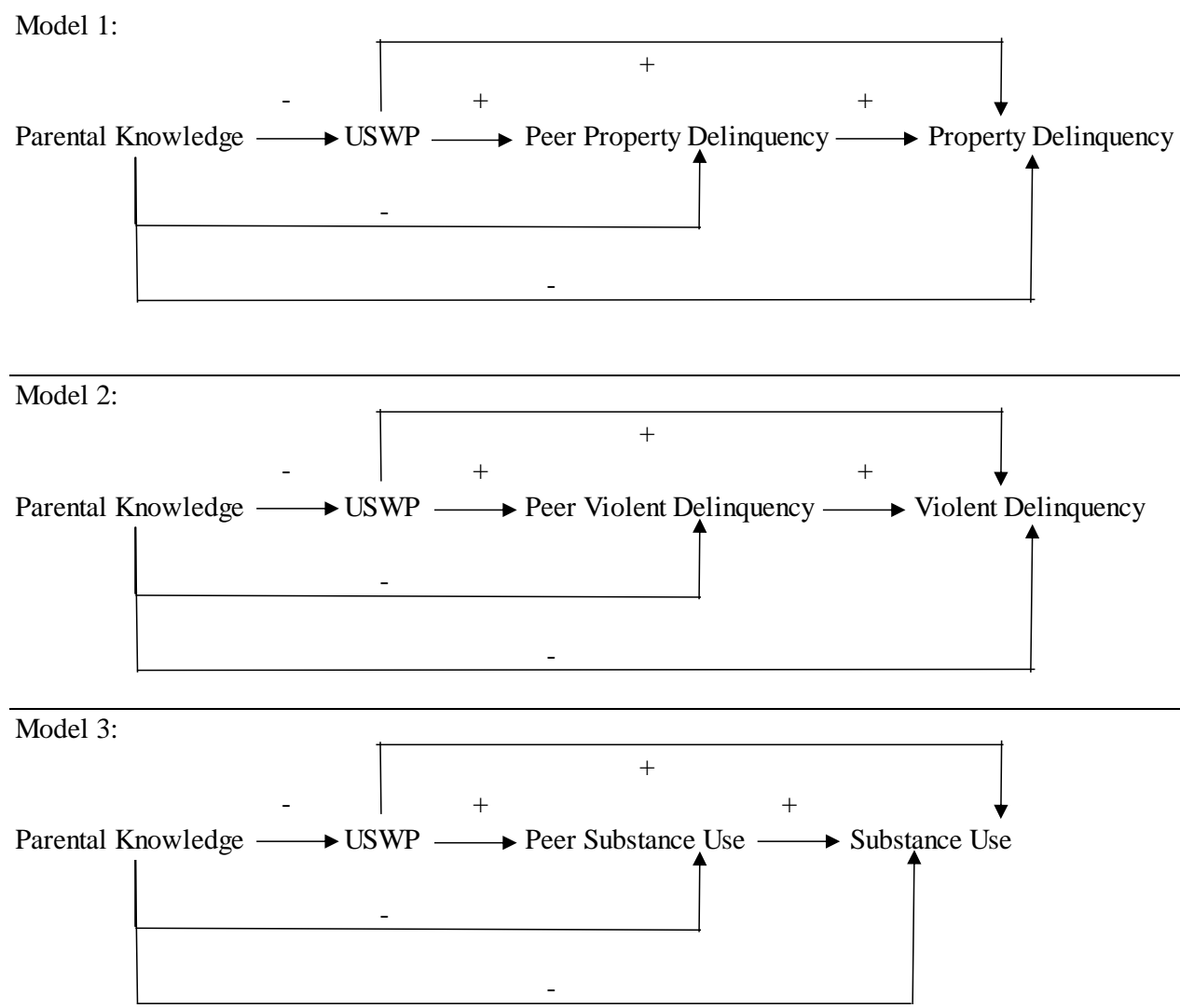

Figure 1. Hypothesized Causal Mediation Models

Second, review of the literature makes clear that few studies have examined reciprocal effects involving USWP and delinquency. However, past research has consistently found that USWP is associated with delinquency (Hoeben et al., 2016) and substance use (Green \& Banerjee, 2009; Hawdon, 1996; Hundleby, 1987), and some research suggests that delinquency may also influence USWP (Hughes \& Short, 2014; Matsuda et al., 2013; Melde \& Esbensen, 2011). Although unexplored, drug use may also cause adolescents to spend more time in USWP, as past research has found that adolescents seek out friends who are like themselves (Urberg, Degirmencioglu, \& Tolson, 1998) especially among those who smoke cigarettes and drink alcohol (Eiser, 
Morgan, Gammage, Brooks, \& Kirby, 1991) and those who engage in aggressive behaviors (Cairns, \& Cairns, 1991; Poulin, et al., 1997). In this regard, people who use substances like tobacco and marijuana may seek out situations where this behavior is likely to occur (e.g., USWP). Therefore, drug use may be positively associated with USWP.

On the issue of reciprocal effects, recent unpublished research presented at the American Society of Criminology annual meeting explicitly explored reciprocal effects between USWP and delinquency (Ward et al., 2017). Specifically, using a sample of serious adolescent offenders, Ward et al. (2017) found evidence that USWP predicted changes in delinquency ( 2 out of 3 waves), and that delinquency, however, did not predict USWP. With these considerations in mind, further research on reciprocal effects is needed for at least three reasons. First, the study by Ward and colleagues (2017) is limited in its generalizability to the general population of adolescents because it focused on serious offenders. Second, the study by Ward et al. (2017) limited its focus to delinquency and did not consider reciprocal effects between USWP and substance use. Third, research has found evidence that delinquency influences USWP (Vasquez and Zimmerman, 2014). With attention to these considerations, a future study improving upon these limitations would assess the cross-lagged effects of USWP and both delinquency and substance use among a more representative sample of adolescents. Figure 2 below displays the hypothesized models to be tested. 
Model 1:

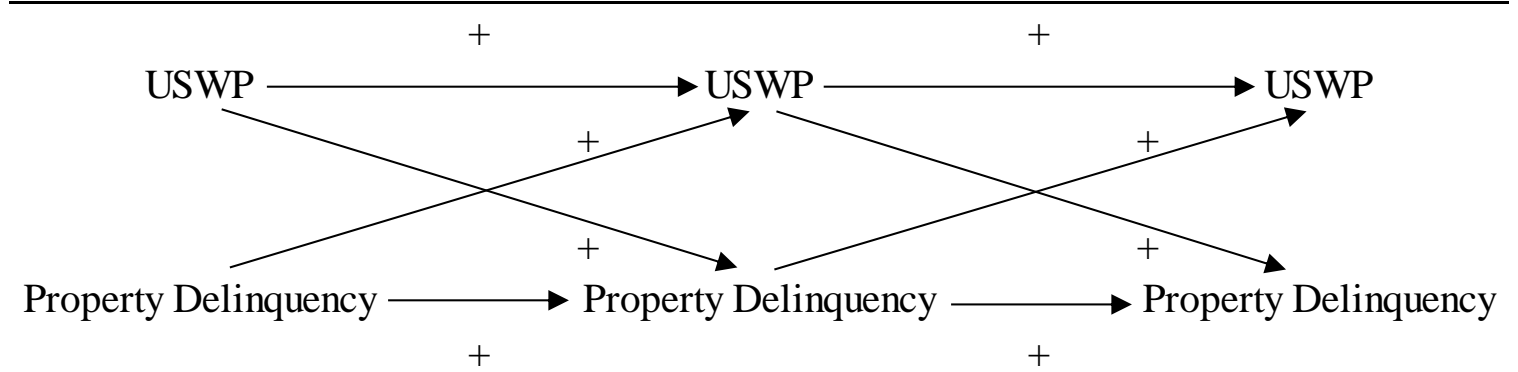

Model 2:

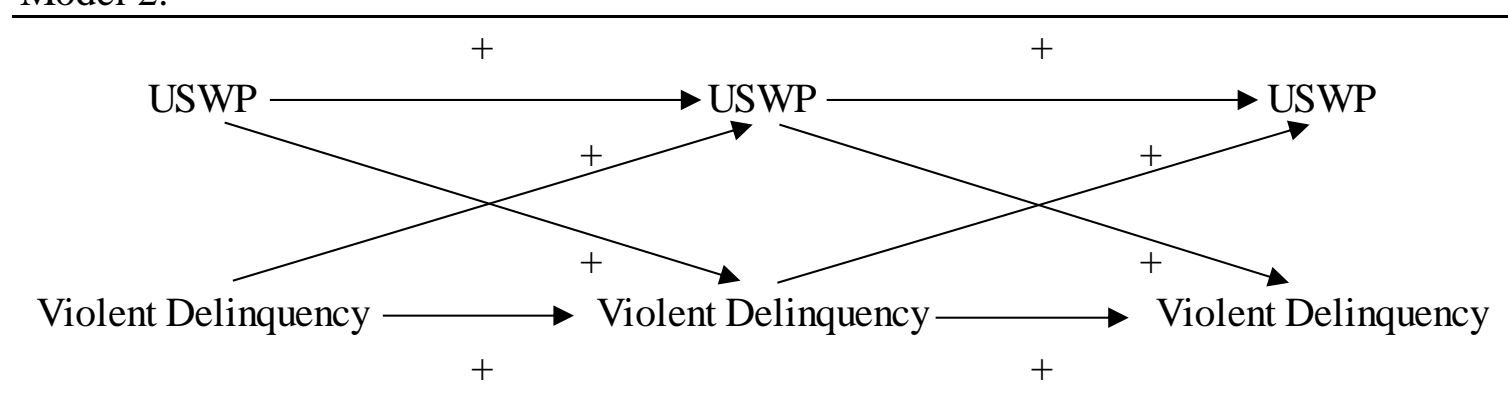

Model 3:

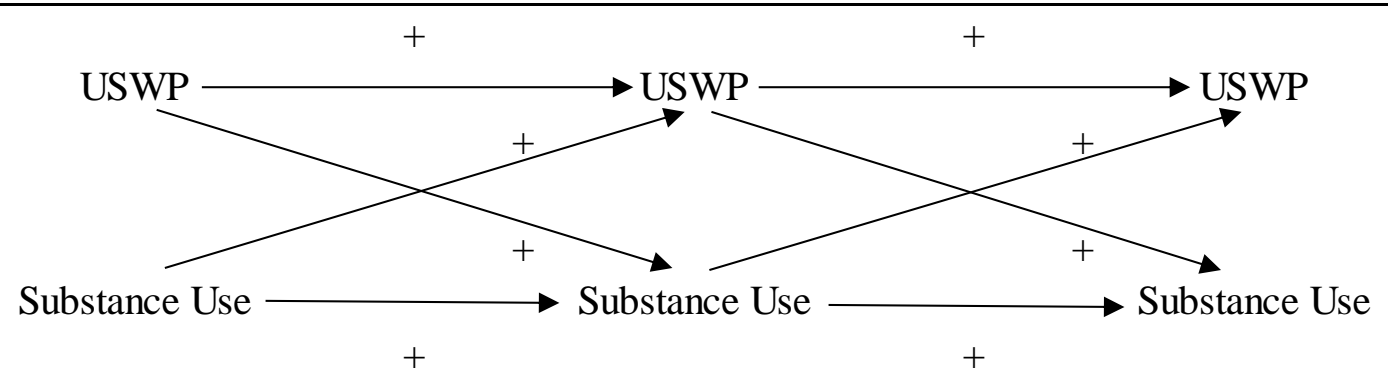

Figure 2. Hypothetical Causal Reciprocal Effects Models

Third, a review of the literature establishes that there has been little attention given to examining whether the association between USWP and delinquency/substance use is nonlinear. For one, past research has found that the relationship between time spent with friends and delinquency is most likely to occur among adolescents who spend most evenings out with friends each week (5-7) than those spending less evenings out (Gage et al., 2005). Additionally, adolescents who spend several evenings out with friends each week (2-4) were only slightly more likely to engage in delinquent behaviors than those spending less evenings out further demonstrating individuals who are spending the 
greatest amount of time in activities such as USWP are more likely to engage in deviance. Given the findings of Gage and colleagues (2005) that adolescents spending five to seven evenings out each with friends per week have a greater chance of engaging in delinquency than those spending less time out each week is suggestive of an accelerating effect. Therefore, the hypothesis to be examined is of an accelerating relationship between USWP and delinquency.

Comparatively, as Meldrum and Leimberg (2018) found, the effect of USWP on substance use (e.g., alcohol and marijuana) reaches a certain saturation point where adolescents spending even more time with their friends are no more likely to engage in greater substance use. Given this, a study that examines whether the relationship between USWP and property delinquency, USWP and violent delinquency, and also USWP and substance use is nonlinear, is needed to better understand how much time is necessary to be spent in USWP before the risk of anti-social behavior increases. The hypothesis to be tested is of a decelerating relationship between USWP and substance use. With consideration to the above assertions, this suggests the arguments set forth by Osgood and colleagues' (1996) that individuals who spend more time in USWP should have higher deviance rates may in fact be a nonlinear association as opposed to linear.

If the findings produced from this dissertation support a nonlinear accelerating effect of USWP on delinquency, then these results would be consistent with Osgood and colleagues' (1996) assertions. Namely, that if delinquent behavior arises from conducive situations, then individuals who spend greater time in these situations should have higher deviance rates. However, this does not require much time for deviance to begin when spending time in such situations. Further, if the findings produced from this dissertation 
support a nonlinear decelerating effect for substance use, this would then be in line with Osgood and colleagues' (1996) assertion that situational factors can give rise to deviance, and that this does not require much time. Evidence from such a study would not only solidify the assertions of Osgood et al. (1996) but would reinforce the findings of Gage et al. (2005). Figure 3 below displays the hypothesized model of the effect of USWP on delinquency (property and violent) illustrating an accelerating effect. Figure 4 displays the hypothesized model of the effect of USWP on substance use illustrating a decelerating effect.

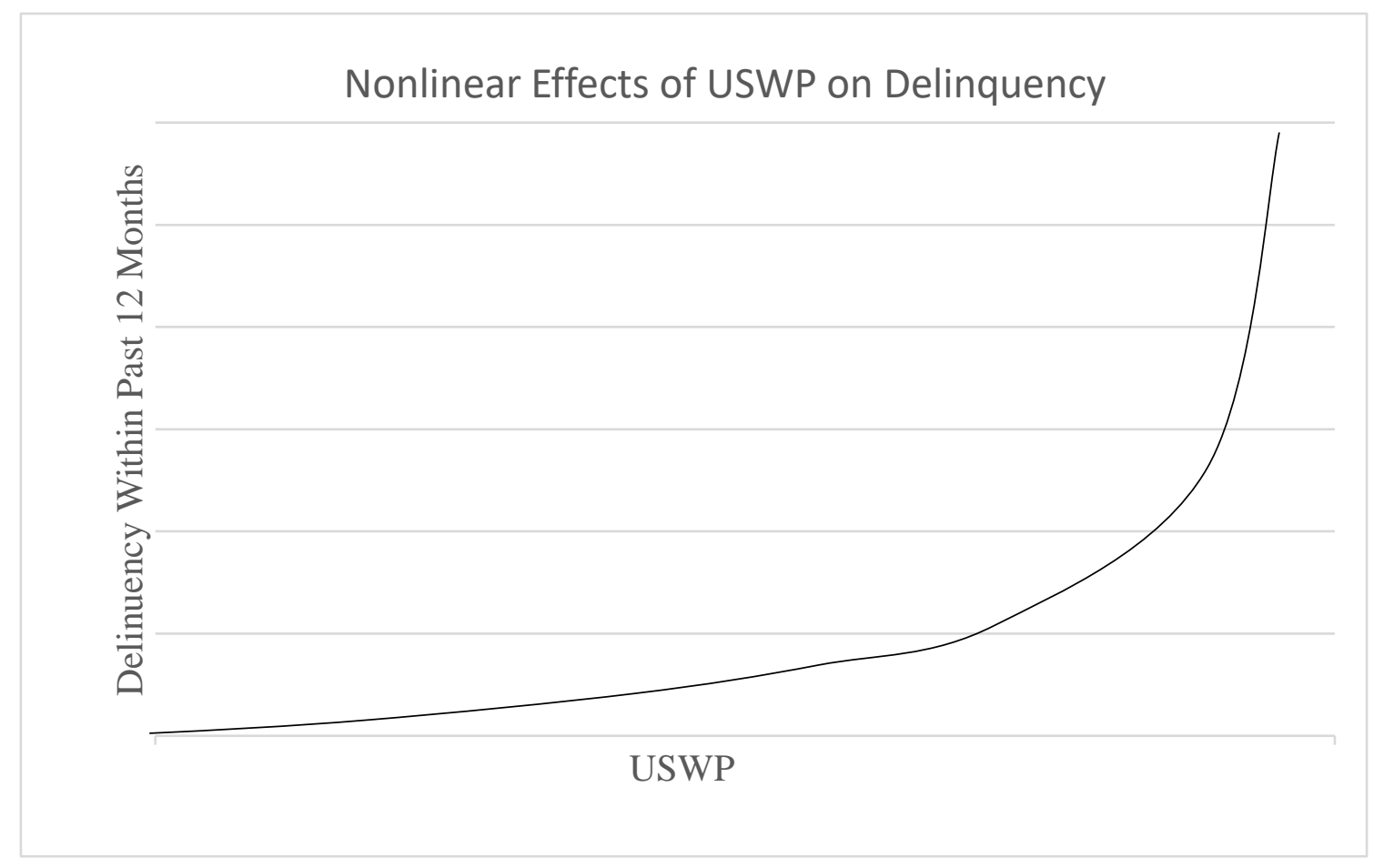

Figure 3. Hypothesized Model Demonstrating an Accelerating Effect 


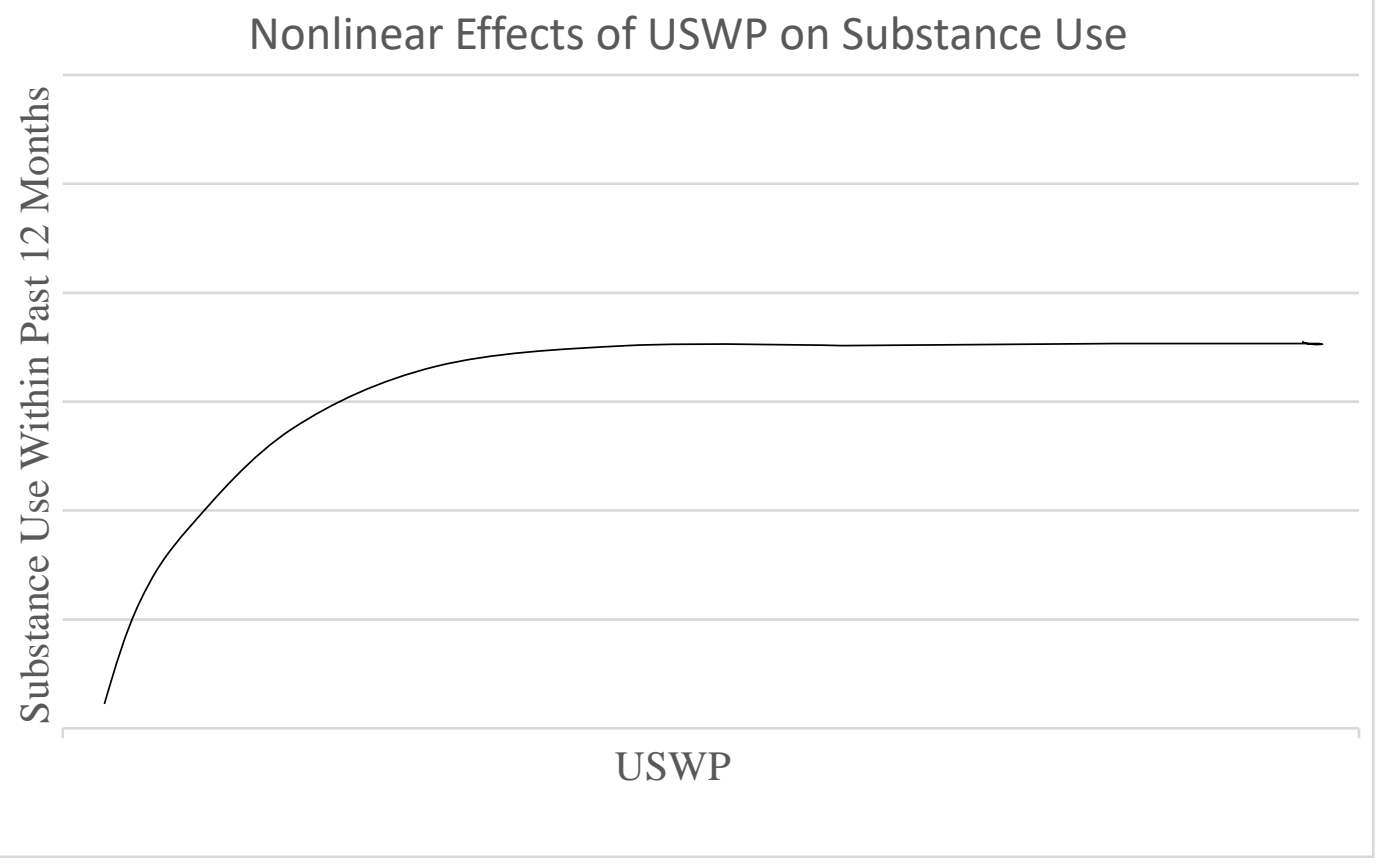

Figure 4. Hypothesized Model Demonstrating a Decelerating Effect

\section{Hypotheses}

Based on prior empirical findings concerning USWP in relation to antisocial behavior, noteworthy associations between USWP and delinquency/substance use are expected. Furthermore, guided theoretically by the most widely recognized conceptualization of USWP (see Osgood et al., 1996), the following hypotheses are tested.

The first hypothesis tested is that the association between parental knowledge and delinquency/substance use will be mediated by both USWP and peer delinquency.

While prior research has found that USWP mediates the association between parental knowledge and delinquency (e.g., Walters, 2018), and that exposure to peer delinquency mediates the association between USWP and delinquency (e.g., Hoeben \& Weerman, 2016), a complete model integrating all four constructs and the separate 
outcome of substance use has not been tested. Such a study would be useful to better understand the nuances of how USWP operates to predict delinquency. Better understanding of this process would be useful so parents can better protect their children from anti-social behavior. Such a study would also be useful to reinforce the findings of both Walters (2018) and Hoeben and Weerman (2016).

The second hypothesis tested is that there are reciprocal (cross-lagged) effects between USWP and delinquency/substance use over time.

Specifically, it is expected that USWP will be correlated with subsequent USWP and a similar association is expected for delinquency/substance use. Next, USWP and delinquency/substance use will influence one another over time in a cross-lagged manner. Particularly, a cross-lagged analysis is used to describe directional associations between variables over time. In a cross-lagged analysis, the association between a causal variable at Time 1 with an outcome variable at Time 2 is compared with the association of the outcome variable at Time 1 and the causal variable at Time 2 . In this manner, an examination in the stability of and relationships between variables over time can be better understood (Kearney, 2017).

Past research has found that USWP is correlated with later USWP (Higgins \& Jennings, 2010) and similar associations have been found for delinquency/substance use (Ford, 2004). Additionally, an abundance of research finds that USWP predicts delinquency (Hoeben et al., 2016) and, to a lesser degree, that delinquency impacts USWP (Hughes \& Short, 2014; Matsuda et al., 2013; Melde \& Esbensen, 2011. Given this, a study is needed to better understand how the relationship between USWP and delinquency/substance use develops over time. By better understanding this relationship, 
strategies targeting individuals who are spending time in unstructured activities with peers and those who are already delinquent can be implemented.

The third hypothesis tested is that there will be an accelerating nonlinear effect of USWP on delinquency and that a decelerating nonlinear effect of USWP on substance use will be found with the possibility of a saturation point.

Past research has found that adolescents spending five to seven evenings out with friends each week are more likely than those spending less evenings out per week to engage in acts of delinquency and substance use (Gage et a., 2005). In addition, those who are spending two to four evenings out with friends each week are only slightly more likely to engage in deviant behavior than those spending less time out with friends. In more recent examinations of the relationship between USWP and substance use, Meldrum and Leimberg (2018) found that the minimum number of hours per week to pose an increased risk for alcohol or marijuana use is three to five hours per week of USWP, the increased risk for e-cigarette use begins at 6-10 hours per week of USWP, and the increased risk for cigarette use begins at more than 20 hours per week of USWP. The findings of Meldrum and Leimberg (2018) further suggest once adolescents have reached the minimum hourly threshold of increased risk for substance use (e.g., alcohol and marijuana) posed by USWP, the effect of additional time spent in USWP on alcohol and marijuana use is a decelerating one.

Thus, a point may be reached where greater time spent engaging in USWP fails to continue to further increase the risk of substance use. Given that Gage et al. (2005) examined the effects of time spent in USWP on delinquency and substance use measured as evenings per week, and that Meldrum and Leimberg (2018) examined substance use in 
categorical formats (e.g., 6-10 hours per week), a finer grain measure of USWP is needed. A future study which examines the amount of time spent in USWP in individual hours per week would not only improve on the limitations of past studies but would help to disentangle a more exact measure of how much time spent in USWP is needed to pose an increased risk for delinquency and substance use.

Findings supportive of this would also buttress the assertion of Osgood et al. (1996) that not much time is needed for situational factors to give rise to deviance. Additionally, the findings supportive of a non-linear, accelerating association between USWP and delinquency would also support the assertion of Osgood et al. (1996) that individuals who spend greater time in situations conducive to deviance (e.g., USWP) should have higher deviance rates. 


\section{DATA AND METHODS}

This dissertation uses data from the evaluation of the Gang Resistance Education and Training (GREAT) program (see Esbensen, 2002). The GREAT evaluation was sponsored by three agencies within the United States through The Department of Justice, including the Bureau of Justice Statistics, the National Institute of Justice, and the Office of Juvenile Justice and Delinquency Prevention. Though intended as an evaluation of a school-based gang and violence prevention program that sought to reduce adolescent involvement in criminal behavior and gangs, the evaluation collected data that will be useful in testing the hypotheses outlined in the previous chapter. Although the development of the GREAT curriculum was not theory driven, the design of the national evaluation was (see Esbensen \& Osgood, 1999).

Elements of Akers' (1985) social learning theory introduced definitions of laws, values, norms, and rules in support of pro-social behavior. Elements of Gottfredson and Hirschi's (1990) self-control theory introduced anger and coping strategies, (conflict resolution), along with impulsive behavior, among others. Further, the GREAT evaluation includes a survey item tapping all three elements of Osgood and colleagues (1996) construct of USWP. Thus, the presence of theoretical constructs in the GREAT evaluation design makes the data useful for this dissertation. Considering the six-wave (Spring 1995, Fall 1995, Fall 1996, 1997, 1998, 1999) longitudinal design of the student questionnaire, and the previously noted strengths of this dataset, discussion of the student sample, recruitment strategies, and survey items used to measure key variables is warranted. 


\section{Participants}

The evaluation of the GREAT program used a classroom-based assignment (i.e., some classrooms were selected to participate in the GREAT program [treatment] and other classrooms were not [control]). The initial longitudinal sample consists of 22 schools, 153 classrooms, and approximately 3,500 students (Esbensen, et al., 2001). Of the 3,568 students who were eligible to participate in the GREAT program, 2,934 students participated in the first wave of the survey during spring of 1995. At the second wave, during fall of 1995, 2,287 students completed the survey, resulting in a $22 \%$ reduction in sample size. Thereafter, follow-up surveys continued yearly, with completion rates representing 1,596 students at fall of 1996 (Wave 3) (46\% reduction), 1,407 students at fall of 1997 (Wave 4) (52\% reduction), 1,286 students at fall of 1998 (Wave 5) (56\% reduction), and 1,261 students at fall of 1999 (Wave 6) (57\% reduction), respectively. Due to the largest amounts of missing data present in Waves 5 and 6 of the GREAT data, this dissertation utilizes data collected through Wave 4. Additional details of the sample are provided in the subsequent sections.

\section{Procedure}

The research strategy of the GREAT evaluation employed a quasi-experimental design of equally sized groups of treatment (GREAT) and control (non-GREAT) students in the seventh grade, which was initiated at the outset of the project. This approach allowed for data collection on two groups of students: (1) those participating in GREAT, and (2) those not participating in GREAT. Furthermore, the random assignment process varied from city to city, as well as from school to school, helping to minimize the possible differences between sets of treatment and control classes. For the student 
questionnaire, six cities were purposively selected for inclusion in the longitudinal phase of the study based on three criteria: (1) the existence of a viable GREAT program, (2) geographical diversity, and (3) the cooperation of the school districts and the police department in each site. The selected sites were: (1) Philadelphia, Pennsylvania, (2) Portland, Oregon, (3) Phoenix, Arizona, (4) Omaha, Nebraska, (5) Lincoln, Nebraska, and (6) Las Cruces, New Mexico.

The University of Nebraska Institutional Review Board approved a component of the research design allowing passive parental consent (i.e., students were included unless specifically prohibited by parents) during the pre and post-test data collection phase. At the beginning of the 1994-1995 academic year, class lists from all participating classrooms were obtained. Each student appearing on these lists was assigned a uniquely identifiable number to be used throughout the longitudinal data collection phase. These lists contained names of students who had moved or failed to enroll for some other reason. Students whose names did not appear on the lists but who were in attendance were added to the list. The pre-test was administered during the spring of 1995 (Wave 1) and the first post-test was administered during fall of 1995 (Wave 2) to 6th and 7thgraders (after GREAT program administration). Follow-up post-test surveys were administered to students annually from 1996-1999 (Waves 3-6).

\section{Study 1 (Multiple Mediation) Measures}

The GREAT student questionnaire includes several key items that can be divided into attitudinal and behavioral indicators. The survey questionnaire also contains important items that were captured in all data collection waves, which were used to measure the key variables of interest for the present investigation, namely parental 
knowledge, USWP, peer delinquency/peer substance use, and individual delinquency/substance use.

Parental knowledge. To measure parental knowledge, respondents that took part in Wave 1 during spring of 1995 were asked to indicate to what extent they agree or disagree with the following statements: "When I go someplace, I leave a note for my parents or call them to tell them where I am.”; "My parents know where I am when I am not at home or at school."; "I know how to get in touch with my parents if they are not home."; and "My parents know who I am with if I am not at home." For each of the four items, the participants were instructed to select one of the following options: $1=$ "Strongly Disagree," 2 = "Disagree," 3 = "Neither Agree nor Disagree," 4 = "Agree," and 5 = "Strongly Agree." A four-item latent factor was created measuring parental knowledge. The factor loadings for this factor and all other variables measured as latent factors are provided in Table 1.

Unstructured socializing with peers. To measure USWP, focus must be given to situations that reflect time spent with peers, in the absence of authority figures, without a structured agenda (Osgood et al., 1996). Therefore, a survey item which captures all of these criteria is an appropriate measure of USWP. In other words, if the survey item of USWP does not include one of these criteria, such as "absence of authority figures," the construct validity of the measure would be weakened. Consistent with prior research using the GREAT data (Higgins \& Jennings 2010; Turanovic \& Pratt, 2014; Wolfe \& McLean, 2017), the survey question utilized from Wave 2 (Fall 1995) reads: "Do you ever spend time hanging around with your current friends not doing anything in particular where no adults are present?" $(\mathrm{No}=1 ; \mathrm{Yes}=2)$. An additional item includes: "If YES, 
how many hours do you spend doing this during an average week?" hours). As

Osgood and Anderson (2004) and Higgins and Jennings (2010) have discussed, the openended nature of this question could lead to issues with misreporting and skewness. In an effort to address the first challenge, and in accordance with the recoding procedure adopted by Higgins and Jennings (2010), in the present study, any responses above 150 hours were coded as missing values and those in the 50-150 h range were coded as 49 hours. Additionally, to overcome the potential for skewness, the process (square root transformation) utilized by Higgins and Jennings (2010) was adopted. The transformation resulted in a $0-7$ range.

Peer delinquency/substance use. To examine the extent to which respondents' friends had engaged in property delinquency (Model 1) in Wave 3 (conducted in the fall of 1996), respondents were read the following prompt: "During the last year, how many of your current friends have done the following?" The items used to measure peer property delinquency included: "Purposely damaged or destroyed property that did not belong to them"; "Stolen something worth less than $\$ 50$ "; "Stolen something worth more than \$50"; and "Gone into or tried to go into a building to steal something." The participants responded to each of the items by selecting one of the five options: $1=$ "None of them"; 2 = "Few of them"; 3 = "Half of them"; 4 = "Most of them"; and 5 = "All of them." A four-item latent factor was created measuring peer property delinquency. In the second model developed as a part of the current study, the items used to measure the three-item latent factor of peer violent delinquency (Model 2) at Wave 3 included whether the respondent's friends had: "Attacked someone with a weapon," "Hit someone with the idea of hurting them," and "Used a weapon or force to get money or 
things from people." Respondents were provided the same five response options as for the property delinquency questions. In the third model of the current study, the items used for measuring the three-item latent factor of peer substance use (Model 3) at Wave 3 included whether the respondent's friends: "Used tobacco products," "Used alcohol," and "Used marijuana." Respondents were again provided with the same five response options noted above.

Individual/Respondent delinquency/substance use. Measures similar to the respondent's friends' delinquency were constructed for individual delinquency/substance use at Wave 4 (conducted in the fall of 1997), wherein respondents were read the following prompt: "Studies have found that everyone breaks the rules and laws sometimes. Indicate how many times in the past 6 months you have done each thing. If you have not done these things, enter 0." Items measuring property delinquency included: "Purposely damaged or destroyed property that did not belong to you," "Stolen or tried to steal something worth less than $\$ 50$," "Stolen or tried to steal something worth more than $\$ 50$," and "Gone into or tried to go into a building to steal something." A four-item latent factor was created measuring individual property delinquency.

This process was repeated for the violent delinquency and substance use measures for each model. Items used to measure violent delinquency asked the respondent to indicate in the past 6 months whether he/she had: "Attacked someone with a weapon," "Hit someone with the idea of hurting them," and "Used a weapon or force to get money or things from people." In accordance with the procedures adopted in previous waves, a three-item latent factor was created measuring violent delinquency. Items used for measuring substance use asked the respondent to indicate in the past 6 months whether 
he/she had: "Used tobacco products," "Used alcohol," and "Used marijuana." Once again, a three-item latent factor was created measuring substance use. In line with the recoding process utilized by Osgood and Schreck (2007) and Higgins and Jennings (2010), the items measuring respondent property delinquency were dichotomized, whereby 0 indicated no participation in each act, while any amount of participation in each act was denoted by 1 (creating a participation index). By following this transformation process, the potential bias in overly skewed results was removed. This process was repeated for the violent delinquency and substance use measures for each model. The descriptive statistics for the latent variables in each model are provided in Table 1 below and the descriptive statistics for the observed variables can be found in Table 2. 
Table 1. Descriptive Statistics of Latent Variables for Mediation Models

Model 1

Property Delinquency $(\mathrm{N}=1,616)$

$\underline{\text { Variable }}$

Parental Knowledge (Wave 1)

Parental Knowledge Item 1

Parental Knowledge Item 2

Parental Knowledge Item 3

Parental Knowledge Item 4

Peer Property Delinquency (Wave 3)

Peer Property Delinquency Item 1

Peer Property Delinquency Item 2

Peer Property Delinquency Item 3

Peer Property Delinquency Item 4

Peer Violent Delinquency (Wave 3)

Peer Violent Delinquency Item 1

Peer Violent Delinquency Item 2

Peer Violent Delinquency Item 3

Peer Substance Use (Wave 3)

Peer Substance Use Item 1

Peer Substance Use Item 2

Peer Substance Use Item 3
Model 2

$\begin{array}{ccccc}\text { Mean } & \underline{\text { SD }} & \underline{\text { FL }} & \underline{\text { Min }} & \text { Max } \\ 4.037 & 0.987 & 0.488 & 1 & 5 \\ 3.789 & 1.104 & 0.825 & 1 & 5 \\ 4.041 & 0.944 & 0.410 & 1 & 5 \\ 3.683 & 1.073 & 0.765 & 1 & 5 \\ & & & & \\ 1.840 & 1.041 & 0.780 & 1 & 5 \\ 1.748 & 1.026 & 0.910 & 1 & 5 \\ 1.374 & 0.790 & 0.920 & 1 & 5 \\ 1.455 & 0.851 & 0.889 & 1 & 5 \\ & & & & \\ --- & --- & --- & --- & -- \\ --- & --- & --- & --- & --- \\ --- & --- & --- & --- & -- \\ & & & & \\ --- & --- & --- & --- & --- \\ --- & --- & --- & --- & --- \\ --- & --- & --- & --- & --\end{array}$

Violent Delinquency $(\mathrm{N}=1,609)$

\begin{tabular}{|c|c|c|c|c|}
\hline \multicolumn{5}{|c|}{ viorent Demquency $(\mathrm{N}=1,009)$} \\
\hline Mean & $\underline{\mathrm{SD}}$ & FL & Min & Max \\
\hline 4.037 & 0.992 & 0.496 & 1 & 5 \\
\hline 3.778 & 1.116 & 0.838 & 1 & 5 \\
\hline 4.039 & 0.948 & 0.411 & 1 & 5 \\
\hline 3.672 & 1.084 & 0.766 & 1 & 5 \\
\hline --- & --- & --- & --- & --- \\
\hline --- & --- & --- & --- & --- \\
\hline --- & --- & --- & --- & --- \\
\hline --- & --- & --- & --- & --- \\
\hline 2.143 & 1.168 & 0.751 & 1 & 5 \\
\hline 1.351 & 0.792 & 0.965 & 1 & 5 \\
\hline 1.241 & 0.645 & 0.892 & 1 & 5 \\
\hline --- & --- & --- & --- & --- \\
\hline --- & --- & --- & --- & --- \\
\hline --- & --- & --- & --- & --- \\
\hline
\end{tabular}

Model 3

Substance Use $(\mathrm{N}=1,604)$

\begin{tabular}{|c|c|c|c|c|}
\hline Mean & $\underline{\mathrm{SD}}$ & $\underline{\text { FL }}$ & $\underline{\text { Min }}$ & $\underline{\text { Max }}$ \\
\hline 4.034 & 0.989 & 0.503 & 1 & 5 \\
\hline 3.774 & 1.116 & 0.846 & 1 & 5 \\
\hline 4.049 & 0.941 & 0.409 & 1 & 5 \\
\hline 3.677 & 1.080 & 0.753 & 1 & 5 \\
\hline --- & --- & --- & --- & --- \\
\hline --- & --- & --- & --- & --- \\
\hline --- & --- & --- & --- & --- \\
\hline --- & --- & --- & --- & --- \\
\hline --- & --- & --- & --- & --- \\
\hline --- & --- & --- & --- & --- \\
\hline --- & --- & --- & --- & --- \\
\hline 1.882 & 1.129 & 0.901 & 1 & 5 \\
\hline 1.939 & 1.168 & 0.954 & 1 & 5 \\
\hline 1.676 & 1.087 & 0.888 & 1 & 5 \\
\hline
\end{tabular}


Table 1 Continued. Descriptive Statistics of Latent Variables for Mediation Models.

\begin{tabular}{|c|c|c|c|c|c|c|c|c|c|c|c|c|c|c|c|}
\hline \multirow[b]{2}{*}{ Variable } & \multicolumn{5}{|c|}{ Property Delinquency $(\mathrm{N}=1,616)$} & \multicolumn{5}{|c|}{$\begin{array}{c}\text { Model } 2 \\
\text { Violent Delinquency } \\
(\mathrm{N}=1,609)\end{array}$} & \multicolumn{5}{|c|}{$\underline{\underline{\text { Model } 3}}$} \\
\hline & $\underline{\text { Mean }}$ & $\underline{\mathrm{SD}}$ & $\underline{\mathrm{FL}}$ & $\underline{\text { Min }}$ & $\underline{\operatorname{Max}}$ & $\underline{\text { Mean }}$ & $\underline{\mathrm{SD}}$ & $\underline{\mathrm{FL}}$ & $\underline{\text { Min }}$ & $\underline{\operatorname{Max}}$ & $\underline{\text { Mean }}$ & $\underline{\mathrm{SD}}$ & $\underline{\mathrm{FL}}$ & $\underline{\text { Min }}$ & $\underline{\operatorname{Max}}$ \\
\hline \multicolumn{16}{|l|}{ Property Delinquency (Wave 4) } \\
\hline Property Delinquency Item 1 & 0.218 & 0.412 & 0.676 & 0 & 1 & --- & --- & --- & --- & --- & --- & --- & --- & --- & --- \\
\hline Property Delinquency Item 2 & 0.187 & 0.390 & 0.743 & 0 & 1 & --- & --- & --- & --- & --- & --- & --- & --- & --- & --- \\
\hline Property Delinquency Item 3 & 0.064 & 0.245 & 0.596 & 0 & 1 & --- & --- & --- & --- & --- & --- & --- & --- & --- & --- \\
\hline Property Delinquency Item 4 & 0.083 & 0.276 & 0.681 & 0 & 1 & --- & --- & --- & --- & --- & --- & --- & --- & --- & --- \\
\hline \multicolumn{16}{|l|}{ Violent Delinquency (Wave 4) } \\
\hline Violent Delinquency Item 1 & --- & --- & --- & --- & --- & 0.387 & 0.487 & 0.445 & 0 & 1 & --- & --- & --- & --- & --- \\
\hline Violent Delinquency Item 2 & --- & --- & --- & --- & --- & 0.062 & 0.241 & 0.749 & 0 & 1 & --- & --- & --- & --- & --- \\
\hline Violent Delinquency Item 3 & --- & --- & --- & --- & --- & 0.026 & 0.158 & 0.579 & 0 & 1 & --- & --- & --- & --- & --- \\
\hline \multicolumn{16}{|l|}{$\underline{\text { Substance Use (Wave 4) }}$} \\
\hline Substance Use Item 1 & --- & --- & --- & --- & --- & --- & --- & --- & --- & --- & 0.275 & 0.446 & 0.709 & 0 & 1 \\
\hline Substance Use Item 2 & --- & --- & --- & --- & --- & --- & --- & --- & --- & --- & 0.394 & 0.489 & 0.846 & 0 & 1 \\
\hline Substance Use Item 3 & --- & --- & --- & --- & --- & --- & --- & --- & --- & --- & 0.203 & 0.402 & 0.662 & 0 & 1 \\
\hline
\end{tabular}

Notes: FL $=$ Factor Loadings 
Covariates. In addition to measuring the primary variables of interest, respondents also reported their biological sex $($ male $=1$; female $=0)$, race $($ White $=1$; non-White $=0$; dummy coded), age (in years), whether the respondent lived in a singleparent household (yes $=1 ;$ no $=0$ ), currently a gang member (yes $=1$; no $=0$ ), ever been a gang member (yes $=1 ;$ no $=0$ ) measured at spring of 1995 (Wave 1), and whether the respondent completed the GREAT program assessed in fall of 1995 (yes $=1$; no $=0$ ). At Wave 1, the respondent's level of self-control was measured by an eight-item scale comprised of attitudinal measures assessing the respondent's impulsivity and risk-seeking behavior (Grasmick, Tittle, Bursik, \& Arneklev, 1993). An example item measuring impulsivity is: "I often act on the spur of the moment without stopping to think." Riskseeking behavior was measured with such items as: "Sometimes I will take a risk just for the fun of it." Respondents selected one of the following five options for each of the eight items: 1 = "Strongly Disagree," 2 = "Disagree," 3 = "Neither Agree nor Disagree," 4 = "Agree," and 5 = "Strongly Agree." The measure for self-control was created by taking the average of the eight items $(\alpha=.74)$, whereby higher scores are indicative of lower self-control. Last, in each particular model of the present study, the respondent's own anti-social behavior (i.e., property delinquency, violent delinquency, substance use) assessed at Spring 1995 (Wave 1) was controlled for by taking the sum of each of the offending items, which were identical to those described above measured at Wave 4.

The descriptive statistics for the observed variables that were incorporated into each model are provided in Table 2. As can be seen, non-Whites (55\%) and females $(51 \%)$ comprised slightly more of the study sample than Whites and males. The youngest student in the sample at wave 1 was 10 and the oldest 14 , with an average of 12 years old. 
Additionally, $35 \%$ of respondents lived in a single-parent household, $8 \%$ reported having been a gang member at some point in their lives, $4 \%$ reported currently being a gang member, and $61 \%$ of the students indicated completing the GREAT program. 
Table 2. Descriptive Statistics of Variables for Mediation Models

Model 1

Property Delinquency (N=1,616)

$\underline{\text { Variable }}$

Age (Wave 1)

Male (Wave 1)

White (Wave 1)

Single-Parent Household

(Wave 1)

Great Program (Wave 2)

Low Self-Control (Wave 1)

Gang Membership Ever (Wave 1)

Gang Membership Currently

(Wave 1)

Property Delinquency

(Wave 1)

Violent Delinquency

(Wave 1)

Substance Use (Wave 1)

Unstructured Socializing

With Peers (Wave 2)
Model 2

Violent Delinquency $(\mathrm{N}=1,609)$

Mean SD Min Max

$\begin{array}{cccc}\underline{\text { Mean }} & \underline{\text { SD }} & \underline{\text { Min }} & \underline{\text { Max }} \\ 12 & 0.632 & 10 & 14 \\ 0.478 & 0.500 & 0 & 1 \\ 0.467 & 0.499 & 0 & 1 \\ 0.330 & 0.470 & 0 & 1 \\ 0.613 & 0.487 & 0 & 1 \\ 2.864 & 0.675 & 1 & 4.875 \\ 0.071 & 0.257 & 0 & 1 \\ 0.034 & 0.182 & 0 & 1 \\ 0.501 & 0.924 & 0 & 4 \\ --- & --- & --- & --- \\ --- & --- & --- & --- \\ 1.426 & 1.602 & 0 & 7\end{array}$

$0.484 \quad 0.500 \quad 0$

$0.466 \quad 0.499 \quad 0$

$0.329 \quad 0.470 \quad 0$

$0.608 \quad 0.488 \quad 0$

$2.869 \quad 0.677$

$0.076 \quad 0.265$

$0.037 \quad 0.187 \quad 0$

$---$

0.422

Model 3

Substance Use $(\mathrm{N}=1,604)$

$\underline{\text { Mean }} \underline{\text { SD }}$ Min $\underline{\text { Max }}$ Mean $\underline{\text { SD }} \underline{\text { Min }}$ Max

\begin{tabular}{llll|llll}
12 & 0.628 & 10 & 14 & 12 & 0.628 & 10 & 14
\end{tabular}


Study 1 analytic plan. To investigate the relationships of interest for the current study, the statistical package Mplus 8.1 was employed to conduct SEM of latent variables for the primary constructs of interest and observed variables (Muthén \& Muthén, 2017). In order to investigate whether the variables representing the mediators explain the association between parental knowledge and delinquency/substance use, two conditions must be met: (1) the independent variable significantly affects the mediator, and (2) the mediator has a significant effect on the dependent variable, which establishes partial mediation (Kenny, Kashy, \& Bolger, 1998). Further, if these two criteria are met, then it is implied, but not required, that a path from the independent variable (IV) to the dependent variable (DV) exists to further solidify partial mediation (Kenny et al., 1998). Contrary to what Baron and Kenny (1986) have noted in their seminal work, there is no requirement for mediation to occur if the IV is not associated with the DV (Collins, Graham, \& Flaherty, 1998; Judd \& Kenny, 1981; Kenny et al., 1998; MacKinnon, 1994, 2000; MacKinnon, Krull, \& Lockwood, 2000; Shrout \& Boulger, 2002). To establish complete mediation, the effect of the IV on the DV while controlling for the mediator should be reduced to zero.

Several fit indices were adopted in the present study to evaluate model fit, including the conventional chi squared $\left(\chi^{2}\right)$ statistic, along with the root mean square error or approximation (RMSEA), which takes into account sample size to correct for the tendency of the chi squared test to reject models based on large samples (Steiger, 1990). According to Browne and Cuedck (1993), values for the RMSEA of less than .05 denote close model fit, those between .05 and .08 are indicative of fair fit to data, and values above .10 are associated with poor fit. The comparative fit index (CFI) (Bentler, 1990) 
was also calculated as a part of this investigation, wherein values of .90 to .95 are considered acceptable and those exceeding .95 are considered good (Hu \& Bentler, 1999). Last, the latent factor $\mathrm{R}^{2}$ is also reported as it indicates how much variation in a particular latent variable is explained by the structural model. Bootstrapped standard errors, indirect effects, and non-symmetric confidence intervals were obtained using the cinterval bootstrap option available in Mplus with 10,000 draws (Muthen, 2016; Muthen, 2018).

Missing data. Following the missing data process of Walters (2019), who also used the GREAT data, revealed that there were 40 relevant study items missing less than $50 \%$ of responses (participants who did not respond to the survey question were coded as 1, all other as 0) at all waves of the GREAT data used in the present study (Waves 1-4). Comparatively, there were 10 relevant study items which were missing more than $50 \%$ of responses (coded in the same manner as previously mentioned) at the final wave of the present study (Wave 4). Further, all responses missing more than $50 \%$ of data appear in Wave 4. Thereafter, each variable was summed to create a singular missing response variable representing less than $50 \%$ of all missing cases. The missing response variable, representing less than $50 \%$ of missing cases, resulted in a range of 0 to 32 wherein 0 represented all those who responded to each variable and all other values represented missing cases. The missing response variable representing more than $50 \%$ of cases was coded in a similar manner as the less than 50\% variable; however, it resulted in a range of 0 to 10 . Before a two-group comparison t-tests could be performed to determine if the missing data groups were statistically different, the variable representing missing values less than $50 \%$ and the variable representing missing cases over $50 \%$ were each 
dichotomized. Results of the t-test revealed that respondents who had less than $50 \%$ of missing data on the current study variables (Waves 1-3) were significantly different than those who had dropped out at later time points in the GREAT survey (Wave 4) (p. < $.001)$.

When current participants from Waves 1-3 were compared to missing responses in variables with over $50 \%$ of missing cases at Wave 4, further analysis (t-tests for continuous variables and chi square tests for categorical variables) revealed that individuals who dropped out of the study at Wave 4 were more likely to be White $(p .<$ $.001)$, older $(p .<.01)$, live in a single parent household $(p .<.001)$, complete the GREAT program $(p .<.05)$, currently be in a gang $(p .<.001)$, ever in their lifetime be in a gang $(p .<.001)$, and spend more time in USWP $(p .<.001)$. Additionally, those leaving the study had greater low self-control at earlier waves $(p .<.001)$, experienced greater parental knowledge $(p .<.001)$, and reported more peer property delinquency $(p .<.001)$, peer violent delinquency $(p .<.001)$, peer substance use $(p .<.001)$, individual property delinquency $(p .<.01)$, individual violent delinquency $(p .<.01)$, as well as individual substance use $(p .<.001)$.

Although dropouts were different than participants who remained in the study, incomplete data is a common problem in longitudinal research (Hansen, Tobler, \& Graham, 1990; Jeličić, Phelps, \& Lerner, 2009). The pioneering work of Rubin (1976) and subsequent investigations conducted by Little and Rubin (2002) proposed three missing data mechanisms. First, missing data may be missing completely at random (MCAR), whereby the observed data can be considered a random subsample had the dataset been complete. Second, missing data may be missing at random (MAR), 
indicating ignorable missingness that is correlated to other study-related variables. Third, data may be missing not at random (MNAR), whereby missingness is related to the hypothetical values that are missing.

The MCAR test developed by Little (1988) revealed that missingness in the GREAT dataset does not meet the assumptions of MCAR. It has been further established that it is only possible to test the assumptions of a MCAR mechanism, because MAR and MNAR assumptions depend on having knowledge of the missing data (Baraldi \& Enders, 2010; Enders, 2010).

As it is common for the findings yielded by studies exploring antisocial behavior to be highly influenced by data pertaining to individuals who did not commit any offending at all, a weighted least squares estimator is preferred over maximum likelihood (ML) estimators because it makes no assumptions about joint normality and violations of these assumptions can produce distortions in model adequacy (Bentler \& Yuan, 1999; Yuan \& Bentler, 1998). In the present study, a robust weighted least squares means and variances (WLSMV) estimator based on a diagonal weight matrix was adopted. This estimator uses univariate and bivariate listwise deletion, in other words, pairwise deletion methods. Specifically, univariate full information maximum likelihood (FIML) is used during the first stage of estimation. Next, estimates are obtained by fixing data parameters to the first stage estimates and then maximizing over the second stage parameters (Asparouhov \& Muthen, 2010). Moreover, pairwise deletion attempts to use all available information present in the data by "discarding cases on a variable to variable basis; each element is calculated separately and only those with cases with missing values on a particular bivariate pair are discarded" (Enders \& Bandalos, 2001, p. 432). In this 
manner, pairwise deletion uses a subset of cases with complete data on both the independent and dependent variables to compute the covariance matrix (Enders, 2010).

\section{Study 2 (Reciprocal Effects) Measures}

Unstructured socializing with peers. Consistent with prior research in which scholars used this survey question and data (Higgins \& Jennings 2010; Turanovic \& Pratt, 2014; Wolfe \& McLean, 2017), the GREAT questionnaire included the survey question "Do you ever spend time hanging around with your current friends not doing anything in particular where no adults are present?" $(\mathrm{No}=1 ;$ Yes $=2)$. This is followed by: "If YES, how many hours do you spend doing this during an average week?"

hours). As previously mentioned, and as Osgood and Anderson (2004) along with Higgins and Jennings (2010) have discussed, the open-ended nature of this question could lead to issues with misreporting and skewness. Thus, the same recoding procedure from the aforementioned studies, and Study 1 of this dissertation, was used to overcome this issue in Waves 1,2, and 3. The transformation resulted in a 0-7 range at each of the three waves.

Individual/Respondent Delinquency/substance use. Individual delinquency/ substance use was measured at all three time points that are the focus of the reciprocal effects models (Spring 1995, Fall 1995, Fall 1996), wherein respondents were read the following prompt: "Studies have found that everyone breaks the rules and laws sometimes. Have you ever done any of the following? If yes, indicate how many times in the past 12 months you have done each thing." Respondents were asked at Wave 1 (Spring 1995) to indicate how many times they had done these things in the past 12 months, while responds at Wave 2 (Fall 1995) were asked to indicate how many times 
they had done these things in the past three months. At Wave 3 (Fall 1996), respondents were required to state the same but for a period covering the preceding six months. Items measuring property delinquency required the respondents to indicate whether they had: "Purposely damaged or destroyed property that did not belong to you?"; "Stolen or tried to steal something worth less than $\$ 50$ ?”; "Stolen or tried to steal something worth more than $\$ 50$ ?"; and "Gone into or tried to go into a building to steal something?” A four-item latent factor was created measuring property delinquency. Items used to measure violent delinquency required the respondent to indicate if he/she had: "Attacked someone with a weapon," "Hit someone with the idea of hurting them," and "Used a weapon or force to get money or things from people." In line with the above, a three-item latent factor was created measuring violent delinquency. Similarly, when responding to items measuring substance use, the participants indicated if they had: “Used tobacco products," "Used alcohol," and "Used marijuana.” A three-item latent variable was created measuring substance use. As previously mentioned, when describing these measures for study one, and employed by Higgins and Jennings (2010), each of the items which represent the three measures (i.e., property delinquency, violent delinquency, substance use $)$ were dummy coded $(0=$ no participation and $1=$ participation in one or more delinquent acts) to address issues with skewness in each model. The descriptive statistics for the latent variables in each model are provided in Table 3. 
Table 3. Descriptive Statistics of Latent Variables for Reciprocal Effects Models

Model 1

Property Delinquency $(\mathrm{N}=1,675)$

Variable

Property Delinquency (Wave 1)

- Property Delinquency Item 1

- Property Delinquency Item 2

- Property Delinquency Item 3

- Property Delinquency Item 4

Property Delinquency (Wave 2)

- Property Delinquency Item 1

- Property Delinquency Item 2

- Property Delinquency Item 3

- Property Delinquency Item 4

Property Delinquency (Wave 3)

- Property Delinquency Item 1

- Property Delinquency Item 2

- Property Delinquency Item 3

- Property Delinquency Item 4

Mean $\quad S D-F L$

Me
0.199
0.196
0.047
0.07
0.178
0.204
0.048
0.068
0.281
0.2
0.059
0.098

F

0.199

0.196

0.047

0.072

0.178

0.204

0.048

0.068

0.281

0.21

0.059

0.098
0.399

$0.396 \quad 0.644$

$0.212 \quad 0.578$

$0.259 \quad 0.665$

$0.382 \quad 0.536$

$0.402 \quad 0.714$

$0.251 \quad 0.663$

$0.449 \quad 0.560$

$0.411 \quad 0.753$

0.237

0.298
$0.214 \quad 0.571$
Model 2 Violent Delinquency $(\mathrm{N}=1,670)$

Mean SD

Mean SD $\underline{\text { FL }} \quad \underline{\text { Min }} \quad \underline{\text { Max }}$

\begin{tabular}{lll} 
& \multicolumn{2}{c}{$\begin{array}{c}\text { Model } 3 \\
\text { Substance Use }(\mathrm{N}=1,665)\end{array}$} \\
Max Mean & SD FL $\quad \underline{\text { Min }}$
\end{tabular} 
Table 3 Continued. Descriptive Statistics of Latent Variables for Reciprocal Effects Models

Model 1

Property Delinquency $(\mathrm{N}=1.675$

Variable

Violent Delinquency (Wave 1)

- Violent Delinquency Item 1

- Violent Delinquency Item 2

- Violent Delinquency Item 3

Violent Delinquency (Wave 2)

- Violent Delinquency Item 1

- Violent Delinquency Item 2

- Violent Delinquency Item 3

Violent Delinquency (Wave 3)

- Violent Delinquency Item 1

- Violent Delinquency Item 2

- Violent Delinquency Item 3
Model 2

Violent Delinquency $(\mathrm{N}=1,670)$

$\begin{array}{ccccc}\text { Mean } & \underline{\text { SD }} & \underline{\text { FL }} & \underline{\text { Min }} & \text { Max } \\ --- & --- & --- & --- & --- \\ --- & --- & --- & --- & --- \\ --- & --- & --- & --- & --- \\ & & & & \\ --- & --- & --- & --- & --- \\ --- & --- & --- & -- & -- \\ --- & --- & --- & -- & -- \\ & & & & \\ --- & --- & --- & --- & --- \\ --- & --- & --- & -- & --- \\ --- & --- & --- & -- & --\end{array}$

\begin{tabular}{|llll}
$\underline{\text { Mean }}$ & $\underline{\text { SD }}$ & $\underline{\text { FL }}$ & $\underline{\text { Min }}$ \\
0.343 & 0.474 & 0.564 & 0 \\
0.055 & 0.228 & 0.513 & 0 \\
0.025 & 0.158 & 0.407 & 0 \\
& & & \\
0.354 & 0.479 & 0.535 & 0 \\
0.048 & 0.212 & 0.484 & 0 \\
0.025 & 0.158 & 0.425 & 0 \\
& & & \\
0.431 & 0.495 & 0.611 & 0 \\
0.074 & 0.261 & 0.500 & 0 \\
0.035 & 0.184 & 0.382 & 0
\end{tabular}

Model 3

Substance Use (N=1,665)

$\underline{\mathrm{SD}} \quad \underline{\mathrm{FL}} \quad \underline{\text { Min }} \quad \underline{\mathrm{Max}}$

\begin{tabular}{l|l} 
& \\
1 & --- \\
1 & --- \\
1 & --- \\
& --- \\
1 & --- \\
1 & --- \\
1 & --- \\
& \\
1 & --- \\
1 & --- \\
1 & ---
\end{tabular}

$\underline{\operatorname{Max}}$

$\begin{array}{cccc}-- & -- & -- & --\end{array}$

$\begin{array}{llll}-- & -- & -- & --\end{array}$

$\begin{array}{lll}--- & -- & --\end{array}$

$\begin{array}{llll}-- & -- & -- & --\end{array}$

$----$

--- --- --- ---

$\begin{array}{llll}-- & -- & -- & -- \\ --- & -- & --\end{array}$ $\begin{array}{llll}-- & -- & -- & -- \\ - & -- & -\end{array}$ 
Table 3 Continued. Descriptive Statistics of Latent Variables for Reciprocal Effects Models

\begin{tabular}{|c|c|c|c|c|c|c|c|c|c|c|c|c|c|c|c|}
\hline \multirow[b]{2}{*}{$\underline{\text { Variable }}$} & \multicolumn{5}{|c|}{$\begin{array}{c}\frac{\text { Model } 1}{\text { Property Delinquency }}(\mathrm{N}=1,675) \\
\underline{ }\end{array}$} & \multicolumn{5}{|c|}{$\frac{\text { Model 2 }}{\text { Violent Delinquency }}(\mathrm{N}=1,670)$} & \multicolumn{5}{|c|}{$\begin{array}{l}\text { Model } 3 \\
\text { Substance Use }(\mathrm{N}=1,665)\end{array}$} \\
\hline & Mean & $\underline{\mathrm{SD}}$ & $\underline{F L}$ & $\underline{\text { Min }}$ & $\underline{\text { Max }}$ & Mean & $\underline{S D}$ & $\underline{F L}$ & $\underline{\text { Min }}$ & $\underline{\operatorname{Max}}$ & Mean & $\underline{\mathrm{SD}}$ & $\underline{\text { FL }}$ & Min & $\underline{\text { Max }}$ \\
\hline \multicolumn{16}{|l|}{ Substance Use (Wave 1) } \\
\hline - Substance Use Item 1 & --- & --- & --- & --- & --- & --- & --- & --- & --- & --- & 0.170 & 0.375 & 0.713 & 0 & 1 \\
\hline - Substance Use Item 2 & --- & --- & --- & --- & --- & --- & --- & --- & --- & --- & 0.226 & 0.418 & 0.714 & 0 & 1 \\
\hline - Substance Use Item 3 & --- & --- & --- & --- & --- & --- & --- & --- & --- & --- & 0.078 & 0.268 & 0.599 & 0 & 1 \\
\hline \multicolumn{16}{|l|}{ Substance Use (Wave 2) } \\
\hline - Substance Use Item 1 & --- & --- & --- & --- & --- & --- & --- & --- & --- & --- & 0.164 & 0.370 & 0.725 & 0 & 1 \\
\hline - Substance Use Item 2 & --- & --- & --- & --- & --- & --- & --- & --- & --- & --- & 0.227 & 0.418 & 0.703 & 0 & 1 \\
\hline - Substance Use Item 3 & --- & --- & --- & --- & --- & --- & --- & --- & --- & --- & 0.081 & 0.274 & 0.651 & 0 & 1 \\
\hline \multicolumn{16}{|l|}{ Substance Use (Wave 3) } \\
\hline - Substance Use Item 1 & --- & --- & --- & --- & --- & --- & --- & --- & --- & --- & 0.241 & 0.428 & 0.734 & 0 & 1 \\
\hline - Substance Use Item 2 & --- & --- & --- & --- & --- & --- & --- & --- & --- & --- & 0.318 & 0.466 & 0.712 & 0 & 1 \\
\hline - Substance Use Item 3 & --- & --- & --- & --- & --- & --- & --- & --- & --- & --- & 0.146 & 0.354 & 0.692 & 0 & 1 \\
\hline
\end{tabular}


Covariates. In addition to measuring the primary theoretical constructs of interest (i.e., USWP, delinquency, and substance use), respondents also reported their biological sex $($ male $=1 ;$ female $=0)$, race $($ White $=1 ;$ non-White $=0 ;$ dummy coded $)$, age (in years), whether the respondent lived in a single-parent household (yes $=1 ;$ no $=0$ ), currently a gang member (yes $=1 ;$ no $=0$ ), ever been a gang member $($ yes $=1$; no $=0$ ) measured at Wave 1, and whether the respondent completed the GREAT program assessed at Wave $2($ yes $=1 ;$ no $=0)$. The respondent's level of self-control was measured at Wave 1 by an eight-item scale comprising of attitudinal measures assessing the respondent's impulsivity and risk seeking behavior (Grasmick et al., 1993). One of the items measuring impulsivity - "I often act on the spur of the moment without stopping to think."-is given here as an example. An example item measuring riskseeking behavior is: "Sometimes I will take a risk just for the fun of it." The respondent was required to select one of the following five options: $1=$ "Strongly Disagree," $2=$ "Disagree," 3 = "Neither Agree nor Disagree," 4 = "Agree," and 5 = "Strongly Agree." This measure of self-control was created by taking the average of the eight items $(\alpha=$ $.74)$, whereby higher scores are indicative of lower self-control.

Respondents at Wave 1 also reported how much they agree or disagree with statements measuring parental knowledge. Parental knowledge was measured using such items as: "When I go someplace, I leave a note for my parents or call them to tell them where I am.” Respondents could choose from a five-point likert scale ranging from "Strongly Disagree" to "Strongly Agree." This measure was created by taking the average of the four items $(\alpha=.70)$. Last, in each particular model of the present study, the peer anti-social behavior assessed at Spring 1995 (Wave 1) was controlled for by taking 
the average of each of the peer offending items previously described for Study 1 (property offending $\alpha=.85$; violent offending $\alpha=.73$; substance use $\alpha=.87$ ).

In order to maintain a substantive sample size and avoid severe attrition in the latter waves of the GREAT data collection $(52 \%, 56 \%$, and 57\% reduction for Wave 4, Wave 5, and Wave 6, respectively), the present investigation focuses on the data collected during only the first three survey waves. Specifically, the aim of this study is to elucidate the potential reciprocal influences of USWP and antisocial behavior (i.e., property delinquency, violent delinquency, substance use). These relationships are based on the information obtained in Wave 1 (Spring 1995), Wave 2 (Fall 1995), and Wave 3 (Fall 1996), retaining a sample size of over 1,600 respondents at Wave 3. Table 4 provides the descriptive statistics for the variables used in the analysis. 
Table 4. Descriptive Statistics of Variables for Reciprocal Effects Models

\begin{tabular}{|c|c|c|c|c|c|c|c|c|c|c|c|c|}
\hline$\underline{\text { Variable }}$ & \multicolumn{4}{|c|}{$\begin{array}{c}\text { Model } 1 \\
\text { Property Delinquency }(\mathrm{N}=1,675)\end{array}$} & \multicolumn{4}{|c|}{$\begin{array}{c}\underline{\text { Model 2 }} \\
\underline{\text { Violent Delinquency }}(\mathrm{N}=1,670)\end{array}$} & \multicolumn{4}{|c|}{$\frac{\text { Model } 3}{\text { Substance Use }(\mathrm{N}=1,665)}$} \\
\hline Age (Wave 1) & 12 & 0.629 & 10 & 14 & 12 & 0.628 & 10 & 14 & 12 & 0.627 & 10 & 14 \\
\hline Male (Wave 1) & 0.486 & 0.500 & 0 & 1 & 0.484 & 0.500 & 0 & 1 & 0.483 & 0.500 & 0 & 1 \\
\hline White (Wave 1) & 0.463 & 0.499 & 0 & 1 & 0.462 & 0.499 & 0 & 1 & 0.465 & 0.499 & 0 & 1 \\
\hline Single-Parent Household (Wave 1) & 0.331 & 0.471 & 0 & 1 & 0.332 & 0.471 & 0 & 1 & 0.332 & 0.471 & 0 & 1 \\
\hline Low Self-Control (Wave 1) & 2.884 & 0.680 & 1 & 4.875 & 2.883 & 0.680 & 1 & 4.875 & 2.882 & 0.678 & 1 & 4.875 \\
\hline Gang Membership Ever (Wave 1) & 0.078 & 0.268 & 0 & 1 & 0.078 & 0.268 & 0 & 1 & 0.077 & 0.266 & 0 & 1 \\
\hline $\begin{array}{l}\text { Gang Membership Currently } \\
\text { (Wave 1) }\end{array}$ & 0.039 & 0.192 & 0 & 1 & 0.039 & 0.192 & 0 & 1 & 0.038 & 0.192 & 0 & 1 \\
\hline Parental Knowledge (Wave 1) & 3.871 & 0.745 & 1 & 5 & 3.871 & 0.745 & 1 & 5 & 3.875 & 0.742 & 1 & 5 \\
\hline $\begin{array}{l}\text { Unstructured Socializing } \\
\text { With Peers (Wave 1) }\end{array}$ & 1.450 & 1.617 & 0 & 7 & 1.446 & 1.611 & 0 & 7 & 1.449 & 1.625 & 0 & 7 \\
\hline $\begin{array}{l}\text { Unstructured Socializing } \\
\text { With Peers (Wave 2) }\end{array}$ & 1.447 & 1.617 & 0 & 7 & 1.451 & 1.618 & 0 & 7 & 1.453 & 1.622 & 0 & 7 \\
\hline $\begin{array}{l}\text { Unstructured Socializing } \\
\text { With Peers (Wave 3) }\end{array}$ & 1.844 & 1.724 & 0 & 7 & 1.843 & 1.726 & 0 & 7 & 1.843 & 1.724 & 0 & 7 \\
\hline
\end{tabular}


Study 2 analytic plan. To investigate the potential reciprocal relationship between USWP and anti-social behavior, the statistical package Mplus 8.1 was employed to conduct SEM of latent and observed variables (Muthén \& Muthén, 2017). SEM was used to analyze the reciprocal (cross-lagged) pathways between USWP and property delinquency, USWP and violent delinquency, and USWP and substance use. A crosslagged panel model (CLPM) incorporated repeated measures of constructs over multiple waves of data to assess: 1) stability in the constructs over time, 2) associations occurring at the same period of time, and 3) cross-lagged effects over time. These associations were examined by means of longitudinal cross-lagged models ranging from 3 to 12-month intervals (i.e., Spring 1995, Fall 1995, Fall 1996) to elucidate the linkage between USWP and delinquency. As with Study 1 of this dissertation, the same fit indices are adopted for the current study.

Missing data. Using the procedure of Walters (2019) as a guiderevealed that, for the present study, there were 61 relevant items missing less than $50 \%$ of responses (participants who did not respond to the survey question were coded as 1 , all other as 0 ) at all waves of the GREAT data (Waves 1-3). Comparatively, only one item was missing more than $50 \%$ of responses (USWP at Wave 3). Further, Esbensen et al. (2001) found that the majority of respondents dropped out at the later waves of the GREAT survey and given the benefits of using FIML to estimate missing data, loss of responses was a less severe issue for the present study than for Study 1 .

For the current study, FIML was employed, which has been known to produce unbiased estimates when missing data meet the MCAR and MAR assumptions. Serious violations of the MAR assumptions, however, are relatively rare (Graham, Hofer, 
Donaldson, MacKinnon, \& Schafer, 1997; Schafer \& Graham, 2002). Further, when missing data is MNAR, maximum likelihood approaches and multiple imputation tend to provide better outcomes compared to the traditional approaches, such as listwise deletion (Baraldi \& Enders, 2010). Additionally, FIML has also been found to be robust in violations of its basic assumptions (Young \& Johnson, 2013). In FIML estimation of unknown parameters, an iterative process that repeatedly auditions various values for the population mean and variances is conducted until the estimates that have most likely produced the data are found (Enders, 2010). Given these considerations and as a state-ofthe-art missing data technique which yields unbiased parameter estimates under the MAR assumptions (Shafer \& Graham, 2002), FIML was employed to analyze the SEM models in Study 2.

\section{Study 3 (Nonlinear effects) Measures}

Unstructured socializing with peers. Consistent with prior research who used the GREAT data and survey question which was measured in this study at Spring1995/Wave 1 (see Higgins \& Jennings, 2010; Turanovic \& Pratt, 2014; Wolfe \& McLean, 2017), the survey question measuring USWP reads: "Do you ever spend time hanging around with your current friends not doing anything in particular where no adults are present?" (No $=1$; Yes $=2$ ). An additional item includes: "If YES, how many hours do you spend doing this during an average week?" (__ hours). As noted earlier, and as Osgood and Anderson (2004) and Higgins and Jennings (2010) have discussed, the openended nature of this question could lead to issues with misreporting and skewness. Thus, the same recoding procedure reported for Study 1 and Study 2 of this dissertation was used to overcome this issue. The transformation resulted in the $[0,7]$ range. 
Individual/Respondent Delinquency/substance use. In order to measure delinquency/substance use at Fall 1995 (Wave 2), respondents were read the following prompt: "Studies have found that everyone breaks the rules and laws sometimes. Indicate how many times in the past 6 months you have done each thing. If you have not done these things, enter 0. ." Four items were used to measure the frequency of property delinquency, namely: (1) "Purposely damaged or destroyed property that did not belong to you?"; (2) “Stolen or tried to steal something worth less than $\$ 50$ ?”; (3) “Stolen or tried to steal something worth more than $\$ 50$ ?"; and (4) “Gone into or tried to go into a building to steal something?" $(\alpha=.67)$. To measure the frequency of violent delinquency without the creation of a latent variable, preliminary analysis revealed a three-item measure to have poor inter-item reliability $(\alpha=.39)$. Thus, a two-item measure was summed revealing a moderately strong correlation $(r=.56)$. The respondent was asked to indicate if he/she had: (1) "Attacked someone with a weapon?" and (2) "Used a weapon or force to get money or things from people?" Last, three items used to measure the frequency of substance use, prompting the respondent to indicate if he/she had: (1) "Used tobacco products," (2) "Used alcohol," and (3) "Used marijuana" $(\alpha=.69)$. Following the procedure in the prior studies of this dissertation, to remove bias in overly skewed results, each of the delinquency and substance use items were dichotomized and then summed resulting in values of 0,1 , and 2 .

Covariates In addition to measuring the primary theoretical constructs of interest, respondents at Wave 1 also reported their biological sex (male $=1$; female $=0$ ), race (White $=1$; non-White $=0$; dummy coded), age (in years), whether the respondent lived in a single-parent household (yes $=1$; no $=0$ ), currently or ever been in a gang (yes $=1$; 
no $=0$ ), and whether the respondent completed the GREAT program assessed at Wave 2 $($ yes $=1 ;$ no $=0)$. As noted before, the respondent's level of self-control was measured by an eight-item scale at Wave 1 where higher measures were indicative of lower selfcontrol $(\alpha=$.74). Respondents were also able to choose from a five-point likert scale ranging from whether they "Strongly Disagree" to "Strongly Agree" about items inquiring of parental knowledge. An example of this item was: "My parents know where I am when I am not at home or at school.” As with Study 2, this measure was created by taking the average of the four items $(\alpha=.70)$. Finally, in each particular model of the current study, peer anti-social behavior assessed at Spring 1995 (Wave 1) was controlled for by taking the average of each of the peer offending items (property offending $\alpha=.85$; violent offending $\alpha=.73$; substance use $\alpha=.87$ ). The descriptive statistics for each model are provided in Table 5. 
Table 5. Descriptive Statistics for Nonlinear Effects Models

Model 1

Model 2

Model 3

Property Delinquency $(\mathrm{N}=1,404) \quad \underline{\text { Violent Delinquency }(\mathrm{N}=1,302)} \quad \underline{\text { Substance Use }(\mathrm{N}=1,361)}$

$\underline{\text { Variable }}$

Unstructured Socializing With Peers (Wave 1)

Age (Wave 1)

Male (Wave 1)

White (Wave 1)

Single-Parent Household (Wave 1)

Great Program (Wave 2)

Low Self-Control (Wave 1)

Gang Membership Ever (Wave 1)

Gang Membership Currently

(Wave 1)

Parental Knowledge (Wave 1)

Property Delinquency (Wave 1)

Violent Delinquency (Wave 1)

Substance Use (Wave 1)

Peer Property Delinquency

(Wave 1)

Peer Violent Delinquency (Wave 1)

Peer Substance Use (Wave 1)

Property Delinquency (Wave 2)

Violent Delinquency (Wave 2)

Substance Use (Wave 2)

Mean $\quad \underline{\text { D }}$

$\underline{\mathrm{SD}}$

Min

.

$\begin{array}{llll}1.474 & 1.642808 & 0 & 7\end{array}$

$\begin{array}{llll}12 & 0.654137 & 10 & 15\end{array}$

$\begin{array}{llll}0.489 & 0.500 & 0 & 1\end{array}$

$0.451 \quad 0.497687$

$0.347 \quad 0.476111$

0.622

2.918

0.083

0.037

3.838

0.500

$---$

1.524

$-$

$--$

0.463

0.485092

0.686197

0.27625

0.18936

0.769124

0.917146

$---$

---

0.754178

$---$

$$
\text { --- }
$$

0.888169

Notes: SD = Standard Deviation

\begin{tabular}{cccc|cccc} 
Mean & $\underline{\text { SD }}$ & $\underline{\text { Min }}$ & $\underline{\text { Max }}$ & $\underline{\text { Mean }}$ & $\underline{\text { SD }}$ & $\underline{\text { Min }}$ & $\underline{\text { Max }}$ \\
1.474 & 1.643 & 0 & 7 & 1.474 & 1.643 & 0 & 7 \\
12.000 & 0.654 & 10 & 15 & 12 & 0.654 & 10 & 15 \\
0.489 & 0.500 & 0 & 1 & 0.489 & 0.500 & 0 & 1 \\
0.451 & 0.498 & 0 & 1 & 0.451 & 0.498 & 0 & 1 \\
0.347 & 0.476 & 0 & 1 & 0.347 & 0.476 & 0 & 1 \\
0.622 & 0.485 & 0 & 1 & 0.622 & 0.485 & 0 & 1 \\
2.918 & 0.686 & 1 & 5 & 2.918 & 0.686 & 1 & 5 \\
0.083 & 0.276 & 0 & 1 & 0.083 & 0.276 & 0 & 1 \\
0.037 & 0.189 & 0 & 1 & 0.037 & 0.189 & 0 & 1 \\
3.838 & 0.769 & 1 & 5 & 3.838 & 0.769 & 1 & 5 \\
--- & --- & --- & --- & --- & --- & --- & --- \\
0.351 & 0.520 & 0 & 2 & --- & --- & --- & --- \\
--- & --- & --- & --- & 0.454 & 0.818 & 0 & 3 \\
--- & --- & --- & --- & --- & --- & --- & --- \\
1.246 & 0.625 & 1 & 5 & --- & --- & --- & --- \\
--- & --- & --- & --- & 1.514 & 0.856 & 1 & 5 \\
--- & --- & --- & --- & --- & --- & --- & --- \\
0.410 & 0.626 & 0 & 3 & --- & --- & --- & --- \\
--- & --- & --- & --- & 0.430 & 0.820 & 0 & 3 \\
\hline & & & & & & &
\end{tabular}


Study 3 analytic plan. To examine whether USWP influences delinquency and substance use in a nonlinear manner, two steps were taken. First, a series of negative binomial and Poisson regression models was used to assess the extent to which USWP (Wave 1) influences a count dependent variable, such as the number of times respondents had engaged in property delinquency (Wave 2) in the past three months (Fall 1995 questionnaire). Given that many adolescents engaged in few acts of delinquency, the data is skewed in a Poisson distribution. Further, as the variance of the outcome variables exceeds their mean values in the property delinquency and substance use models (Models 1 and 3), negative binomial regression is preferred to Poisson regression (Meldrum \& Leimberg, 2018). On the other hand, as the variance of the outcome variables in the violent delinquency model did not exceed their mean values, Poisson regression was used in this instance (Model 2).

Second, analysis was conducted for each model through adding a squared (quadratic) term to assess the degree to which the relationship between USWP and delinquency may in fact be nonlinear. If the statistically significant incidence rate ratio (IRR) exceeded 1.00 (squared term), this would be interpreted as evidence indicating that the nonlinear association between USWP and delinquency is increasing in an accelerating manner. Conversely, a statistically significant IRR for the squared term below 1.00 would indicate that the relationship between USWP and delinquency is still strengthening, albeit in a decelerating manner. This same process was repeated separately for the models capturing the effect of USWP on property delinquency, violent delinquency, and substance use. All models are estimated using STATA 14.2, which handles missing data by default through listwise deletion (Long \& Freese, 2006). 


\section{RESULTS}

\section{Study 1 (Multiple Mediation)}

\section{Model 1, Property Delinquency}

Table 6 provides the results of the structural equation modeling conducted to examine the hypothesized influence of parental knowledge (Spring 1995/Wave 1) on property delinquency (Fall 1997/Wave 4) running through both USWP (Fall 1995/Wave

2) and peer property delinquency (Fall 1996/Wave 3), as depicted earlier in Figure 1. The correlation matrix for the key variables used in the analysis appears in Appendix A. In addition, several demographic variables that served as controls in the model are reported in Table 6, along with the fit statistics. The model developed as a part of the present study incorporated one exogenous latent variable (parental knowledge), one endogenous observed variable (USWP), and two endogenous latent variables (peer property delinquency and individual property delinquency). Although the likelihood ratio test of Model 1 indicates unacceptable model fit $\left(\chi^{2}\right.$ of $\left.487.607 p .<.001\right)$, this is a common issue for larger samples (Elmore, 2005; Kenny, 2015) and model complexity can affect interpretation of the chi square statistic (Bearden, Sharma, \& Teel, 1982). Given this assertion, additional and more reliable model fit statistics are provided such as the RMSEA of .037, which indicate close fit to the data, that is further supported by the CFI (.952) and TLI (.938).

\section{Study 1, Model 1, USWP (Wave 2) Equation}

The model estimates of the direct effect of parental knowledge (Wave 1) on USWP (Wave 2) is statistically significant and suggests a relationship in the expected direction, providing support for the first hypothesis of the present study. Specifically, the 
results show a direct negative effect of parental knowledge on USWP $(b=-.271, p$. < $.01 ; \beta=-.083$,$) . The findings further indicate that being White (b=.332, p .<.001, \beta=$ $.104)$, living in a single-parent household $(b=.196, p .<.05, \beta=.058)$, having low selfcontrol $(b=.383, p .<.001, \beta=.161)$, being a gang member at some point in life $(b=$ $.652, p .<.001, \beta=.105)$, and prior engagement in property delinquency at Wave $1(b=$ $.319, p .<.001, \beta=.184$ ) are factors positively associated with USWP. The $\mathrm{R}^{2}$ value of .127 indicates that $12.7 \%$ of the variation in the observed variable of USWP is explained by the model capturing the aforementioned factors.

\section{Study 1, Model 1, Peer Property Delinquency (Wave 3) Equation}

Next, a direct positive effect is found for the relationship between USWP (Wave 2) and peer property delinquency (Wave 3$)(b=.108, p .<.001, \beta=.206)$. Additionally, the results show that being male $(b=.317, p .<.001, \beta=.189)$, having low self-control $(b$ $=.235, p .<.001, \beta=.189)$, previous gang membership $(b=.361, p<.05, \beta=.111)$, and prior property delinquency at Wave $1(b=.152, p .<.001, \beta=.167)$ are factors positively associated with peer property delinquency. Furthermore, identifying as White $(b=-.126$, $p .<.05, \beta=-.075)$ and currently being a gang member $(b=-.547, p .<.05, \beta=-.118)$ are factors negatively associated with peer property delinquency. The $\mathrm{R}^{2}$ value of .257 indicates that $25.7 \%$ of the variation in the latent factor of peer property delinquency is explained by the structural model.

\section{Study 1, Model 1, Property Delinquency (Wave 4) Equation}

The portion of the model capturing the effect of peer property delinquency (Wave 3) on individual property delinquency (Wave 4) revealed a significant direct path between these variables $(b=.114, p .<.001, \beta=.357)$. A second direct path between 
parental knowledge and property delinquency is also established $(b=-.051, p .<.05, \beta=$ -.093). The results further indicate that engagement in property delinquency at Wave 1 is associated with property delinquency at Wave $4(b=.041, p .<.05, \beta=.143)$. The $\mathrm{R}^{2}$ value of .323 indicates that $32.3 \%$ of the variation in the latent factor of individual delinquency is explained by the structural model.

\section{Study 1, Model 1, Property Delinquency, Indirect Effects}

As a part of the structural modeling process, the indirect relationship between parental knowledge (Wave 1) and peer property delinquency (Wave 3) via USWP (Wave 2) was examined and confirmed $[(b=-.029, p .<.05, \beta=-.017), 95 \%$ bootstrapped confidence interval $=-0.056$ to -0.008$]$, whereby the findings indicate that approximately $58 \%$ of the total effect of parental knowledge on peer property delinquency is exhibited through USWP. Following the recommendations by Ditlevsen, Christensen, Lynch, Damsgaard, and Keiding (2005) to calculate the proportion of the effect being mediated by a variable(s), the indirect effect is divided by the total effect. The results show that the indirect relationship between USWP and individual property delinquency via peer property delinquency has the expected direction $[(b=.012, p .<.001, \beta=.073), 95 \%$ bootstrapped confidence interval $=.007$ to .018$]$, with about $60 \%$ of the total effect of USWP on property delinquency operating through peer property delinquency. Finally, the most informative estimate of the model pertains to the indirect relationship between parental knowledge and property delinquency via both USWP and peer property delinquency. This was also supported by the model results $(b=-.003, p .<.05, \beta=-.006)$, bootstrapped confidence interval $=-.007$ to -.001$]$. Moreover, the findings suggest that approximately $5.1 \%$ of the total effect of parental knowledge on property delinquency is 
exerted through both USWP and peer property delinquency. Figure 5 shows the path diagram for the property delinquency model. 
Table 6. Weighted Least Squares with Mean and Variance Adjusted Estimates of Unstandardized Coefficients, Standard Errors, and Standardized Coefficients for Property Delinquency Mediation Model

Model 1: Property Delinquency $\underline{(\mathrm{N}=1,616)}$

Predictor

Age

Male

White

Single-Parent Household

Great Program

Low Self-Control

Gang Membership Ever

Gang Membership Currently

Property Delinquency (Wave 1)

Parental Knowledge (Wave 1)

Unstructured Socializing

With Peers (Wave 2)

Peer Property Delinquency (Wave 3)
Endogenous Factors
Unstructured

Socializing

With Peers (Wave 2)

0.045

0.066

0.018

$-0.067$

0.081

$-0.021$

$0.332 * * *$

0.081

0.104

$0.196 *$

0.086

0.058

$-0.110$

0.082

$-0.034$

$0.383 * * *$

0.064

0.161

$0.652^{* *}$

0.251

0.105

$-0.084$

0.328

$-0.009$

$0.319 * * *$

0.055

0.184

-0.271 **

0.099

$-0.083$

---

\begin{tabular}{|c|c|}
\hline Peer Property & $\underline{\text { Property }}$ \\
\hline Delinquency & Delinquency \\
\hline (Wave 3) & (Wave 4) \\
\hline 0.023 & -0.030 \\
\hline 0.047 & 0.016 \\
\hline 0.017 & -0.070 \\
\hline $0.317 * * *$ & 0.039 \\
\hline 0.058 & 0.020 \\
\hline 0.189 & 0.072 \\
\hline$-0.126^{*}$ & 0.010 \\
\hline 0.060 & 0.019 \\
\hline-0.075 & 0.018 \\
\hline 0.089 & -0.040 \\
\hline 0.065 & 0.022 \\
\hline 0.050 & -0.070 \\
\hline 0.010 & 0.006 \\
\hline 0.059 & 0.018 \\
\hline 0.006 & 0.011 \\
\hline $0.235^{* * *}$ & 0.012 \\
\hline 0.050 & 0.015 \\
\hline 0.189 & 0.030 \\
\hline $0.361 *$ & 0.157 \\
\hline 0.150 & 0.084 \\
\hline 0.111 & 0.150 \\
\hline$-0.547 *$ & 0.065 \\
\hline 0.228 & 0.144 \\
\hline-0.118 & 0.044 \\
\hline $0.152 * * *$ & $0.041 *$ \\
\hline 0.033 & 0.017 \\
\hline 0.167 & 0.143 \\
\hline-0.021 & $-0.051 *$ \\
\hline 0.069 & 0.021 \\
\hline-0.012 & -0.093 \\
\hline & 0.008 \\
\hline $0.108 * * *$ & 0.008 \\
\hline 0.019 & 0.049 \\
\hline 0.206 & \\
\hline --- & $\begin{array}{l}0.114^{* * * *} \\
0.018 \\
0.357\end{array}$ \\
\hline
\end{tabular}


Table 6. Continued. Weighted Least Squares with Mean and Variance Adjusted Estimates of Unstandardized Coefficients, Standard Errors, and Standardized Coefficients for Property Delinquency Mediation Model

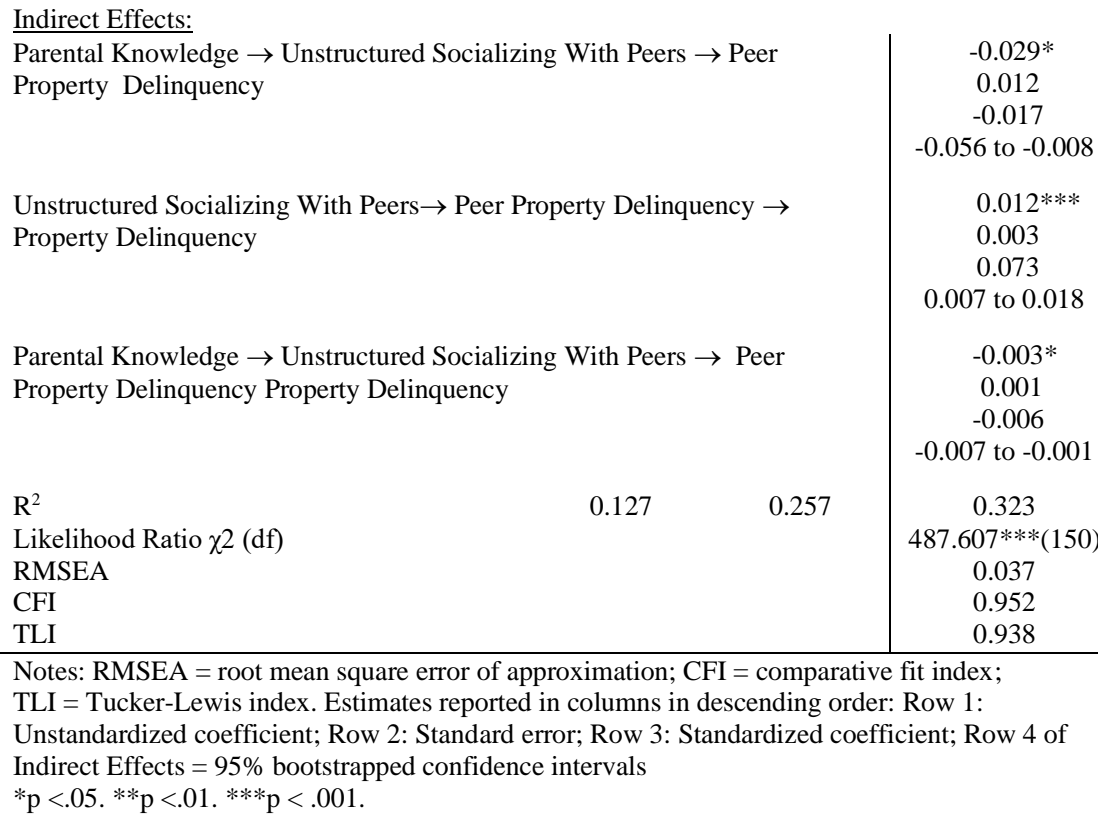

$* \mathrm{p}<.05 . * * \mathrm{p}<.01 . * * * \mathrm{p}<.001$. 


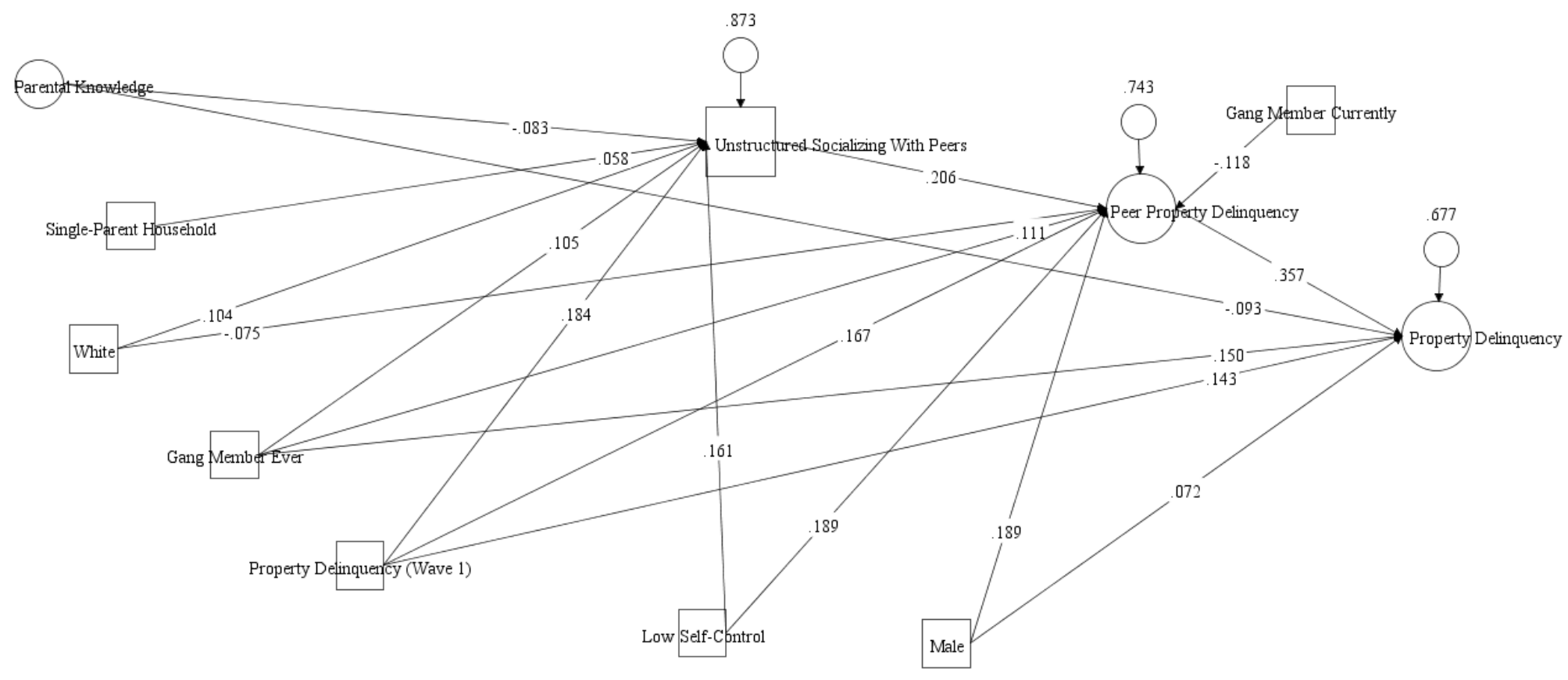

Figure 5. Property Delinquency Mediation Model with Significant Pathways and Standardized Coefficients $(\mathrm{N}=1,616)$. 


\section{Study 1, Model 2, Violent Delinquency}

The results reported in Table 7 pertain to the second model of the present study, assessing the influence of parental knowledge (Wave 1) on violent delinquency (Wave 4) via both USWP (Wave 2) and peer violent delinquency (Wave 3). The likelihood-ratio test of Model 2 (violent delinquency) ( $\chi^{2}$ of $397.862 p .<.001$ ) indicates unacceptable model fit; however, the RMSEA of .040, along with the CFI (.933) and the TLI (.907), indicate acceptable model fit. This model captured one exogenous latent variable (parental knowledge), one endogenous observed variable (USWP), and two endogenous latent variables (peer violent delinquency and violent delinquency). In line with the approach adopted for the property delinquency model (Model 1), duplicate control variables were included.

Study 1, Model 2, USWP (Wave 2) Equation

The model estimate of the direct effect of parental knowledge (Wave 1) on USWP (Wave 2) was statistically significant and predicted a relationship in the expected direction, i.e., it demonstrated a direct negative effect of parental knowledge on USWP ( $b$ $=-.308, p .<.001, \beta=-.095)$. The results also indicate that being White $(b=.351, p .<$ $.001, \beta=.109)$, living in a single-parent household $(b=.183, p .<.05, \beta=.054)$, having lower self-control $(b=.430, p .<.001, \beta=.181)$, prior gang membership $(b=.612, p .<$ $.01, \beta=.101)$, and greater engagement in violent delinquency at Wave $1(b=.477, p .<$ $.001, \beta=.188$ ) are factors positively associated with USWP at Wave 2 . The $\mathrm{R}^{2}$ value of .143 indicates that $14.3 \%$ of the variation in the observed variable of USWP is explained by the model. 


\section{Study 1, Model 2, Peer Violent Delinquency (Wave 3) Equation}

In addition, a direct, positive relationship is found between USWP (Wave 2) and peer violent delinquency (Wave 3$)(b=.100, p .<.001, \beta=.197)$. Being male $(b=.367$, p. $<.001, \beta=.225)$, having lower self-control $(b=.141, p .<.01, \beta=.118)$, prior gang membership $(b=.286, p .<.05, \beta=.093)$, and greater engagement in violent delinquency at Wave $1(b=.303, p .<.001, \beta=.237)$ are also positively associated with peer violent delinquency. Conversely, being White $(b=-.131, p .<.05, \beta=-.080)$ is negatively associated with peer violent delinquency. The $\mathrm{R}^{2}$ value of .295 indicates that $29.5 \%$ of the variation in the latent factor of peer violent delinquency is explained by the structural model.

Study 1, Model 2, Violent Delinquency (Wave 4) Equation The model also predicted a direct, positive relationship between peer violent delinquency and violent delinquency, which was observed $(b=.075, p .<.001, \beta=.292)$. The effects of other control variables failed to achieve statistical significance. The $\mathrm{R}^{2}$ value of .245 indicates that $24.5 \%$ of the variation in the latent factor of violent delinquency is explained by the structural model.

Study 1, Model 2, Violent Delinquency, Indirect Effects The model results also supported an indirect effect of parental knowledge on peer violent delinquency via USWP $[(b=-.031, p .<.01, \beta=-.019), 95 \%$ bootstrapped confidence interval $=-.055$ to $.011]$, whereby approximately $46.3 \%$ of the total effect of parental knowledge on peer violent delinquency is exerted through USWP. Further, the relationship between USWP and violent delinquency is mediated by peer violent delinquency $[(b=.007, p .<.01, \beta=$ .057 ), $95 \%$ bootstrapped confidence interval $=.003$ to .013 ], with $36.8 \%$ of the total 
effect of USWP on violent delinquency operating through peer violent delinquency. Lastly, the model results indicate that the relationship between parental knowledge and violent delinquency is mediated by both USWP and peer violent delinquency [ $(b=-.002$, $p .<.05, \beta=-.005)$, bootstrapped confidence interval $=-.005$ to -.001$]$ with approximately $4.3 \%$ of the total effect of parental knowledge on violent delinquency exerted via both USWP and peer violent delinquency. Figure 6 displays the path diagram for the violent delinquency model. 
Table 7. Weighted Least Squares with Mean and Variance Adjusted Estimates of Unstandardized Coefficients, Standard Errors, and Standardized Coefficients for Violent Delinquency Mediation Model

Model 2: Violent Delinquency $\underline{(\mathrm{N}=1,610)}$

Predictor

Age

Male

White

Single-Parent Household

Great Program

Low Self-Control

Gang Membership Ever

Gang Membership Currently

Violent Delinquency (Wave 1)

Parental Knowledge (Wave 1)

Unstructured Socializing With Peers (Wave 2)

Peer Violent Delinquency (Wave 3)
Endogenous Factors

Peer Violent Violent $\frac{\text { Socializing }}{\text { Peers (Wave 2) }} \quad \frac{\text { Delinquency }}{\text { (Wave 3) }} \quad \frac{\text { Delinquency }}{\text { (Wave 4) }}$

\begin{tabular}{|c|c|c|}
\hline With Peers (Wave 2) & (Wave 3) & (Wave 4) \\
\hline 0.077 & 0.013 & -0.023 \\
\hline 0.064 & 0.051 & 0.017 \\
\hline 0.030 & 0.010 & -0.070 \\
\hline-0.070 & $0.367 * * *$ & 0.018 \\
\hline 0.083 & 0.062 & 0.017 \\
\hline-0.022 & 0.225 & 0.042 \\
\hline $0.351 * * *$ & $-0.131 *$ & -0.019 \\
\hline 0.081 & 0.061 & 0.019 \\
\hline 0.109 & -0.080 & -0.046 \\
\hline $0.183^{*}$ & 0.077 & -0.013 \\
\hline 0.086 & 0.067 & 0.019 \\
\hline 0.054 & 0.044 & -0.029 \\
\hline-0.119 & 0.039 & 0.001 \\
\hline 0.082 & 0.061 & 0.017 \\
\hline-0.036 & 0.023 & 0.002 \\
\hline $0.430 * * *$ & $0.141 * *$ & 0.004 \\
\hline 0.065 & 0.050 & 0.014 \\
\hline 0.181 & 0.118 & 0.013 \\
\hline $0.612 * *$ & $0.286^{*}$ & 0.065 \\
\hline 0.232 & 0.133 & 0.092 \\
\hline 0.101 & 0.093 & 0.082 \\
\hline 0.075 & -0.067 & 0.098 \\
\hline 0.312 & 0.236 & 0.127 \\
\hline 0.009 & -0.015 & 0.088 \\
\hline $0.477 * * *$ & $0.303 * * *$ & 0.037 \\
\hline 0.076 & 0.051 & 0.025 \\
\hline 0.188 & 0.237 & 0.114 \\
\hline$-0.308 * * *$ & -0.036 & -0.038 \\
\hline 0.095 & 0.071 & 0.021 \\
\hline-0.095 & -0.022 & -0.090 \\
\hline \multirow{4}{*}{---} & $0.100 * * *$ & 0.012 \\
\hline & 0.019 & 0.008 \\
\hline & 0.197 & 0.091 \\
\hline & & $0.075^{* * *}$ \\
\hline \multirow[t]{2}{*}{---} & --- & 0.022 \\
\hline & & 0.292 \\
\hline
\end{tabular}


Table 7 Continued. Weighted Least Squares with Mean and Variance Adjusted Estimates of Unstandardized

Coefficients, Standard Errors, and Standardized Coefficients for Violent Delinquency Mediation Model

Indirect Effects:

Parental Knowledge $\rightarrow$ Unstructured Socializing With Peers $\rightarrow$ Peer Violent

Delinquency

Unstructured Socializing With Peers $\rightarrow$ Peer Violent Delinquency

-0.055 to -0.011

$\rightarrow$ Violent Delinquency

$0.007 * *$

0.003

0.057

0.003 to 0.013

Parental Knowledge $\rightarrow$ Unstructured Socializing With Peers $\rightarrow$ Peer Violent Delinquency

$-0.002^{*}$

$\rightarrow$ Violent Delinquency

0.001

$-0.005$

$\mathrm{R}^{2}$

0.143

0.295

-0.005 to -0.001

Likelihood Ratio $\chi^{2}(\mathrm{df})$

RMSEA

CFI

0.040

0.933

TLI

0.907

Notes: RMSEA = root mean square error of approximation; CFI = comparative fit index, TLI = Tucker-Lewis index. Estimates reported in columns in descending order:

Row 1: Unstandardized coefficient; Row 2: Standard error; Row 3: Standardized coefficient; Row 4 of Indirect Effects $=95 \%$ bootstrapped confidence intervals

$* \mathrm{p}<.05 . * * \mathrm{p}<.01 . * * * \mathrm{p}<.001$ 


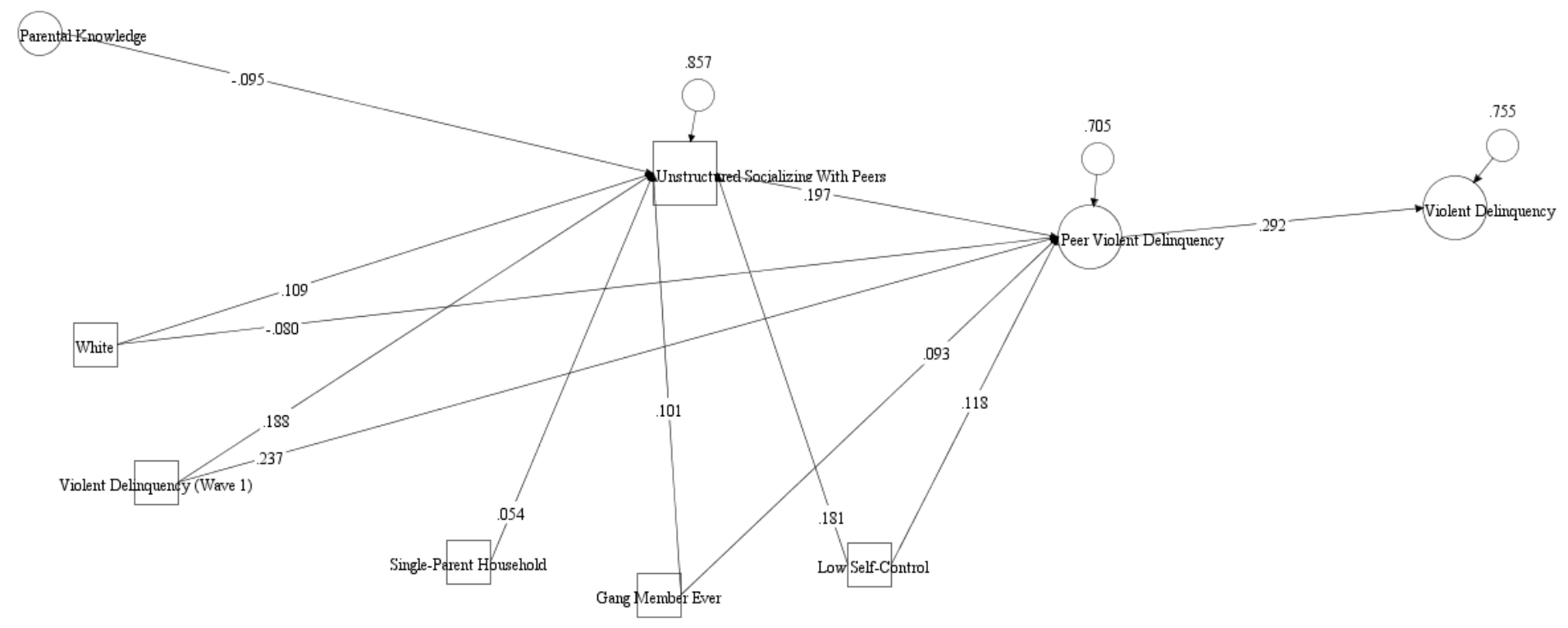

Figure 6. Violent Delinquency Mediation Model with Significant Pathways and Standardized Coefficients $(\mathrm{N}=1,610)$ 


\section{Study 1, Model 3, Substance Use}

The findings of Model 3, which assessed the influence of parental knowledge (Wave 1) on individual substance use (Wave 4) via both USWP (Wave 2) and peer substance use (Wave 3) are reported in Table 8. The fit indices, namely the likelihoodratio test of Model 3 ( $\chi^{2}$ of $421.883, p .<.001$ ) indicates unacceptable model fit; however, and the RMSEA of .042, along with the CFI (.961) and the TLI (.946) indicate acceptable model fit. This model incorporated one exogenous latent variable (parental knowledge), one endogenous observed variable (USWP), and two endogenous latent variables (peer substance use and substance use), while also including duplicate control variables from Models 1 and 2.

\section{Study 1, Model 3, USWP (Wave 2) Equation}

The model estimate of the direct effect of parental knowledge on USWP indicated the presence of a statistically significant and direct negative effect of parental knowledge on USWP $(b=-.259, p .<.01, \beta=-.081)$. Moreover, being White $(b=.326, p .<.001, \beta=$ $.102)$, living in a single-parent household $(b=.202, p .<.05, \beta=.059)$, having lower selfcontrol $(b=.385, p .<.001, \beta=.162)$, prior gang membership $(b=.608, p .<.05, \beta=$ $.096)$, and greater engagement in substance use at Wave $1(b=.330, p .<.001, \beta=.172)$ were identified as factors positively associated with USWP. The $\mathrm{R}^{2}$ value of .126 indicates that $12.6 \%$ of the variation in the observed variable of USWP is explained by the model.

Study 1, Model 3, Peer Substance Use (Wave 3) Equation

Next, the model revealed that USWP exerts a direct positive effect on peer substance use $(b=.154, p .<.001, \beta=.246)$. Additionally, the results show that low self- 
control $(b=.281, p .<.001, \beta=.190)$, prior gang membership $(b=.393, p .<.01, \beta=$ .099), and engagement in substance use at Wave $1(b=.330, p .<.001, \beta=.275)$ are factors positively associated with peer substance use. The $\mathrm{R}^{2}$ value of .293 indicates that $29.3 \%$ of the variation in the latent factor of peer substance use is explained by the structural model.

\section{Study 1, Model 3, Substance Use (Wave 4) Equation}

The model also revealed a direct positive relationship between peer substance use and individual substance use $(b=.136, p<.001, \beta=.430)$. Further, the model shows that substance use at Wave $1(b=.081, p<.001, \beta=.213)$ was positively associated with individual substance use at Wave 4 , and additionally that males $(b=-.045, p<.05, \beta=-$ .071) were less likely to engage in substance use than females. The $\mathrm{R}^{2}$ value of .360 indicates that $36 \%$ of the variation in the latent factor of individual substance use is explained by the structural model.

\section{Study 1, Model 3, Substance Use, Indirect Effects}

Finally, the model results shown in Table 8 provide support for the indirect effect of parental knowledge on peer substance use via USWP $[(b=-.040, p<.01, \beta=-.020)$, $95 \%$ confidence interval $=-.073$ to -.012 , while suggesting that $28.6 \%$ of the total effect of parental knowledge on peer substance use operates through USWP. The results also show that USWP affects substance use indirectly through peer substance use $[(b=.021, p$ $<.001, \beta=.106), 95 \%$ bootstrapped confidence interval $=.014$ to .029$]$ with approximately $75 \%$ of the total effect of USWP on substance use operating through peer substance use. Finally, Model 3 results provide support for the indirect effect of parental knowledge on delinquency through both USWP and peer substance use $(b=-.005, p<$ 
$.05, \beta=-.009)$, bootstrapped confidence interval $=-.010$ to -.002$]$, while indicating that $14.3 \%$ of the total effect of parental knowledge on substance use is exerted through both USWP and peer substance use. Figure 7 displays the path diagram for the substance use model. 
Table 8. Weighted Least Squares with Mean and Variance Adjusted Estimates of Unstandardized Coefficients, Standardized Errors, and Standardized Coefficients for Substance Use Mediation Model

Model 3: Substance Use

$(\mathrm{N}=1,604)$

Predictor

Age

Male

White

Single-Parent Household

Great Program

Low Self-Control

Gang Membership Ever

Gang Membership Currently

Substance Use (Wave 1)

Parental Knowledge (Wave 1)

Unstructured Socializing With Peers (Wave 2)

Peer Substance Use (Wave 3)
Endogenous Factors

\begin{tabular}{|c|c|c|}
\hline Unstructured & $\underline{\text { Peer }}$ & $\underline{\text { Substance }}$ \\
\hline$\stackrel{\text { Socializing }}{\text { Peerc }}$ & Substance Use & $\underline{\text { Use }}$ \\
\hline With Peers (Wave 2) & (Wave 3) & (Wave 4) \\
\hline 0.024 & 0.038 & -0.026 \\
\hline 0.065 & 0.054 & 0.018 \\
\hline 0.009 & 0.024 & -0.052 \\
\hline 0.013 & -0.104 & $-0.045^{*}$ \\
\hline 0.080 & 0.064 & 0.023 \\
\hline 0.004 & -0.052 & -0.071 \\
\hline $0.326^{* * *}$ & 0.106 & 0.006 \\
\hline 0.082 & 0.068 & 0.024 \\
\hline 0.102 & 0.053 & 0.009 \\
\hline $0.202 *$ & 0.072 & 0.035 \\
\hline 0.088 & 0.073 & 0.025 \\
\hline 0.059 & 0.034 & 0.052 \\
\hline-0.114 & 0.009 & -0.002 \\
\hline 0.082 & 0.065 & 0.022 \\
\hline-0.035 & 0.004 & -0.004 \\
\hline $0.385^{* * *}$ & $0.281 * * *$ & 0.034 \\
\hline 0.067 & 0.055 & 0.019 \\
\hline 0.162 & 0.190 & 0.071 \\
\hline $0.608^{*}$ & $0.393 * *$ & -0.080 \\
\hline 0.249 & 0.152 & 0.081 \\
\hline 0.096 & 0.099 & -0.063 \\
\hline 0.151 & -0.461 & 0.119 \\
\hline 0.330 & 0.265 & 0.110 \\
\hline 0.017 & -0.081 & 0.065 \\
\hline $0.330 * * *$ & $0.330^{* * *}$ & $0.081 * * *$ \\
\hline 0.060 & 0.044 & 0.019 \\
\hline 0.172 & 0.275 & 0.213 \\
\hline$-0.259 * *$ & -0.100 & -0.014 \\
\hline 0.094 & 0.077 & 0.026 \\
\hline-0.081 & -0.050 & -0.023 \\
\hline--- & $0.154 * * *$ & 0.007 \\
\hline & 0.020 & 0.009 \\
\hline & 0.246 & 0.035 \\
\hline \multirow{3}{*}{---} & \multirow{3}{*}{---} & $0.136^{* * *}$ \\
\hline & & 0.016 \\
\hline & & 0.430 \\
\hline
\end{tabular}


Table 8 Continued. Weighted Least Squares with Mean and Variance Adjusted Estimates of Unstandardized Coefficients, Standard Errors, and Standardized Coefficients for Substance Use Mediation Model

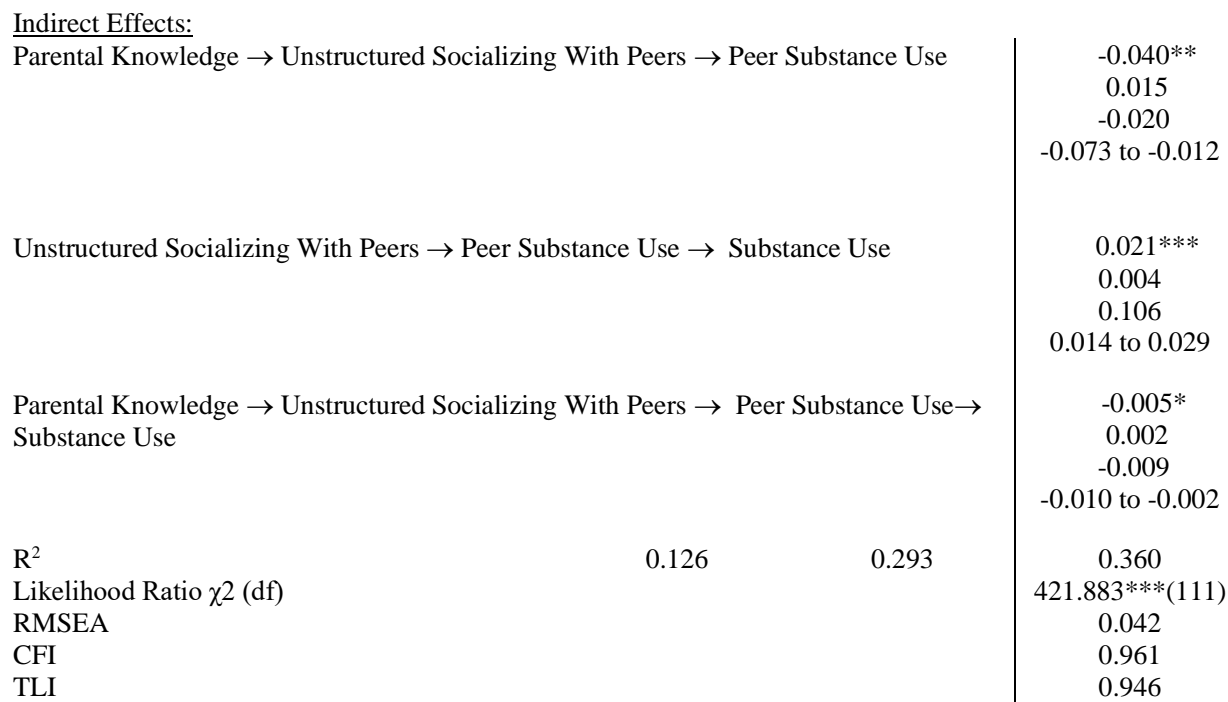

Notes: RMSEA = root mean square error of approximation; $\mathrm{CFI}=$ comparative fit index, TLI = TuckerLewis index. Estimates reported in columns in descending order:

Row 1: Unstandardized coefficient; Row 2: Standard error; Row 3: Standardized coefficient; Row 4 of Indirect Effects $=95 \%$ bootstrapped confidence intervals

$* \mathrm{p}<.05 . * * \mathrm{p}<.01 . * * * \mathrm{p}<.001$. 


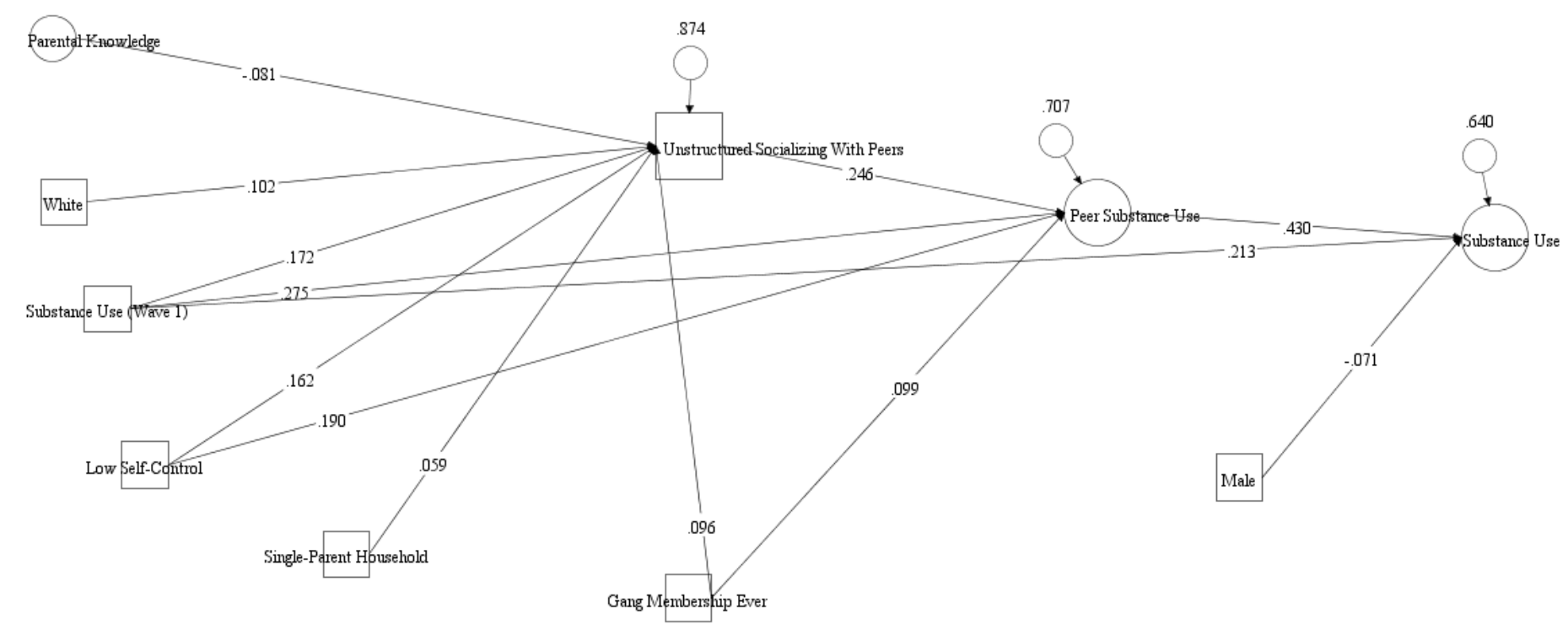

Figure 7. Substance Use Mediation Model with Significant Pathways and Standardized Coefficients $(N=1,604)$. 


\section{Study 2 (Reciprocal Effects)}

\section{Model 1, Property Delinquency}

Table 9 reports the estimates for the reciprocal (cross lagged) relationships between USWP and property delinquency across three waves of data (Spring 1995/Wave 1, Fall 1995/Wave 2, and Fall 1996/Wave 3). The correlation matrix for the key variables used in the analysis of the current study is shown in Appendix B. In addition, demographics and other control variables are reported, along with model fit statistics. As recommended by Whittaker (2012), modification indices that would result in a large reduction in the $\chi^{2}$, if theoretically justified, may be incorporated into a model in an iterative manner to improve fit. Thus, two indices were included into the property delinquency model. Specifically, whether the respondent had stolen something worth more than $\$ 50$ at Wave 1 was allowed to correlate with this same item at Wave 2. Additionally, whether the respondent had purposely damaged or destroyed property that did not belong to him/her at Wave 1 was allowed to correlate with this same item at Wave 2. The $\chi^{2}$ of Model 1, while remaining significant, was reduced from 890.580 (212) p. $<.001$ to $738.402(210)$ p. $<.001)$, and the RMSEA improved from .044 to .039, indicating close model fit. Similarly, the CFI improved from .897 to .920 and the TLI from .876 to .903 , further confirming that model provided acceptable fit to the data. Along with several control variables assessed at Wave 1 and capturing information on whether the respondent had completed the GREAT program assessed at Wave 2, one observed variable (USWP) and one latent variable (property delinquency) were included in the model at Waves 1, 2, and 3. 


\section{Study 2, Model 1, Sequential Effects of USWP}

The model results pertaining to the sequential pathways between USWP and property delinquency are shown in Table 9, while Figure 8 depicts the path diagram. It can be seen that the subsequent influence of USWP from Wave 1 to Wave 2 and Wave 2 to Wave 3 is significant across all survey waves. Specifically, USWP at Wave 1 influences USWP at Wave $2(b=.409, p<.001, \beta=.410)$ and USWP at Wave 2 influences USWP at Wave $3(b=.456, p<.001, \beta=.425)$.

\section{Study 2, Model 1, Sequential Effects of Property Delinquency}

Next, in assessing the sequential effect of property delinquency, significant associations were found across all waves; however, there is a slight downward trend in its effect. Specifically, property delinquency at Wave 1 influences property delinquency at Wave $2(b=.671, p<.001, \beta=.777)$, which in turn influences property delinquency at Wave $3(b=.744, p<.001, \beta=.601)$. Having established that each of these variables operates sequentially, the results providing support for the hypothesis that these variables influence one another in a reciprocal manner are discussed below.

\section{Study 2, Model 1, Reciprocal Effects between USWP and Property Delinquency}

As can be seen from Table 9, property delinquency at Wave 1 influences USWP at Wave $2(b=1.443, p<.001, \beta=.212)$, and property delinquency at Wave 2 influences USWP at Wave $3(b=1.110, p<.001, \beta=.131)$. Contrary to Hypothesis 2 , which predicted that USWP would be associated with property delinquency across all waves, no support was found for the association between USWP at Wave 1 and property offending at Wave 2.The model results however indicate that USWP at Wave 2 influences property 
delinquency at Wave $3(b=.021, p<.001, \beta=.134)$, providing partial support for what was hypothesized.

\section{Study 2, Model 1, Controls}

Effects of several control variables incorporated into the model also achieved statistical significance (see Table 9). For instance, older individuals $(b=.134, p<.05, \beta$ $=.052)$, being White $(b=.166, p<.05, \beta=.051)$, living in a single-parent household $(b=$ $.403, p<.001, \beta=.117)$, having lower self-control $(b=.460, p<.001, \beta=.193)$, having been in a gang $(b=.685, p<.001, \beta=.113)$, and prior affiliation with peers who engage in property delinquency $(b=.302, p<.001, \beta=.135)$ emerged as factors positively associated with USWP at Wave 1. In addition, model results indicated that low selfcontrol $(b=.059, p<.001, \beta=.168)$, prior gang membership $(b=.132, p<.001, \beta=$ $.148)$, current gang membership $(b=.135, p<.001, \beta=.109)$, and engagement in peer property delinquency $(b=.171, p<.001, \beta=.522)$ are positively associated with individual property delinquency at Wave 1. Finally, parental knowledge $(b=-.021, p<$ $.01, \beta=-.067$ ) was negatively associated with individual property delinquency.

The $\mathrm{R}^{2}$ values of .142 at Wave 1,.270 at Wave 2, and .237 at Wave 3 indicate respectively that $14.2 \%, 27.0 \%$, and $23.7 \%$ of the variation in the observed variable of USWP is explained by the model. In addition, the $\mathrm{R}^{2}$ value of .575 at Wave $1, .616$ at Wave 2, and .436 at Wave 3 indicate in turn that $57.5 \%, 61.6 \%$, and $43.6 \%$ of the variation in the latent factor of property delinquency is explained by the structural model. 
Table 9. Maximum Likelihood Estimation of Unstandardized Coefficients, Standard Errors, and Standardized Coefficients for Property Delinquency Reciprocal Effects Model

Model 1: Property Delinquency $(\mathrm{N}=1,675)$

\begin{tabular}{|c|c|c|c|c|c|c|}
\hline$\underline{\text { Covariates }}$ & $\begin{array}{l}\frac{\text { Unstructured }}{\text { Socializing }} \\
\underline{\text { With Peers }} \\
\text { (Wave 1) }\end{array}$ & $\frac{\text { Unstructured }}{\underline{\text { Socializing }}} \frac{\text { With Peers }}{\underline{\text { (Wave 2) }}}$ & $\frac{\frac{\text { Unstructured }}{\text { Socializing }}}{\text { With Peers }}$ & $\begin{array}{c}\begin{array}{c}\text { Property } \\
\text { Delinquency }\end{array} \\
\text { (Wave 1) }\end{array}$ & $\begin{array}{c}\begin{array}{c}\text { Property } \\
\text { Delinquency }\end{array} \\
\text { (Wave 2) }\end{array}$ & $\begin{array}{c}\begin{array}{c}\text { Property } \\
\text { Delinquency }\end{array} \\
\text { (Wave 3) }\end{array}$ \\
\hline Age & $\begin{array}{l}0.134^{*} \\
0.062 \\
0.052\end{array}$ & --- & --- & $\begin{array}{r}-0.003 \\
0.008 \\
-0.007\end{array}$ & --- & --- \\
\hline Male & $\begin{array}{c}-0.046 \\
0.080 \\
-0.014\end{array}$ & --- & --- & $\begin{array}{l}0.019 \\
0.010 \\
0.039\end{array}$ & --- & --- \\
\hline White & $\begin{array}{l}0.166^{*} \\
0.079 \\
0.051\end{array}$ & --- & --- & $\begin{array}{r}-0.008 \\
0.010 \\
-0.016\end{array}$ & --- & --- \\
\hline Single-Parent Household & $\begin{array}{l}0.403^{* * *} \\
0.083 \\
0.117\end{array}$ & --- & --- & $\begin{array}{r}-0.018 \\
0.011 \\
-0.035\end{array}$ & --- & --- \\
\hline Great Program & $\begin{array}{c}-0.064 \\
0.079 \\
-0.019\end{array}$ & --- & --- & $\begin{array}{r}-0.015 \\
0.010 \\
-0.031\end{array}$ & --- & --- \\
\hline Low Self-Control & $\begin{array}{l}0.460 * * * \\
0.064 \\
0.193\end{array}$ & --- & --- & $\begin{array}{l}0.059 * * * \\
0.009 \\
0.168\end{array}$ & --- & --- \\
\hline Gang Membership Ever & $\begin{array}{l}0.685^{* * * *} \\
0.197 \\
0.113\end{array}$ & --- & --- & $\begin{array}{l}0.132 * * * \\
0.026 \\
0.148\end{array}$ & --- & --- \\
\hline Gang Membership Currently & $\begin{array}{l}0.141 \\
0.273 \\
0.017\end{array}$ & --- & --- & $\begin{array}{l}0.135^{* * * *} \\
0.035 \\
0.109\end{array}$ & --- & --- \\
\hline Parental Knowledge & $\begin{array}{c}-0.036 \\
0.056 \\
-0.016\end{array}$ & --- & --- & $\begin{array}{l}-0.021 * * \\
0.007 \\
-0.067\end{array}$ & --- & --- \\
\hline $\begin{array}{l}\text { Peer Property Delinquency } \\
\text { (Wave 1) }\end{array}$ & $\begin{array}{l}0.302 * * * \\
0.062 \\
0.135\end{array}$ & --- & --- & $\begin{array}{l}0.171 * * * \\
0.010 \\
0.522\end{array}$ & --- & --- \\
\hline
\end{tabular}


Table 9 Continued. Maximum Likelihood Estimation of Unstandardized Coefficients, Standard Errors, and Standardized Coefficients for Property Delinquency Reciprocal Effects Model

\begin{tabular}{|c|c|c|c|c|c|c|}
\hline $\begin{array}{l}\text { Unstructured Socializing With Peers } \\
\text { (Wave 1) }\end{array}$ & --- & $\begin{array}{l}0.409^{* * * *} \\
0.025 \\
0.410\end{array}$ & --- & --- & $\begin{array}{l}0.003 \\
0.003 \\
0.023\end{array}$ & --- \\
\hline $\begin{array}{l}\text { Unstructured Socializing With Peers } \\
\text { (Wave 2) }\end{array}$ & --- & --- & $\begin{array}{l}0.456^{* * * *} \\
0.035 \\
0.425\end{array}$ & --- & --- & $\begin{array}{l}0.021 \text { *** } \\
0.006 \\
0.134\end{array}$ \\
\hline $\begin{array}{l}\text { Unstructured Socializing With Peers } \\
\text { (Wave 3) }\end{array}$ & --- & --- & --- & --- & --- & --- \\
\hline Property Delinquency (Wave 1) & --- & $\begin{array}{l}1.443^{* * * *} \\
0.192 \\
0.212\end{array}$ & --- & --- & $\begin{array}{l}0.671 \text { *** } \\
0.042 \\
0.777\end{array}$ & \\
\hline Property Delinquency (Wave 2) & --- & --- & $\begin{array}{l}1.110^{* * * *} \\
0.314 \\
0.131\end{array}$ & --- & --- & $\begin{array}{l}0.744 * * * \\
0.072 \\
0.601\end{array}$ \\
\hline Property Delinquency (Wave 3) & --- & --- & -- & --- & --- & --- \\
\hline $\begin{array}{l}\mathrm{R}^{2} \\
\text { Likelihood Ratio } \chi 2(\mathrm{df}) \\
\text { RMSEA } \\
\text { CFI } \\
\text { TLI }\end{array}$ & 0.142 & 0.270 & 0.237 & 0.575 & 0.616 & $\begin{array}{c}0.436 \\
738.402 * * *(210) \\
0.039 \\
0.920 \\
0.903\end{array}$ \\
\hline
\end{tabular}




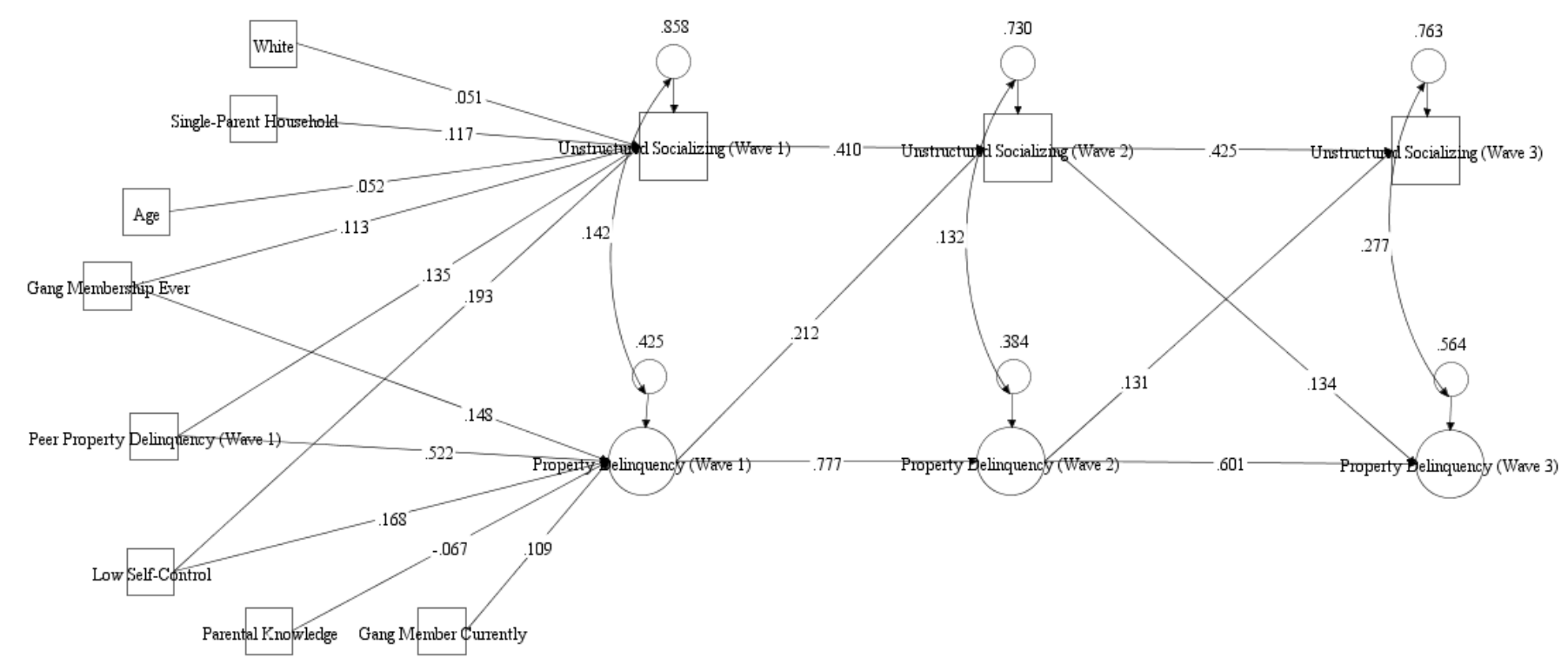

Figure 8. Property Delinquency Reciprocal Effects Model with Significant Pathways and Standardized Coefficients $(\mathrm{N}=1,675)$. 


\section{Study 2, Model 2, Violent Delinquency}

Table 10 reports the model estimates for the reciprocal relationship between USWP and violent delinquency across three waves and includes demographic and other control variables into the model. In order to improve model fit, five modification indices were included in an iterative manner into the violent delinquency model. First, at Wave 1, whether the respondent had attacked someone with a weapon was allowed to correlate with the item inquiring if the respondent had used a weapon or force to get money or things from people. These same items were allowed to correlate at Wave 2. Next, whether the respondent had hit someone with the intent to cause harm at Wave 1 was allowed to correlate with this same item at Wave 2. Additionally, whether the respondent had attacked someone with a weapon at Wave 1 was allowed to correlate with this same item at Wave 2. Last, at Wave 3, whether the respondent had attacked someone with a weapon was allowed to correlate with whether the respondent used a weapon or force to get money or things from people. While the $\chi^{2}$ fit index of Model 2 remained significant, its value declined from 898.327 (146) p. <.001) to 450.024 (141) p. $<.001$ ), whereas the RMSEA improved from .056 to .036, indicating close model fit. In addition, both the CFI and the TLI improved, from .820 to .926 , and from .771 to .903 , respectively, each indicating acceptable model fit. Along with incorporating several control variables assessed at Wave 1 and capturing whether the respondent had completed the GREAT program assessed at Wave 2, the model included one observed variable (USWP) and one latent variable (violent delinquency) at Waves 1, 2, and 3. 


\section{Study 2, Model 2, Sequential Effects of USWP}

The model results related to the sequential pathways between USWP and violent delinquency are reported in Table 10, and the path diagram of the violent delinquency model is shown in Figure 9, which indicate that USWP is significant across all waves. Particularly, USWP at Wave 1 influences USWP at Wave $2(b=.383, p<.001, \beta=$ $.381)$, and USWP at Wave 2 influences USWP at Wave $3(b=.426, p<.001, \beta=.396)$. Study 2, Model 2, Sequential Effects of Violent Delinquency

The sequential influence of violent delinquency is significant across all waves (see Table 10). Specifically, violent delinquency at Wave 1 influences violent delinquency at Wave $2(b=.720, p<.001, \beta=.758)$, which in turn influences violent delinquency at Wave $3(b=.967, p<.001, \beta=.803)$. Given that each of these variables has been shown to operate sequentially, the influence of these variables on one another in a reciprocal manner is discussed next.

\section{Study 2, Model 2, Reciprocal Effects between USWP and Violent Delinquency}

First, the results show that violent delinquency at Wave 1 influences USWP at Wave $2(b=1.448, p<.001, \beta=.241)$ and violent delinquency at Wave 2 influences USWP at Wave $3(b=1.192, p<.001, \beta=.175)$. No support was found for the influence of USWP at Wave 1 on violent delinquency at Wave 2, nor was any support found for the association between USWP at Wave 2 and violent delinquency at Wave 3. Given these findings, the results of the model run counter to Osgood et al.'s (1996) arguments, as well as Hypothesis 2. That is, the model indicates that violent delinquency predicts USWP, but USWP does not predict later violent delinquency. 


\section{Study 2, Model 2, Controls}

Many control variables included in the model are positively associated with USWP at Wave 1 , namely being older ( $b=.146, p<.05, \beta=.057)$, being White ( $b=$ $.179, p<.05, \beta=.055)$, living in a single-parent household $(b=.398, p<.001, \beta=.116)$, having low self-control $(b=.457, p<.001, \beta=.192)$, prior gang membership $(b=.684, p$ $<.001, \beta=.113)$, and peer violent delinquency $(b=.321, p<.001, \beta=.135)$.

Additionally, the results revealed that males $(b=.044, p<.01, \beta=.082)$, individuals with low self-control $(b=.058, p<.001, \beta=.146)$, individuals who have ever been a gang member $(b=.156, p<.001, \beta=.155)$, those who are currently in a gang $(b=.123, p<$ $.001, \beta=.088)$, and having violent peers $(b=.253, p<.001, \beta=.638)$ are more likely to engage in violent delinquency at Wave 1. In addition, the results show that greater parental knowledge is negatively associated with violent delinquency $(b=-.021, p<.01$, $\beta=-.058)$.

The $\mathrm{R}^{2}$ values of .143 at Wave 1,.279 at Wave 2, and .245 at Wave 3 indicate correspondingly that $14.3 \%, 27.9 \%$, and $24.5 \%$ of the variation in the observed variable of USWP is explained by the model. Further, the $\mathrm{R}^{2}$ value of .741 at Wave $1, .583$ at Wave 2, and .720 at Wave 3 respectively indicate that $74.1 \%, 58.3 \%$, and $72 \%$ of the variation in the latent factor violent delinquency is explained by the structural model. 
Table 10. Maximum Likelihood Estimation of Unstandardized Coefficients, Standard Errors, and Standardized Coefficients for Violent Delinquency Reciprocal Effects Model

Model 2: Violent Delinquency ( $\mathrm{N}=1,670)$

\begin{tabular}{|c|c|c|c|c|c|c|}
\hline Covariates & $\begin{array}{l}\frac{\text { Unstructured }}{\text { Socializing }} \\
\frac{\text { With Peers }}{\text { (Wave 1) }}\end{array}$ & $\begin{array}{l}\frac{\text { Unstructured }}{\text { Socializing }} \\
\frac{\text { With Peers }}{\text { (Wave 2) }}\end{array}$ & $\begin{array}{l}\frac{\text { Unstructured }}{\text { Socializing }} \\
\text { With Peers } \\
\text { (Wave 3) }\end{array}$ & $\frac{\begin{array}{l}\text { Violent } \\
\text { Delinquency }\end{array}}{\text { (Wave 1) }}$ & 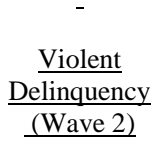 & $\frac{\begin{array}{c}\text { Violent } \\
\text { Delinquency }\end{array}}{\text { (Wave 3) }}$ \\
\hline$\overline{\text { Age }}$ & $\begin{array}{l}0.146^{*} \\
0.062 \\
0.057\end{array}$ & --- & --- & $\begin{array}{l}0.020 \\
0.011 \\
0.046\end{array}$ & --- & --- \\
\hline Male & $\begin{array}{c}-0.054 \\
0.080 \\
-0.017\end{array}$ & --- & --- & $\begin{array}{l}0.044 * * \\
0.014 \\
0.082\end{array}$ & --- & --- \\
\hline White & $\begin{array}{l}0.179^{*} \\
0.079 \\
0.055\end{array}$ & --- & --- & $\begin{array}{l}0.020 \\
0.014 \\
0.036\end{array}$ & --- & --- \\
\hline Single-Parent Household & $\begin{array}{l}0.398^{* * * *} \\
0.083 \\
0.116\end{array}$ & --- & --- & $\begin{array}{l}0.028 \\
0.015 \\
0.049\end{array}$ & --- & --- \\
\hline Great Program & $\begin{array}{r}-0.061 \\
0.079 \\
-0.018\end{array}$ & --- & --- & $\begin{array}{c}-0.004 \\
0.014 \\
-0.007\end{array}$ & --- & --- \\
\hline Low Self-Control & $\begin{array}{l}0.457 * * * \\
0.063 \\
0.192\end{array}$ & --- & --- & $\begin{array}{l}0.058 \text { *** } \\
0.011 \\
0.146\end{array}$ & --- & --- \\
\hline Gang Membership Ever & $\begin{array}{l}0.684 * * * \\
0.196 \\
0.113\end{array}$ & --- & --- & $\begin{array}{l}0.156 \text { *** } \\
0.035 \\
0.155\end{array}$ & --- & --- \\
\hline Gang Membership Currently & $\begin{array}{l}0.143 \\
0.272 \\
0.017\end{array}$ & --- & --- & $\begin{array}{l}0.123 * * \\
0.048 \\
0.088\end{array}$ & --- & --- \\
\hline Parental Knowledge & $\begin{array}{c}-0.057 \\
0.055 \\
-0.026\end{array}$ & --- & --- & $\begin{array}{l}-0.021 * \\
0.010 \\
-0.058\end{array}$ & --- & --- \\
\hline $\begin{array}{l}\text { Peer Violent Delinquency } \\
\text { (Wave 1) }\end{array}$ & $\begin{array}{l}0.321 \text { *** } \\
0.064 \\
0.135\end{array}$ & --- & --- & $\begin{array}{l}0.253 * * * \\
0.015 \\
0.638\end{array}$ & --- & --- \\
\hline
\end{tabular}


Table 10 Continued. Maximum Likelihood Estimation of Unstandardized Coefficients, Standard Errors, and Standardized Coefficients for Violent Delinquency Reciprocal Effects Model

Unstructured Socializing With Peers (Wave 1)

Unstructured Socializing With Peers (Wave 2)

Unstructured Socializing With Peers (Wave 3)

Violent Delinquency (Wave 1)

Violent Delinquency (Wave 2)

Violent Delinquency (Wave 3)

$\mathrm{R}^{2}$

Likelihood Ratio $\chi^{2}$ (df)

RMSEA

CFI

TLI

Notes: RMSEA = root mean square error of approximation; $\mathrm{CFI}=$ comparative fit index, TLI = Tucker-Lewis index. Estimates reported in columns in descending order: Row 1: Unstandardized coefficient, Row 2: Standard error of standardized coefficient, Row 3: Standardized coefficient. *p <.05. **p <.01. $* * * \mathrm{p}<.001$

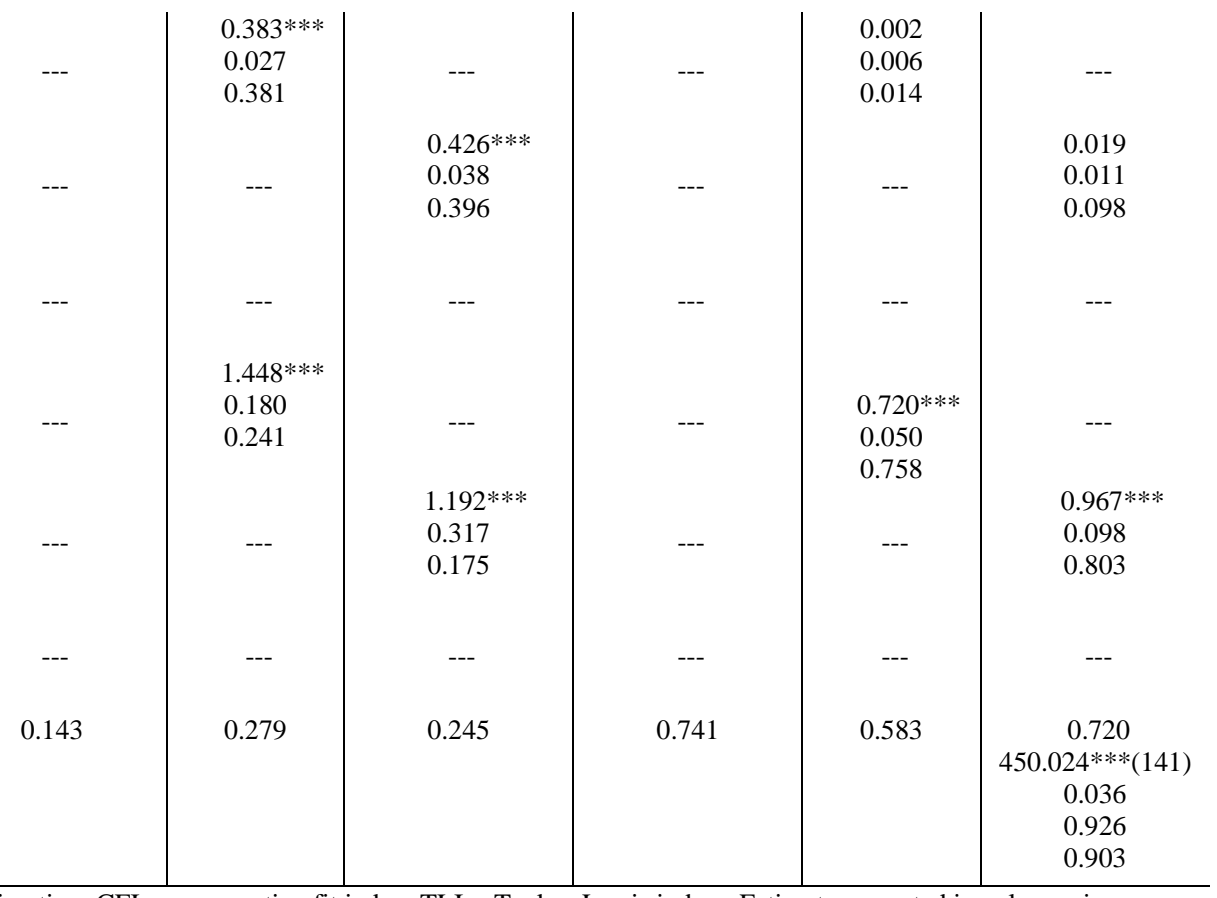

$\mathrm{p}<.01$ 


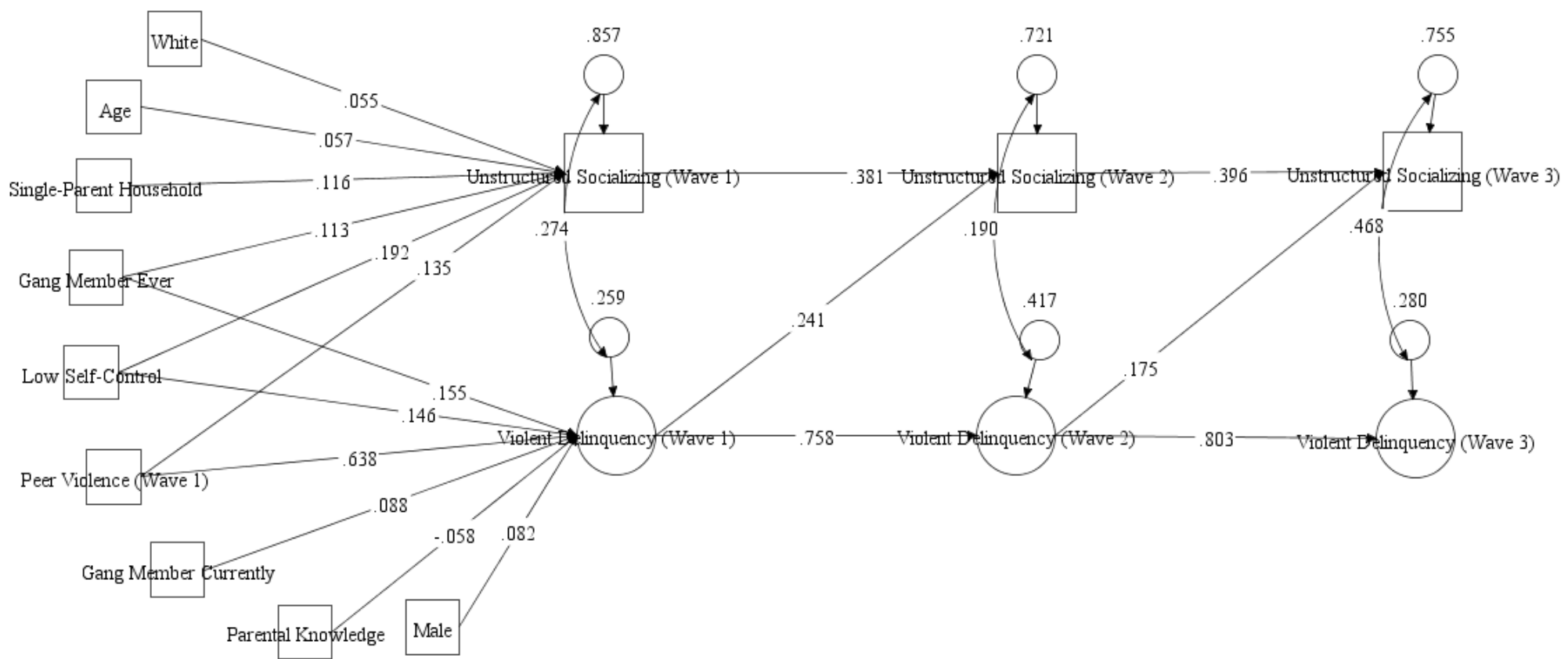

Figure 9. Violent Delinquency Reciprocal Effects Model with Significant Pathways, Standard Errors, and Standardized Coefficients $(\mathrm{N}=1,670)$. 


\section{Study 2, Model 3, Substance Use}

Table 11 reports the estimates for the reciprocal relationship between USWP and substance use across the three waves of data. In addition, like Models 1 and 2, the table includes the demographic and other control variables. Two modification indices were adopted in an iterative fashion to improve model fit. Specifically, at Wave 1, whether the respondent had ever used marijuana was allowed to correlate with this same item at Wave 2 , and whether the respondent had ever used alcohol was allowed to correlate with this same item at Wave 2. By incorporating these modification indices into the model, the $\chi^{2}$, although significant, was reduced from $1102.758(146) p .<.001)$ to 624.067 (144) $p .<$ .001 ), while the RMSEA improved from .063 to .045 , indicating close model fit. As the CFI improved from .860 to .930 and the TLI improved from .822 to .909 , acceptable model fit was confirmed. Along with adopting several control variables assessed at Wave 1 and capturing whether the respondent had completed the GREAT program assessed at Wave 2, the model incorporated one observed variable (USWP) and one latent variable (substance use) at Wave 1,2, and 3.

\section{Study 2, Model 3, Sequential Effects of USWP}

The results pertaining to the sequential pathways between USWP and substance use reported in Table 11 and depicted in Figure 10 indicate that USWP is significant across all waves. Specifically, USWP at Wave 1 influences USWP at Wave $2(b=.405, p$ $<.001, \beta=.406)$ and USWP at Wave 2 influences USWP at Wave $3(b=.436, p<.001$, $\beta=.407)$. 


\section{Study 2, Model 3, Sequential Effects of Substance Use}

Additionally, the sequential influence of substance use is significant across all waves and as anticipated exhibits a slight downward trend. That is, substance use at Wave 1 influences substance use at Wave $2(b=.804, p<.001, \beta=.802)$, which in turn influences substance use at Wave $3(b=.843, p<.001, \beta=.718)$. Given that each of these variables operates sequentially, the results providing support for the hypothesis that these variables influence one another in a reciprocal manner are presented next.

\section{Study 2, Model 3, Reciprocal Effects between USWP and Substance Use}

The model results indicate that substance use at Wave 1 influences USWP at Wave $2(b=1.279, p<.001, \beta=.216)$ and substance use at Wave 2 influences USWP at Wave $3(b=1.015, p<.001, \beta=.160)$. Further, USWP at Wave 2 influences substance use at Wave $3(b=.025, p<.001, \beta=.127)$, offering partial support for Hypothesis 2 that USWP and substance use will be reciprocally related over time as well as illustrating partial support for Osgood and colleagues' (1996) theory.

\section{Study 2, Model 3, Controls}

The model also indicated that the following control variables were significant predictors of USWP at Wave 1: being White $(b=.183, p<.05, \beta=.056)$, living in a single-parent household $(b=.396, p<.001, \beta=.114)$, lower self-control $(b=.447, p<$ $.001, \beta=.186)$, prior gang membership $(b=.677, p<.001, \beta=.111)$, and having peers who engage in substance use $(b=.342, p<.001, \beta=.178)$. The results further revealed that age $(b=.034, p<.001, \beta=.078)$, lower self-control $(b=.060, p<.001, \beta=.149)$, previous gang membership $(b=.097, p<.001, \beta=.094)$, and peer substance use $(b=$ 
$.233, p<.001, \beta=.688$ ) are factors positively associated with individual substance use at Wave 1.

The $\mathrm{R}^{2}$ values of .158 at Wave 1,.276 at Wave 2, and .243 at Wave 3 correspond to $15.8 \%, 27.6 \%$, and $24.3 \%$ of the variation in the observed variable of USWP explained by the model. Further, the $\mathrm{R}^{2}$ value of .696 at Wave 1, .668 at Wave 2, and .605 at Wave 3 indicate, in turn, that $69.6 \%, 66.8 \%$, and $60.5 \%$ of the variation in the latent factor of substance use is explained by the structural model. 
Table 11. Maximum Likelihood Estimation of Unstandardized Coefficients, Standard Errors, and Standardized Coefficients for Substance Use Reciprocal Effects Model Model 3: Substance Use $(\mathrm{N}=1,665)$

\begin{tabular}{|c|c|c|c|c|c|c|}
\hline Covariates & 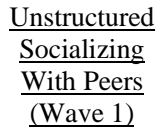 & $\frac{\text { Unstructured }}{\text { Socializing }}$ & $\frac{\text { Unstructured }}{\frac{\text { Socializing }}{\text { With Peers }}}$ & $\frac{\text { Substance Use }}{\text { (Wave 1) }}$ & $\frac{\text { Substance Use }}{\text { (Wave 2) }}$ & $\frac{\text { Substance Use }}{\text { (Wave 3) }}$ \\
\hline Age & $\begin{array}{l}0.109 \\
0.062 \\
0.042\end{array}$ & --- & --- & $\begin{array}{l}0.034 * * * \\
0.009 \\
0.078\end{array}$ & --- & --- \\
\hline Male & $\begin{array}{l}0.015 \\
0.079 \\
0.005\end{array}$ & --- & --- & $\begin{array}{c}-0.020 \\
0.011 \\
-0.036\end{array}$ & --- & --- \\
\hline White & $\begin{array}{l}0.183^{*} \\
0.079 \\
0.056\end{array}$ & --- & --- & $\begin{array}{c}-0.003 \\
0.011 \\
-0.006\end{array}$ & --- & --- \\
\hline Single-Parent Household & $\begin{array}{l}0.396 * * * \\
0.083 \\
0.114\end{array}$ & --- & --- & $\begin{array}{l}-0.005 \\
0.011 \\
-0.009\end{array}$ & --- & --- \\
\hline Great Program & $\begin{array}{l}-0.073 \\
0.079 \\
-0.022\end{array}$ & --- & --- & $\begin{array}{l}-0.012 \\
0.011 \\
-0.022\end{array}$ & --- & --- \\
\hline Low Self-Control & $\begin{array}{l}0.447 * * * \\
0.063 \\
0.186\end{array}$ & --- & --- & $\begin{array}{l}0.060 * * * \\
0.009 \\
0.149\end{array}$ & --- & --- \\
\hline Gang Membership Ever & $\begin{array}{l}0.677 * * * \\
0.198 \\
0.111\end{array}$ & --- & --- & $\begin{array}{l}0.097 * * * \\
0.028 \\
0.094\end{array}$ & --- & --- \\
\hline Gang Membership Currently & $\begin{array}{l}0.034 \\
0.274 \\
0.004\end{array}$ & --- & --- & $\begin{array}{l}0.032 \\
0.038 \\
0.022\end{array}$ & --- & --- \\
\hline Parental Knowledge & $\begin{array}{l}-0.026 \\
0.056 \\
-0.012\end{array}$ & --- & --- & $\begin{array}{l}-0.014 \\
0.008 \\
-0.037\end{array}$ & --- & --- \\
\hline Peer Substance Use (Wave 1) & $\begin{array}{l}0.342^{* * *} \\
0.053 \\
0.178\end{array}$ & --- & --- & $\begin{array}{l}0.223 * * * \\
0.009 \\
0.688\end{array}$ & --- & --- \\
\hline
\end{tabular}


Table 11 Continued. Maximum Likelihood Estimation of Unstandardized Coefficients, Standard Errors, and Standardized Coefficients for Substance Use Reciprocal Effects Model

Unstructured Socializing With Peers (Wave 1)

Unstructured Socializing With Peers

(Wave 2)

Unstructured Socializing With Peers

(Wave 3 )

Substance Use (Wave 1)

Substance Use (Wave 2)

Substance Use (Wave 3 )

$\mathrm{R}^{2}$

Likelihood Ratio $\chi^{2}(\mathrm{df})$

RMSEA

CFI

Notes: RMSEA = root mean square error of approximation; $\mathrm{CFI}=$ comparative fit index, TLI $=$ Tucker-Lewis index. Estimates reported in columns in descending order: Row 1: Unstandardized coefficient, Row 2: Standard error of standardized coefficient, Row 3: Standardized coefficient. *p <.05. **p <.01.

$* * * p<.001$.

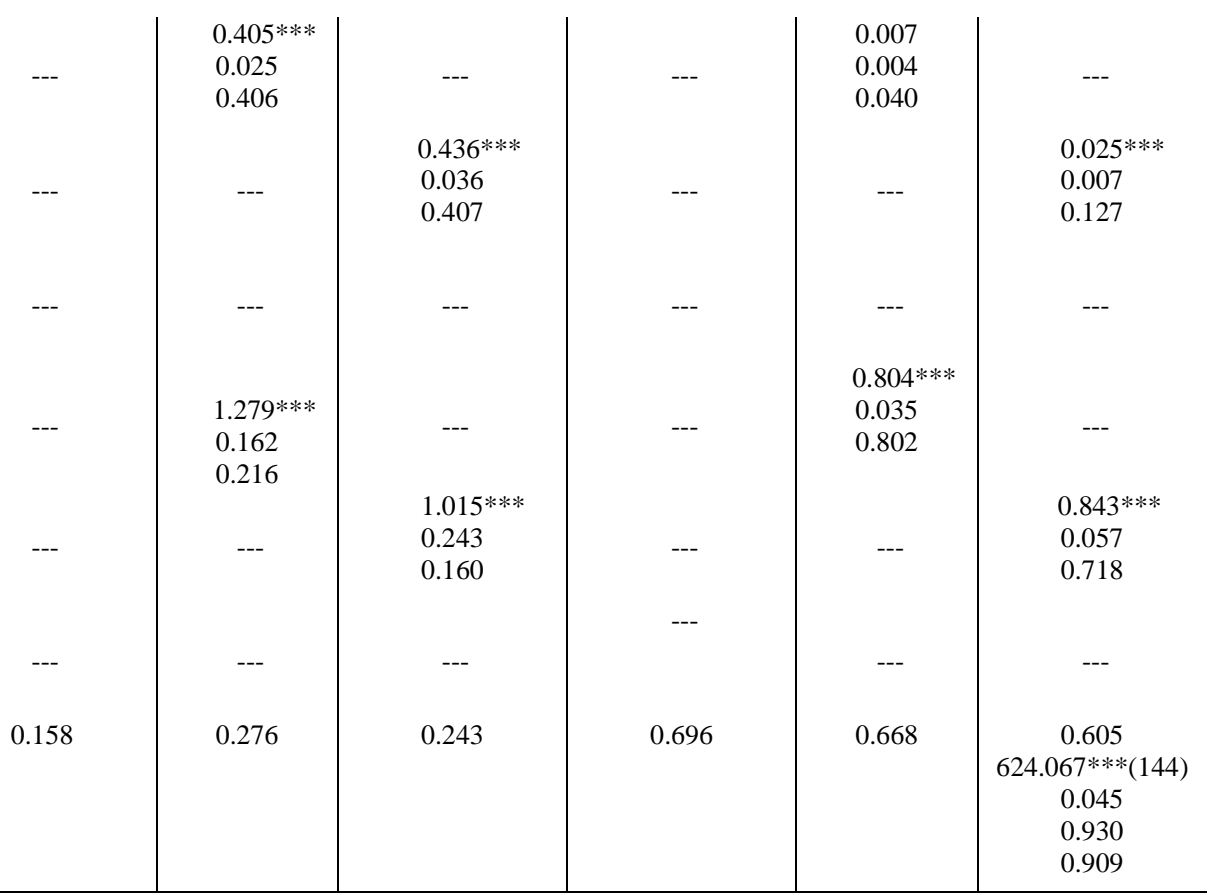




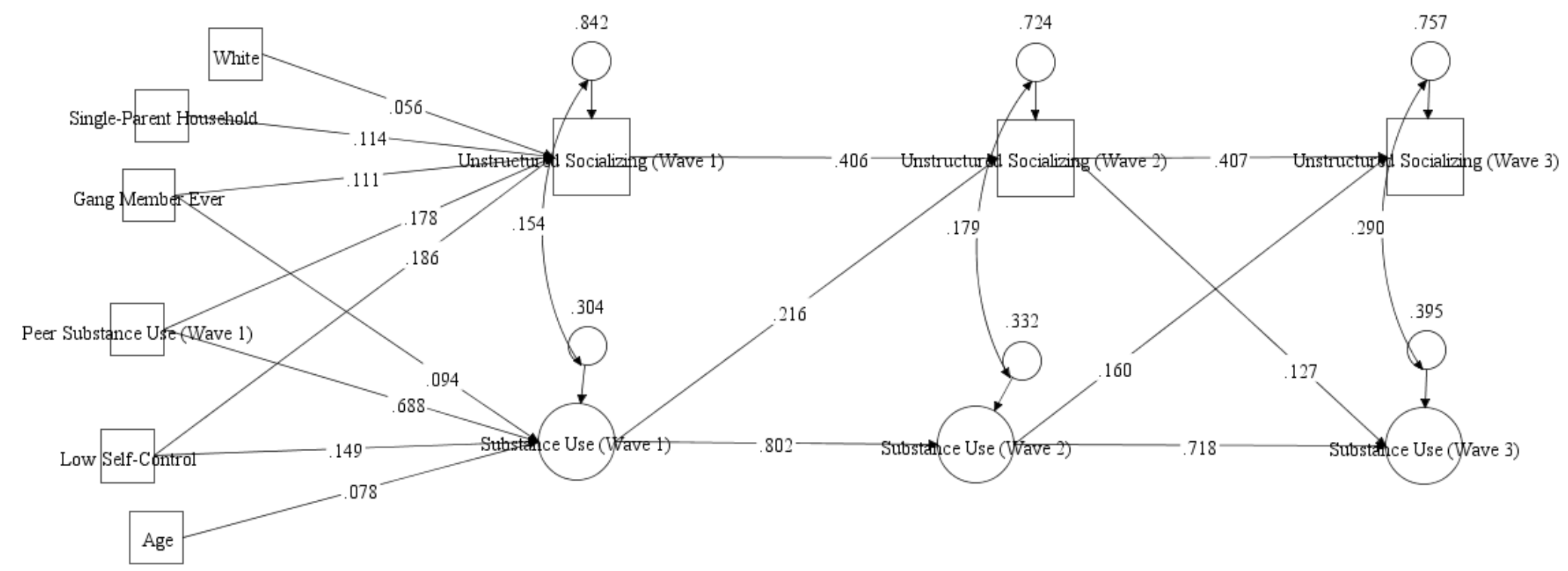

Figure 10. Substance Use Reciprocal Effects Model with Significant Pathways, Standard Errors, and Standardized Coefficients $(\mathrm{N}=1,665)$ 


\section{Study 3 (Nonlinear Effects)}

The model estimates related to the relationship between USWP (Wave 1) and property delinquency (Model 1), violent delinquency (Model 2), and substance use (Model 3), which are each measured at Wave 2, are reported in Table 12. Results for all of the models are interpreted in terms of incidence rate ratios (IRRs). A statistically significant IRR above 1.00 indicates a positive effect on the frequency of each measure of antisocial behavior, and a statistically significant IRR below 1.00 indicates a negative effect on the frequency of each measure of antisocial behavior. Table 12 reports the results for whether USWP (Wave 1/Spring 1995) and antisocial behavior (Wave 2/Fall 1995) are nonlinear and additionally the results of many control variables across multiple waves of data.

\section{Study 3, Model 1, Property Delinquency Equation}

As can be seen in Table 12, USWP is positively associated with property delinquency $(\mathrm{IRR}=1.32, p<.001)$. Additionally, although the association between USWP and property delinquency is positive, the squared term for USWP is statistically significant, and the IIR is less than 1.00 (IRR $=.97, p<.01)$, indicating a decelerating effect. Thus, contrary to Hypothesis 3 and past research by Gage et al. (2005), the positive effect of USWP on property delinquency tends to become weaker rather than accelerate at higher amounts of USWP.

\section{Study 3, Model 1, Controls}

Model 1 of Table 12 also provides results of analyses testing the influence of a wide range of covariates on property delinquency. Specifically, males are more likely than females to engage in property delinquency $(\operatorname{IRR}=1.26, p<.05)$, as are individuals 
with lower self-control (IRR $=1.38, p<.001)$, and those with friends who engage in property delinquency $(\operatorname{IRR}=1.19, p<.01)$. In addition, individuals that engaged in more property delinquency at Wave $1(\operatorname{IRR}=1.56, p<.001)$ are more likely to engage in property delinquency at Wave 2. Conversely, individuals who have completed the GREAT program are less likely to engage in property delinquency $(\operatorname{IRR}=.80, p<.01)$.

\section{Study 3, Model 2, Violent Delinquency Equation}

As shown in Model 2 of Table 12, USWP is positively associated with violent delinquency $(\mathrm{IRR}=1.16, p<.05)$. Further, the IRR of 1.16 in Model 2 shows that the occurrence of violent delinquency increases by $16 \%$ for each unit increase in USWP. Additionally, the squared term for USWP was not statistically significant, lending no support for nonlinearity in the relationship between USWP and violent delinquency and that of Hypothesis 2 of the current study which predicted that the relationship between USWP and violent delinquency will be nonlinear in an accelerating manner.

\section{Study 3, Model 2, Controls}

Model 2 of Table 12 provides support for the effect of a limited number of covariates on violent delinquency and indicate a notable covariate is statistically significant in the positive direction. Particularly, individuals who have engaged in violent delinquency at Wave 1 are more likely to engage in violent delinquency at Wave 2 (IRR $=1.99, p<.001)$.

\section{Study 3, Model 3, Substance Use Equation}

As displayed in Model 3 of Table 12, USWP is positively associated with substance use $(\operatorname{IRR}=1.23, p<.01)$. Further, the IRR of 1.23 in Model 3 shows that the occurrence of substance use increases by $23 \%$ for each unit increase in USWP. The 
results reported here are similar to those seen with the property delinquency model (Model 1), which emerged regarding the squared term of USWP in the relationship of USWP on substance use. Specifically, while the association between USWP and substance use is increasing, the statistically significant squared term in the effect of USWP on substance use that is less than one $(\operatorname{IRR}=.98, p<.05)$ indicates a decelerating effect, lending support for Hypothesis 3 and prior research (Meldrum \& Leimberg, 2018).

\section{Study 3, Model 3, Controls}

Model 3 also examines the influence of the covariates on substance use, and the results reported in Table 12 indicate that a few of these variables attained statistical significance in the positive direction. It can be seen that individuals with lower selfcontrol are more likely to engage in substance use $(\operatorname{IRR}=1.27, p<.01)$, peer substance use is positively associated with individual substance use (IRR $=1.14, p<.05$ ), and substance use at Wave 1 is positively associated with substance use at Wave 2 (IRR = $1.97, p<.001)$. 
Table 12. Negative Binomial and Poisson Regressions of Unstructured Socializing on Property Delinquency, Violent Delinquency, and Substance Use

\begin{tabular}{|c|c|c|c|c|c|c|}
\hline \multirow[b]{2}{*}{$\underline{\text { Predictors }}$} & \multicolumn{2}{|c|}{$\begin{array}{c}\text { Model } 1 \\
\text { Property Delinquency } \\
\text { (Wave 2) } \\
(\mathrm{N}=1,404)\end{array}$} & \multicolumn{2}{|c|}{$\begin{array}{c}\text { Model } 2 \\
\text { Violent Delinquency } \\
\text { (Wave 2) } \\
(\mathrm{N}=1,303)\end{array}$} & \multicolumn{2}{|c|}{$\begin{array}{c}\text { Model } 3 \\
\text { Substance Use } \\
\text { (Wave 2) } \\
(\mathrm{N}=1,361)\end{array}$} \\
\hline & IRR & SE & IRR & SE & IRR & SE \\
\hline $\begin{array}{l}\text { Unstructured Socializing (Wave } \\
\text { 1) }\end{array}$ & $1.32 * * *$ & 0.10 & $1.16^{*}$ & 0.08 & $1.23 * *$ & 0.09 \\
\hline $\begin{array}{l}\text { Unstructured Socializing }{ }^{2} \text { (Wave } \\
\text { 1) }\end{array}$ & $0.97 * *$ & 0.01 & 0.98 & 0.01 & $0.98^{*}$ & 0.01 \\
\hline \multicolumn{7}{|l|}{ Covariates } \\
\hline Age & 1.03 & 0.07 & 0.94 & 0.07 & 1.11 & 0.08 \\
\hline Male & $1.26^{*}$ & 0.12 & 1.18 & 0.11 & 0.87 & 0.08 \\
\hline White & 0.84 & 0.08 & 0.94 & 0.09 & 0.88 & 0.08 \\
\hline Single-Parent Household & 0.89 & 0.09 & 1.06 & 0.10 & 0.94 & 0.09 \\
\hline Great Program (Wave 2) & $0.80 * *$ & 0.07 & 0.91 & 0.08 & 0.97 & 0.09 \\
\hline Low Self-Control & $1.38 * * *$ & 0.11 & 1.11 & 0.09 & $1.27 * *$ & 0.10 \\
\hline Gang Membership Ever & 1.15 & 0.19 & 1.12 & 0.21 & 1.18 & 0.20 \\
\hline Gang Membership Currently & 0.84 & 0.19 & 0.85 & 0.21 & 0.85 & 0.20 \\
\hline Parental Knowledge & 0.92 & 0.06 & 0.91 & 0.09 & 0.92 & 0.06 \\
\hline Peer Property Delinquency & $1.19 * *$ & 0.08 & --- & --- & --- & --- \\
\hline Peer Violent Delinquency & --- & --- & 0.92 & 0.07 & --- & --- \\
\hline Peer Substance Use & --- & --- & --- & --- & $1.14^{*}$ & 0.07 \\
\hline Property Delinquency (Wave 1) & $1.56^{* * *}$ & 0.07 & --- & --- & --- & --- \\
\hline Violent Delinquency (Wave 1) & --- & --- & $1.99 * * *$ & 0.13 & --- & --- \\
\hline Substance Use (Wave 1) & --- & --- & --- & --- & $1.97 * * *$ & 0.11 \\
\hline Pseudo $\mathrm{R}^{2}$ & 0.16 & & 0.14 & & 0.18 & \\
\hline
\end{tabular}

Notes: IRR = Incidence Rate Ratio; SE = Standard Error; $* \mathrm{p}<.05 ; * * \mathrm{p}<.01 ; * * * \mathrm{p}<.001$

Negative binomial regression was used to estimate the property delinquency and substance use models while poisson regression was used to estimate the violent delinquency model. 


\section{DISCUSSION}

\section{Study 1 (Multiple Mediation)}

In the present study, Osgood and colleagues' (1996) routine activity theory of general deviance served as the theoretical foundation for examining the interrelationships between parental knowledge, USWP, peer delinquency/substance use, and delinquency/substance use. Although some prior research on multiple mediating mechanisms in the context of USWP exists (Hoeben \& Weerman, 2016), the present analyses advance our understanding of these processes by demonstrating that both USWP and peer delinquency/substance use mediate the relationship between parental knowledge and delinquency/substance use. In this section, the theoretical and practical implications of the findings will be discussed, along with the study limitations and recommendations for future research, before closing with concluding remarks.

Consistent with the results obtained in prior research, this study revealed that a lack of parental knowledge is positively associated with USWP (Bernburg \& Thorlindsson, 2007; Osgood \& Anderson, 2004; Walters, 2018). Similarly, assertions made by other researchers have found that lack of parental monitoring is associated with USWP (Janssen et al., 2014; Janssen et al., 2016). Additionally, findings reported by other authors indicate that USWP influences peer delinquency (Hoeben \& Weerman, 2016; Svensson \& Oberwittler, 2010) and substance use (Thorlindsson \& Bernburg, 2006), while also suggesting that peer delinquency/substance use influences individual delinquency/substance use (for a review, see Hoeben et al., 2016). The current study not only adds to this emerging body of research establishing that each of these relationships operate alone, but also supports findings related to simple mediation models (i.e., one 
mediating variable) in this context (Walters, 2018). Considering that Hoeben and Weerman (2016) examined processes stemming from USWP, like peer delinquency, the current study advances our understanding of these processes by providing evidence that both USWP and peer delinquency/substance use mediate the relationship between parental knowledge and delinquency/substance use in a sequential manner.

From a theoretical standpoint, this finding implies that the routine activity theory of general deviance may need to be modified to explain a more complex set of relationships. Specifically, results obtained in the present study indicate that USWP is not the sole situational cause of deviant behavior as Osgood et al. (1996) postulated. In this relationship, USWP is a mediator between the more distal factor of parental knowledge and the end result of involvement in delinquency. Moreover, the results showed that a lack of parental knowledge leads to greater USWP, which leads to peer delinquency and then influences individual delinquency. Given this, USWP provides the context for a wide variety of delinquent behaviors and exposure to delinquent peers, as previously observed by Hoeben and Weerman (2016).

From a policy standpoint, these findings imply that parents should remain apprised of their children's whereabouts when they socialize with friends in unstructured and unsupervised situations to promote a positive parent to child relationship and reduce the opportunities available for future delinquency. An ample body of evidence indicates that after school programs, despite aiming to limit unsupervised routine activities, are relatively ineffective at reducing delinquency (Cross, Gottfredson, Wilson, Rorie, \& Connell, 2009). Hence, individuals in charge of such programs should provide parents with information about the importance of having knowledge of their children's 
whereabouts. Consistent with the results reported by Walters (2018), the current study's findings suggest that parental knowledge does not influence delinquency directly, but rather indirectly through USWP. This information, coupled with the observation that parental knowledge indirectly influences peer delinquency through USWP, further highlights the importance of parental oversight in understanding factors that may contribute to greater USWP, which then result in associating with delinquent peers.

\section{Study Limitations and Future Research}

With these implications in mind, it is important to discuss the limitations of the present study, as this provides directions for future research. One of the main limitations stems from the reliance on the GREAT dataset and the large amount of attrition. Almost half of the participants from Wave 3 (46\%) had dropped out from the study. While attrition is a common issue in longitudinal studies (Jeličić et al., 2009; Hansen et al., 1990), the use of methods that could alleviate the effects of missing data, such as full information maximum likelihood (FIML) employed in the current study, was proven beneficial. Schlomer, Bauman, and Card (2010) found that the use of FIML provided acceptable estimates of regression coefficient and standard errors across data meeting the missing completely at random (MCAR) and missing at random (MAR) assumptions.

FIML has also been found to perform well with samples containing moderate percentages of missing data (e.g., 25\%) that meet the not missing at random (NMAR) assumptions (Buhi, Goodson, \& Neilands, 2008). Authors of future studies in this domain should thus attempt to replicate the findings yielded by the present investigation using datasets less affected by attrition to provide a more definitive answer to the research questions proposed in this examination. 
A second limitation pertains to the fact that the data used in the present study is neither recent (1995-1999) nor nationally representative. While this is certainly a notable limitation, Scheuerman, Grosholz, and Thaxton (2018), Thaxton and Agnew (2018), and Walters (2019) utilized this same dataset in their analyses, demonstrating that the findings produced still hold merit today. Given this shortcoming, the aim of future research should be to replicate the results of this study by conducting surveys involving more recent and representative samples of adolescents to verify if the findings reported here are still applicable.

Next, a single-item measure of USWP measured in an hourly format, which has been used in previous research (Higgins \& Jennings, 2010; Meldrum \& Leimberg, 2018; Osgood \& Anderson, 2004), has its benefits, such as providing a more exact measure of USWP than evenings out per week (see Gage et al., 2005). Yet, it is possible that USWP is a more complex process and relying on a single item to measure the construct does not reveal specific days of the week or times of the day when this activity occurs. Specifically, it is impossible to discern whether adolescents are spending all of the reported time in USWP over the weekend, or whether this time is spread out over multiple days of the week (e.g., Mon-Fri). To address this potential issue, it would be beneficial to replicate studies of other scholars, such as Hoeben and Weerman (2016), using space-time budget data which can provide a more fine-grained measure of when adolescents are spending time in USWP. The use of space-time budget data could also be beneficial to better understand whether the number of friends could alter the amount and type of USWP and delinquency. Specifically, greater amounts of time available in USWP and larger friendship networks would likely result in parties where substance use would 
prominently occur. Comparatively, Tillyer and Tillyer (2015) found in their examination of co-offending and robbery that the likelihood of arrest significantly increased with greater numbers of offenders. Taking into account these assertions, the number of friends present during USWP could alter the type of USWP which occurs (e.g., riding around in a car for fun, unsupervised parties) and subsequent deviant behavior.

Multiple measures of USWP may be necessary to provide a rigorous assessment of the USWP-delinquency relationship. For instance, Weerman, Bernasco, Bruinsma, and Pauwels (2015) found that time spent with peers was only independently related to delinquency when two or more risk-inducing conditions were included, such as just socializing, being in public, and being unsupervised. Moreover, the authors found that the potential for delinquency was the greatest when all three of these conditions were met. Hence, having a construct such as that used in the GREAT data, which captures two of these criteria, is important to ensure item validity.

An additional limitation of this study stems from the potential for respondents to project their own delinquency onto that of their friends (i.e., projection effects). The traditional measure of peer delinquency often relies on respondents reporting the behavior of their peers, which may result in ascribing their own delinquent behavior to their friends (Davies \& Kandel, 1981; Gottfredson \& Hirschi, 1987, 1990; Jussim \& Osgood, 1989; Wilcox \& Udry, 1986). To overcome this potential source of bias, Coleman (1961), Reiss and Rhodes (1964) and Kandel (1978) have adopted alternative measures requiring respondents to identify their peers, which can then be used to directly obtain measures of peer behavior. This method is known as the "direct method" or the 
“social network method" (Aseltine, 1995; Baerveldt, Van Duijn, Vermeij, \& Van Hemert, 2004; Haynie, 2001, 2002; Haynie \& Osgood, 2005; Weerman \& Smeenk, 2005).

Results yielded by prior empirical research indicate that the effect size of indirect measures (i.e., traditional measures wherein respondents are asked of their friends' delinquent acts) of peer behavior on respondent delinquency are substantially higher than the effect size of direct peer measures (i.e., measures which ask respondents friends' directly about their behavior) (Weerman \& Smeenk, 2005). Similar results have been obtained in examinations comparing the effects of low self-control and delinquent peers on respondent delinquency (Meldrum et al., 2009). Given such findings, traditional measures of peer behavior may be overestimating effect sizes between peer and respondent delinquency. Future research would benefit from the use of data captured by the 'direct method' to elucidate if the use of direct peer delinquency measures yields a stronger effect size of USWP (on peer delinquency directly and on one's own delinquency indirectly via peer delinquency) relative to that obtained via the traditional measure of peer delinquency adopted in this study.

Next, an important issue to consider is the amount of time adolescents spend with peers engaging in unstructured socializing in digital space. For instance, Lenhart, Ling, Campbell \& Purcell (2010) report that $72 \%$ of all U.S. adolescents between the ages of 12 and 17 text-message or instant-message one another. The authors further noted that in 2006 only $27 \%$ of adolescents reported text-messaging others on a daily basis, which suggests mobile messaging is on the rise. In addition, Meldrum and Clark (2013) found that virtual time spent engaging in USWP was associated with delinquency and substance use. These findings suggest that USWP may not be as spontaneous and opportunistic as 
claimed by Osgood and colleagues (1996). Specifically, the use of mobile media devices may be a mechanism for adolescents to plan deviant behavior while avoiding the supervision of authority figures. Given the notions above, accompanied with the results of the present study, which found that lack of sufficient parental knowledge leads to more USWP, parents should consider more strictly monitoring adolescents use of mobile devices.

A final limitation in the present study is common method bias (CMB), which may increase the strength in relationships among variables stemming from using self-report data to measure each of the variables in an analysis (Conway \& Lance, 2010). Conway and Lance (2010) claim that CMB may be less problematic when 1) construct validity is present, 2) when there is a lack of overlap between study items, and 3) the author proactively considered CMB. In this regard, concerns over CMB might be tempered as it pertains to the current study. First, the primary measures of this dissertation have been used in previous research, which suggests construct validity is present. Second, with the exception of the variables examining former and current gang membership, which a pearson correlation test $(r=.64)$ revealed moderately strong correlation between the items, the other measures appear to not overlap (without doing formal statistical testing). Third, as advocated by Podsakoff, MacKenzie, Lee, and Podsakoff (2003) study design techniques may proactively consider CMB such as "protecting respondent anonymity" (p. 888). Given the confidential design of the GREAT questionnaire (Esbensen et al., 2011), such methods helped to reduce the possibility of CMB. 


\section{Concluding Remarks}

Continued attention to these underlying processes is needed to develop a more rigorous understanding of why USWP is such a strong predictor of delinquency (Osgood et al., 1996). For example, future research would benefit from a more thorough examination in the type of parenting factors that are most likely to reduce USWP. Research has probed how various parenting factors such as greater child disclosure (Stattin \& Kerr, 2000) and children who have a positive relationship with their parents (Kerr and Stattin, 2000) exhibit less delinquency. Additionally, research by Janssen and colleagues (2014) found that adolescents who perceive greater parental monitoring, greater parental limit setting, and those who report a more positive relationship with their parents tend to spend less time in USWP. Considering the limitations of Janssen et al. (2014) who were only able to examine a four day time span per week of adolescent activities like USWP, further research is warranted to ascertain a more definitive answer as to what type of parenting factors are most likely to reduce USWP and what days of the week USWP is most likely to occur. Additionally, given the assertion that no parent wants their child to grow up as a delinquent, continued research on common settings that are conductive to antisocial behavior among adolescents; such as USWP, should be at the forefront of social science research. Findings yielded by such studies would ensure that the health and safety of children continues to improve, leading to a safer environment for all of society.

\section{Study 2 (Reciprocal Effects)}

Prior research investigating Osgood and colleagues' (1996) routine activity theory of general deviance indicates that USWP is a robust predictor of delinquency (for a 
review, see Hoeben et al., 2016). Empirical evidence also indicates that delinquency leads to USWP (Taylor et al., 2007; Vasquez \& Zimmerman, 2014). The current study advances our understanding of these associations by demonstrating that the relationship between USWP and property delinquency and that between USWP and substance use influence one another over time; however, this association does not emerge instantly. As Osgood et al. (1996) contended that the USWP-delinquency relationship is onedirectional, assessing the degree to which USWP is reciprocally related to a variety of antisocial behaviors is necessary in order to establish a robust understanding of theoretical arguments put forth by these authors. Several main findings emerged from the models developed as a part of this study and are elaborated on below. Additionally, as it pertains to each of these results, the theoretical implications for Osgood and colleagues' (1996) routine activity theory of general deviance will be provided. Within this section, the practical implications of the study will also be discussed, along with the study limitations, thus providing suggestions for future research, before concluding with some final remarks.

The first finding of this study is that USWP remains relatively stable over time. For instance, in Model 1 which examined USWP and property delinquency, the standardized estimates of USWP from Wave 1 to Wave 2 was .410 and from Wave 2 to Wave 3 was .425 , showing only a slight increase. The standardized estimates of property delinquency from Wave 1 to Wave 2 of .777 and Wave 2 to Wave 3 of .601; however, demonstrate a slight decline. Second, this study found that USWP is a predictor of property delinquency over time; albeit not instantly. Specifically, USWP measured at Wave 1 did not influence property delinquency at Wave 2; however, USWP measured at 
Wave 2 (Fall 1995) predicted property delinquency at Wave 3 (Fall 1996). Additionally, property delinquency at Wave 1 significantly and positively predicted property delinquency at Wave 2, and the same findings emerged at Wave 3. Given, Osgood et al. (1996) argued that unstructured activities that carry no agenda are conducive to deviance. The findings yielded by the present study only partially support this assertion. Particularly, property delinquency was a significant and consistent predictor of later USWP across all three waves that were subjected to analyses in the present study. Therefore, it is apparent that both USWP and property delinquency mutually influence one another in a cross-lagged manner, but only at later time points (Wave 2 and 3). In other words, these associations are reciprocal, indicating that Osgood and colleagues' (1996) routine activity theory of general deviance should be extended to account for these complexities.

The second finding of this study examining the stability of USWP over time (Model 2), reported by the standardized estimates from Wave 1 to Wave 2 of .381 and from Wave 2 to Wave 3 of .396 demonstrate USWP remains relatively stable over time. Additionally, the standardized violent delinquency estimates from Wave 1 to Wave 2 of .758 and Wave 2 to Wave 3 of .803 offer support that violent delinquency only slightly increases over time. The next finding which offered some evidence of the reciprocal influence of USWP and violent delinquency over time is partially consistent with those captured by the property delinquency model. Like the property delinquency model, violent delinquency was found to be a positive predictor of later USWP across all survey waves, Specifically, the standardized estimate found from Wave 1 to Wave 2 was .381 and Wave 2 to Wave 3 was .396. Unlike the property delinquency model (Model 1); 
however, USWP did not predict later violent delinquency across any of the waves. Though inconsistent with the postulates of Osgood et al.'s (1996) theory, this finding is consistent with the results reported by other authors indicating that delinquents may spend greater time in USWP (Taylor et al., 2007; Vásquez \& Zimmerman, 2014). Hence, in order for Osgood et al.'s (1996) theory, to retain its empirical validity, , which states USWP leads to delinquency, an extension is needed to better explain why delinquency contributes to greater USWP.

The third main finding pertains to the relationship between USWP and substance use over time (Model 3), which was very similar to findings yielded by the property delinquency model. Indeed, not only does USWP remain relatively stable over time, as the standardized estimates of USWP from Wave 1 to Wave 2 of .406 and from Wave 2 to Wave 3 of .407 offer support, substance use only slightly declines overtime which is supported by the standardized estimates from Wave 1 to Wave 2 of .802 and Wave 2 to Wave 3 of .718. In addition, substance use was found to be a consistent predictor of later USWP. Further, and similar to the results of the property delinquency model, a crosslagged relationship was found between USWP and substance use at Waves 2 and 3. Particularly, USWP at Wave 2 (Fall 1995) predicted substance use at Wave 3 (Fall 1996) and substance use at Wave 2 (Fall 1995) predicted USWP at Wave 3 (Fall 1996). The finding that USWP leads to substance use is in accordance with Osgood et al.'s (1996) theory claiming USWP leads to substance use. Additionally, the finding that substance use predicted USWP supports prior research suggesting that drug-related delinquency (e.g., drug use and drug sales) is associated with spending more time with peers (Vásquez \& Zimmerman, 2014). 


\section{Study Limitations and Future Research}

While utilizing longitudinal survey data of adolescents residing in the U.S. is one of the strengths of the present study, along with using a measure of USWP that taps into all three components of the construct (e.g., unstructured and unsupervised, time with peers), and controlling for a wide variety of variables, the limitations noted earlier should be considered when interpreting the findings reported here. The main issue stems from attrition, which was addressed through FIML. As mentioned, FIML is well-suited to handle missing data, especially if it meets MCAR and MAR assumptions (Schlomer et al., 2010), and to a lesser extent MNAR data (Buhi et al., 2008). Authors of future research should therefore seek to replicate the findings of this study by conducting analyses on more recent samples of adolescents for whom more complete data are available.

An additional limitation worth noting is the rarity of antisocial behavior among the general population of adolescents and the design of the GREAT survey. Focusing on a general sample of adolescents means that engagement in serious delinquency, particularly violence, will be quite low, which can make it difficult to detect associations between such types of delinquency and predictor variables. In addition, nonuniformity exists between the waves of the current study with regard to asking respondents about their previous delinquency. For example, the Fall of 1996 (Wave 3) questionnaire asked respondents to indicate how many delinquent acts they had committed in the past 6 months. The preceding survey was administered in Fall of 1995 (Wave 2), which would suggest a 12-month reference point. Given these considerations, issues may exist as to whether some responses were missing due to lack of reference to a full year between 
survey distributions. Inquiring by respondent's delinquency within the past six months is also evident in the later waves of the GREAT data, particularly, Fall 1997, 1998, and 1999. Lacking reference of a full range between time points (i.e., asking respondents about their delinquency in the past 12 months) may have resulted in low variability, which could explain the pattern of findings wherein USWP failed to predict later involvement in violent delinquency. Considering the rare nature of antisocial behavior and loss of responses from attrition of the GREAT data, which likely was a result stemming from delinquents who dropped out of the survey, statistical power was lost, which could help explain the pattern of findings of the present study. Given this, future research should use larger samples and seek to achieve greater retention in order to ensure sufficient statistical power and reduce any potential bias in study findings.

As postulated by Osgood et al. (1996) and confirmed by extensive research (Hoeben et al., 2016), USWP predicts a wide range of antisocial behaviors. Hence, it is important to elucidate why USWP was not a predictor of substance use as well as other types of delinquent behavior like property delinquency at Wave 1 and violent delinquency across all survey waves. Prior research could provide a much-needed perspective on this issue. For example, without capturing the degree to which authority figures were present when adolescents aged 9 to 12 years socialized with their friends, Wong (2005) found that the duration of time spent with peers often increases with age. Similarly, Higgins and Jennings (2010) found that USWP increases from age 12 to 16. Other researchers have found that older individuals (those aged 18 to 26 years) are likely to spend time in USWP but this decreases as individuals get older (Osgood et al., 1996). 
Considering the findings yielded by the aforementioned studies, at Wave 1 of the GREAT survey, adolescents in the present study would be less likely to spend time in USWP compared to later waves that were conducted when they were older. Although adolescence appears to be the time when USWP is likely to have the greatest effect on delinquency (Higgins \& Jennings, 2010), it would be beneficial to probe further into the degree to which USWP has its greatest impact in other age brackets, such as early adulthood. Prior studies have demonstrated that time spent with peers increases as the child ages (Higgins \& Jennings, 2010; Wong, 2005), and this trend extends into early adulthood (Osgood et al., 1996). Thus, in future research, it would be beneficial to examine the entire period of early adolescence to adulthood. Such an investigation would help elucidate the age(s) at which USWP has the largest effect on delinquency. Based on the findings yielded by the aforementioned studies, it would seem that 9 to 18 -year-olds are most prone to delinquency if allowed to spend time in USWP; however, further research is still needed. Such a study would be useful to better understand why USWP leads to anti-social behavior, but only at certain time points.

Additionally, Study 1 found that USWP indirectly influences delinquency through peer delinquency, (see also, Hoeben and Weerman, 2016). Thus, it is possible that peer delinquency may be a more immediate predictor of delinquency than USWP. Given this consideration, future research could provide a more definitive answer as to why USWP did not predict delinquency from all Waves of the GREAT data. Specifically, a reciprocal examination of USWP, peer delinquency, and individual delinquency would be useful to not only better understand the multifaceted ways in which USWP leads to delinquency, but would also help to provide a more definitive answer as to why USWP was not a 
predictor of delinquency across all waves of the current study. Therefore, it is possible that USWP is running through peer delinquency to then lead to delinquency; however, further examination is still warranted.

From a policy standpoint, these findings suggest that individuals who are already involved in delinquency should be more closely monitored. Vasquez and Zimmerman (2014) found that delinquents spend more time with their peers than is average for adolescents. Thus, it is likely that adolescent offenders may spend more time in unstructured and unsupervised situations with peers than those not already involved in delinquency. Further, offender release efforts that incorporate family management and parent effectiveness training can be beneficial for younger adolescents, increasing the likelihood that they would reenter society as law abiding citizens (Altschuler \& Brash, 2004) and perhaps be less likely to increase involvement in USWP.

\section{Concluding Remarks}

In sum, the findings yielded by the current examination suggest that, although Osgood and colleagues' (1996) routine activity theory of general deviance and its' arguments concerning the USWP-delinquency relationship are partially supported, it cannot fully elucidate why delinquents may end up spending more time in USWP in the future. Continued research efforts should thus be dedicated to this issue, with potential revisions to Osgood et al.'s (1996) theory that could explain why involvement in delinquency might cause an increase in USWP.

\section{Study 3 (Nonlinear Effects)}

The current study adds to the emerging body of research examining Osgood and colleagues' (1996) theory of USWP by assessing the extent to which USWP influences a 
variety of antisocial behaviors in a nonlinear manner. Although the nonlinearity aspect has received some attention (Gage et al., 2005; Meldrum \& Leimburg, 2018), the current study advances our understanding of these processes by demonstrating that the relationship between USWP and both property delinquency and substance use is nonlinear. In the following paragraphs, the findings obtained as a part of this study are outlined, along with their theoretical and practical implications. Thereafter, the key study limitations are delineated, along with directions for future research. The section ends with and concluding remarks.

While controlling for a wide variety of covariates, such as self-control, parental knowledge, peer delinquency, and prior delinquency among others, this study has yielded findings consistent with those reported by other authors suggesting that USWP is associated with property delinquency (Bernburg \& Thorlindsson, 2001) and violent delinquency (Gage et al., 2005; Maimon \& Browning, 2010). Similarly, the link between USWP and substance use established in this work supports the conclusions reached in past research on this topic (Barnes et al., 2007; Green \& Banerjee, 2009; Hawdon, 1996; Meldrum \& Leimburg, 2018; Miller, 2013). These findings add to the emerging literature indicating that USWP is a robust predictor of a wide variety of delinquent acts (for a review, see Hoeben et al., 2016).

Next, the relationship between USWP and property delinquency, and that between USWP and substance use, was found to be nonlinear in a decelerating manner. These findings mirror those reported by Meldrum and Leimberg (2018), who examined a sample of adolescents establishing that while the effect of USWP on the frequency of drinking, marijuana use, and a variety index of substances including cigarette, e-cigarette, 
drinking, and marijuana use is positive, the effect is a decelerating one. However, Gage et al. (2005) offered evidence that the relationship between USWP and deviance may be nonlinear in an accelerating manner. Specifically, whereas children who spent two to four evenings out with friends per week were only slightly more likely to engage in occasional or frequent involvement in problem behaviors compared to students that rarely go out with friends, students who reported spending five to seven evenings out per week were significantly more likely to engage in problem behaviors.

Given that the relationship between USWP and property delinquency/substance use is nonlinear in a decelerating manner, it is reasonable to assume that a tipping point may exist, whereby adolescents do not desire to be involved in delinquency or substance use all of the time. In addition, only so much drug use can occur before parents become aware of such behavior among their children. Given these assertions, adolescents involved in USWP may be spending time doing other things rather than continuing to use drugs. Future research should continue to probe this finding by examining other forms of illicit behaviors that have been associated with USWP, such as vandalism (Hoeben \& Weerman, 2016).

As a further point, the relationship between USWP and violent delinquency was supported in this study, albeit without any evidence of its nonlinearity. Given that Osgood and colleagues (1996) state "being accompanied by friends reduces the danger in challenging a rival to a fight" (p. 639), it is plausible that individuals spending greater amounts of time in USWP may actually be those who are most shielded from violent delinquency, due to the protection offered from fellow group members. This notion has been supported in the gang literature, wherein being part of a gang protects members 
from general violent victimization but not serious violent victimization (Taylor et al., 2007). Therefore, it would be beneficial to explore whether this association holds across other samples involving adolescents or individuals entering early adulthood, which would help develop a firmer understanding of whether these associations are nonlinear.

Considering results yielded by the model indicated that the relationship between USWP and property delinquency is decelerating, this counters Hypothesis 3 postulating an accelerating association. With attention to this assertion, it is logical that property delinquency would require more effort by the offender to carry out than consuming an alcoholic beverage, lighting up a cigarette, or using marijuana (Meldrum \& Leimburg, 2018). Despite the findings in the reciprocal examination of USWP and antisocial behavior (Study 2) of this dissertation, which found that although USWP does lead to delinquency, this may not occur instantly. Osgood et al.'s (1996) theory, nonetheless, continues to provide a valid explanation as to why spending time in unsupervised and unstructured settings with friends is so conducive to adolescent deviance.

\section{Study Limitations and Future Research}

Despite the strengths of the current study, namely the use of a longitudinal sample necessary to determine proper causal ordering, a measure of USWP that taps into all three elements of the construct, and a wide variety of control variables, it also has limitations which merit discussion. First, the data is not as recent as one would like (1995-1999). Still, several authors have conducted recent studies utilizing the same dataset (Scheuerman et al., 2018; Thaxton \& Agnew, 2018; Walters, 2019), suggesting that the findings yielded still have merit. Next, although USWP was captured via a single questionnaire item, which prompted respondents to report the number of hours they 
spend in USWP during an average week, (see also Higgins \& Jennings, 2010; Meldrum \& Leimburg, 2018; Osgood \& Anderson, 2004), the reliability of this item cannot be assessed. Clearly, it would be more informative to measure USWP by asking respondents to indicate the specific number of hours and specific times of day they typically engage in USWP, as is common when gathering space-time budget data (Hoeben \& Weerman, 2016). Considering that respondents may be spending all of their time in USWP over the weekend or spending a couple hours after school during the week in USWP, having this information would be useful for future research to distinguish more fine-grained time points at which USWP is taking place. Parents would also benefit from such a study in order to better understand when their children need to be more closely monitored to prevent delinquency.

Past research conducted by Gage et al. (2005) found that the relationship between USWP and delinquency may be nonlinear in an accelerating manner. Comparatively, other research by Meldrum and Leimburg (2018) found that the relationship between USWP and substance use may be nonlinear albeit decelerating, which was also confirmed by the results of the current study for the property delinquency and substance use models. Considering the rapidly expanding use of media devices, like smart phones among adolescents (Lenhart et al., 2010), this could be a possible explanation as to why the results of this study offered evidence of decelerating associations. Specifically, the use of media devices allows greater planning to occur than what typically would happen during the timeframe of Osgood and colleagues (1996) study. Therefore, adolescents may be planning deviant activities in unsupervised and unstructured time spent with friends through means of virtual communication. 
Although a common approach in dealing with missing data (Kang, 2013), an additional study limitation worth noting is the use of listwise deletion. Considering the initially large sample size offered by the GREAT data of almost 3,000 respondents, which would offer sufficient power for the present analysis, this was reduced by more than half through the use of listwise deletion. Further, preliminary analysis of the data revealed that it does not meet the assumptions of MCAR necessary for listwise deletion, thus, parameter bias may be present (Kang, 2013). Future studies should consider the use of software packages which can assess nonlinearity with strategies to regain missing data like FIML or multiple imputation. Such a study would be useful to determine if the results offered in the present analysis sill hold across alternative strategies for dealing with attrition and missing data.

\section{Concluding Remarks}

In conclusion, the current study adds to the USWP literature by demonstrating that the relationship between USWP and property delinquency/substance use is nonlinear. This study also highlights the need for a better understanding of the USWP/delinquency relationship, with the ultimate aim of reducing delinquency. Specifically, although the current study advances our understanding of the nonlinear effects of USWP on delinquency/substance use, the varied ways this relationship may be nonlinear with respect to males or females and gang or non-gang members remains unexplored. By gaining a more comprehensive explanation of the varied ways USWP influences delinquency, a more robust understanding of Osgood and colleagues' (1996) theory of USWP can be found. 


\section{REFERENCES}

Agnew, R., \& Petersen, D. M. (1989). Leisure and delinquency. Social Problems, 36(4), 332-350.

Akers, R. L. (1985). Deviant Behavior: A social learning approach. Belmount, CA: Wadsworth.

Akers, R. L. (1992). Drugs, alcohol, and society: Social structure, process, and policy. Wadsworth Publishing Company.

Altschuler, D. M., \& Brash, R. (2004). Adolescent and teenage offenders confronting the challenges and opportunities of reentry. Youth Violence and Juvenile Justice, 2(1), $72-87$.

Aseltine Jr, R. H. (1995). A reconsideration of parental and peer influences on adolescent deviance. Journal of Health and Social Behavior, 36(2), 103-121.

Asparouhov, T., \& Muthén, B. (2010). Weighted least squares estimation with missing data. Mplus Technical Appendix, 1-10.

Baerveldt, C., Van Duijn, M. A., Vermeij, L., \& Van Hemert, D. A. (2004). Ethnic boundaries and personal choice. Assessing the influence of individual inclinations to choose intra-ethnic relationships on pupils' networks. Social Networks, 26(1), $55-74$.

Baraldi, A. N., \& Enders, C. K. (2010). An introduction to modern missing data analyses. Journal of School Psychology, 48(1), 5-37.

Barnes, G. M., Hoffman, J. H., Welte, J. W., Farrell, M. P., \& Dintcheff, B. A. (2007). Adolescents' time use: Effects on substance use, delinquency and sexual activity. Journal of Youth and Adolescence, 36(5), 697-710.

Baron, R. \& Kenny, D. (1986). The moderator-mediator variable distinction in social psychological research: Conceptual, strategic, and statistical considerations. Journal of Personality and Social Psychology, 51(6), 1173-1182.

Bearden, W. O., Sharma, S., \& Teel, J. E. (1982). Sample size effects on chi square and other statistics used in evaluating causal models. Journal of marketing research, 19(4), 425-430.

Bentler, P. M. (1990). Comparative fit indexes in structural models. Psychological Bulletin, 107(2), 238-246. 
Bentler, P. M., \& Yuan, K. H. (1999). Structural equation modeling with small samples: Test statistics. Multivariate behavioral research, 34(2), 181-197.

Bernasco, W., Ruiter, S., Bruinsma, G. J., Pauwels, L. J., \& Weerman, F. M. (2013). Situational causes of offending: A fixed-effects analysis of space-time budget data. Criminology, 51(4), 895-926.

Bernburg, J. G., \& Thorlindsson, T. (2001). Routine activities in social context: A closer look at the role of opportunity in deviant behavior. Justice Quarterly, 18(3), 543567.

Bernburg, J. G., \& Thorlindsson, T. (2007). Community structure and adolescent delinquency in Iceland: A contextual analysis. Criminology, 45(2), 415-444.

Birbeck, C., \& LaFree, G. (1993). The situational analysis of crime and deviance. Annual Review of Sociology, 19(1), 113-137.

Bogg, R. A., \& Hughes, J. W. (1973). Correlates of marijuana usage at a Canadian technological institute. International Journal of the Addictions, 8(3), 489-504.

Boman IV, J. H. (2013). The intersection of friendships, networks, and crime: A developmental extension and test of Sutherland's differential association theory. University of Florida.

Briar, S., \& Piliavin, I. (1965). Delinquency, situational inducements, and commitment to conformity. Social Problems, 13(1), 35-45.

Brown, B. (1990). Peer Groups and Peer Cultures. In S.S. Feldman and G. R. Eliott (Eds.) At the Threshold: The Developing Adolescent. Harvard University Press.

Browne, M. W., \& Cudeck, R. (1993). Alternative ways of assessing model fit. Sage Focus Editions, 154, 136-136.

Buhi, E. R., Goodson, P., \& Neilands, T. B. (2008). Out of sight, not out of mind: strategies for handling missing data. American Journal of Health Behavior, 32(1), 83-92.

Cairns, R. B., \& Cairns, B. D. (1991). Social cognition and social networks: A developmental perspective. The development and treatment of childhood aggression, 249-278.

Catalano, R. F. \& Hawkins, J. D. (1996). The social development model: A theory of antisocial behavior. In J. D. Hawkins (Ed.) Delinquency and Crime: Current Theories (pp. 149-197). New York: Cambridge University Press. 
Cheung, G. W., \& Lau, R. S. (2008). Testing mediation and suppression effects of latent variables: Bootstrapping with structural equation models. Organizational Research Methods, 11(2), 296-325.

Cloward, R. A., \& Ohlin, L. E. (1960). Delinquency and opportunity. New York: Free Press.

Cohen, A. K. (1955). Delinquent boys. New York: Free Press.

Cohen, L. E., Cantor, D., \& Kluegel, J. R. (1981). Robbery victimization in the United States: An analysis of a nonrandom event. Social Science Quarterly, 62(4), 644.

Cohen, L. E., \& Felson, M. (1979). Social change and crime rate trends: A routine activity approach. American Sociological Review, 44(4), 588-608.

Cohen, D. A., \& Rice, J. C. (1995). A parent-targeted intervention for adolescent substance use prevention: Lessons learned. Evaluation Review, 19(2), 159-180.

Collins, L. M., Graham, J. J., \& Flaherty, B. P. (1998). An alternative framework for defining mediation. Multivariate Behavioral Research, 33(2), 295-312.

Coleman, J. (1961). The adolescent society. Glencoe, IL: Free Press.

Coleman, J. (1988). Social capital in the creation of human capital. American Journal of Sociology, 94, S95-S120.

Conway, J. M., \& Lance, C. E. (2010). What reviewers should expect from authors regarding common method bias in organizational research. Journal of Business and Psychology, 25(3), 325-334.

Cornish, D., \& Clarke R. (1986). The reasoning criminal: Rational choice perspectives on offending. New York: Springer-Verlag.

Cross, A. B., Gottfredson, D. C., Wilson, D. M., Rorie, M., \& Connell, N. (2009). The impact of after-school programs on the routine activities of middle-school students: Results from a randomized, controlled trial. Criminology \& Public Policy, 8(2), 391-412.

Crouter, A., \& Head, M. (2002). Parental monitoring and knowledge of children. In M. Bornstein (Ed.), Handbook of parenting ( $2^{\text {nd }}$ ed., Vol. 3, pp. 461-483). Mahwah, NJ: Lawrence Erlbaum.

Davies, M., \& Kandel, D. B. (1981). Parental and peer influences on adolescents' educational plans: Some further evidence. American Journal of Sociology, 87(2), 363-387. 
Dishion, T. J., \& Patterson, G. R. (2006). The Development and Ecology of Antisocial Behavior in Children and Adolescents. Developmental Psychopathology: Risk, Disorder, and Adaptation, 3, 503-541. John Wiley \& Sons Inc.

Ditlevsen, S., Christensen, U., Lynch, J., Damsgaard, M. T., \& Keiding, N. (2005). The mediation proportion: a structural equation approach for estimating the proportion of exposure effect on outcome explained by an intermediate variable. Epidemiology, 16(1). 114-120.

Eiser, J. R., Morgan, M., Gammage, P., Brooks, N., \& Kirby, R. (1991). Adolescent health behaviour and similarity-attraction: Friends share smoking habits (really), but much else besides. British Journal of Social Psychology, 30(4), 339-348.

Elliott, D., \& Menard, S. (1996). Delinquent friends and delinquent behavior: Temporal and developmental patterns. In J.D. Hawkins (Ed.), Delinquency and Crime, New York, NY: Cambridge University Press.

Elmore, K. L. (2005). Alternatives to the chi-square test for evaluating rank histograms from ensemble forecasts. Weather and forecasting, 20(5), 789-795.

Enders, C. K. (2010). Applied missing data analysis. Guilford press.

Enders, C. K., \& Bandalos, D. L. (2001). The relative performance of full information maximum likelihood estimation for missing data in structural equation models. Structural equation modeling, 8(3), 430-457.

Erickson, M. L., \& Jensen, G. F. (1977). Delinquency is still group behavior!: Toward revitalizing the group premise in the sociology of deviance. The Journal of Criminal Law and Criminology, (68(2), 262-273.

Esbensen, F. A. (2002). National evaluation of the Gang Resistance Education and Training (GREAT) program. Final report. Washington, DC: US Department of Justice.

Esbensen, F. A., \& Osgood, D. W. (1999). Gang resistance education and training (GREAT): Results from the national evaluation. Journal of Research in Crime and Delinquency, 36(2), 194-225.

Esbensen, F. A., Osgood, D. W., Taylor, T. J., Peterson, D., \& Freng, A. (2001). How great is GREAT? Results from a longitudinal quasi-experimental design. Criminology \& Public Policy, 1(1), 87-118. 
Esbensen, F. A., Peterson, D., Taylor, T. J., Freng, A., Osgood, D. W., Carson, D. C., \& Matsuda, K. N. (2011). Evaluation and evolution of the Gang Resistance Education and Training (GREAT) program. Journal of School Violence, 10(1), 53-70.

Felson, M. (1998). Crime and everyday life. Thousand Oaks, CA: Pine Forge Press.

Felson, M. (2003). The process of co-offending. Crime Prevention Studies, 16, 149-168.

Fleming, C. B., Catalano, R. F., Mazza, J. J., Brown, E. C., Haggerty, K. P., \& Harachi, T. W. (2008). After-school activities, misbehavior in school, and delinquency from the end of elementary school through the beginning of high school: A test of social development model hypotheses. The Journal of Early Adolescence, 28(2), 277-303.

Fletcher, A. C., Steinberg, L., \& Williams-Wheeler, M. (2004). Parental influences on adolescent problem behavior: Revisiting Stattin and Kerr. Child Development, 75(3), 781-796.

Ford, J. A. (2005). Substance use, the social bond, and delinquency. Sociological inquiry, 75(1), 109-128.

Gage, J. C., Overpeck, M. D., Nansel, T. R., \& Kogan, M. D. (2005). Peer activity in the evenings and participation in aggressive and problem behaviors. Journal of Adolescent Health, 37(6), 517.e7-517.e14.

Gibbs, J. P. (1981). Norms, deviance, and social control: Conceptual matters. New York: Elsevier Science Ltd.

Glaser, D. (1971). Social deviance. Markham Publishing. Company.

Gottfredson, M., \& Hirschi, T. (1987). The methodological adequacy of longitudinal research on crime. Criminology, 25(3), 581-614.

Gottfredson, M. R., \& Hirschi, T. (1990). A general theory of crime. Stanford University Press.

Gold, M. (1970). Delinquent behavior in an American city. Belmont, CA: Brooks/Cole.

Goode, E. (1989). Drugs in American society. New York: McGraw-Hill.

Gottfredson, M. R., \& Hirschi, T. (1990). A general theory of crime. Stanford University Press. 
Goldstein, S. E., Davis-Kean, P. E., \& Eccles, J. S. (2005). Parents, peers, and problem behavior: A longitudinal investigation of the impact of relationship perceptions and characteristics on the development of adolescent problem behavior. Developmental Psychology, 41(2), 401-413.

Graham, J. W. (2009). Missing data analysis: Making it work in the real world. Annual Review of Psychology, 60, 549-576.

Graham, J. W., Hofer, S. M., Donaldson, S. I., MacKinnon, D. P., \& Schafer, J. L. (1997). Analysis with missing data in prevention research. In K. J. Bryant, M. Windle, \& S. G. West (Eds.), The science of prevention: Methodological advances from alcohol and substance abuse research (pp. 325-366). Washington, DC: American Psychological Association.

Grasmick, H. G., Tittle, C. R., Bursik Jr, R. J., \& Arneklev, B. J. (1993). Testing the core empirical implications of Gottfredson and Hirschi's general theory of crime. Journal of Research in Crime and Delinquency, 30(1), 5-29.

Greene, K., \& Banerjee, S. C. (2009). Examining unsupervised time with peers and the role of association with delinquent peers on adolescent smoking. Nicotine \& Tobacco Research, 11(4), 371-380.

Hansen, W. B., Tobler, N. S., \& Graham, J. W. (1990). Attrition in substance abuse prevention research: A meta-analysis of 85 longitudinally followed cohorts. Evaluation Review, 14(6), 677-685.

Hawdon, J. E. (1996). Deviant lifestyles: The social control of daily routines. Youth \& Society, 28(2), 162-188.

Hawkins, J. D., \& Weis, J. G. (1985). The social development model: An integrated approach to delinquency prevention. Journal of Primary Prevention, 6(2), 73-97.

Haynie, D. L. (2001). Delinquent peers revisited: Does network structure matter? American journal of sociology, 106(4), 1013-1057.

Haynie, D. L. (2002). Friendship networks and delinquency: The relative nature of peer delinquency. Journal of Quantitative Criminology, 18(2), 99-134.

Haynie, D. L., \& Osgood, D. W. (2005). Reconsidering peers and delinquency: How do peers matter? Social Forces, 84(2), 1109-1130.

Higgins, G. E., \& Jennings, W. G. (2010). Is unstructured socializing a dynamic process? An exploratory analysis using a semiparametric group-based modeling approach. Criminal Justice Review, 35(4), 514-532. 
Hirschi, T. (1969). Causes of delinquency. Berkeley, CA: University of California Press.

Hoeben, E. M., Meldrum, R. C., \& Young, J. T. (2016). The role of peer delinquency and unstructured socializing in explaining delinquency and substance use: A state-ofthe-art review. Journal of Criminal Justice, 47, 108-122.

Hoeben, E. M., \& Weerman, F. M. (2016). Why is involvement in unstructured socializing related to adolescent delinquency? Criminology, 54(2), 242-281.

Hoeve, M., Dubas, J. S., Eichelsheim, V. I., Van der Laan, P. H., Smeenk, W., \& Gerris, J. R. (2009). The relationship between parenting and delinquency: A metaanalysis. Journal of Abnormal Child Psychology, 37(6), 749-775.

Hu, L. T., \& Bentler, P. M. (1999). Cutoff criteria for fit indexes in covariance structure analysis: Conventional criteria versus new alternatives. Structural Equation Modeling: A Multidisciplinary Journal, 6(1), 1-55.

Hughes, L. A., \& Short, J. F. (2014). Partying, cruising, and hanging in the streets: Gangs, routine activities, and delinquency and violence in Chicago, 1959-1962. Journal of Quantitative Criminology, 30(3), 415-451.

Hundleby, J. D. (1987). Adolescent drug use in a behavioral matrix: A confirmation and comparison of the sexes. Addictive Behaviors, 12(2), 103-112.

Inciardi, J. A. (1992). The war on drugs II: The continuing epic of heroin, cocaine, crack, crime, AIDS, and public policy (Vol. 2). McGraw-Hill Humanities, Social Sciences \& World Languages.

Janssen, H. J., Bruinsma, G. J., Deković, M., \& Eichelsheim, V. I. (2016). A between-and within-person analysis of parenting and time spent in criminogenic settings during adolescence: The role of self-control and delinquent attitudes. Youth \& Society, 50(2), 229-254.

Janssen, H. J., Deković, M., \& Bruinsma, G. J. (2014). Parenting and time adolescents spend in criminogenic settings: A between-and within-person analysis. British Journal of Criminology, 54(4), 551-567.

Jeličić, H., Phelps, E., \& Lerner, R. M. (2009). Use of missing data methods in longitudinal studies: The persistence of bad practices in developmental psychology. Developmental Psychology, 45(4), 1195.

Johnston, L. D., Bachman, J., \& O'Malley, P. (1987). Monitoring the future: The continuous study of lifestyles and values of youth. Ann Arbor, MI: Institute for Social Research. 
Johnston, L. D., O'Malley, P. M., \& Eveland, L. K. (1978). Drugs and delinquency: A search for causal connections. Longitudinal Research on Drug Use: Empirical Findings and Methodological Issues, 137-156.

Judd, C. M., \& Kenny, D. A. (1981). Process analysis: Estimating mediation in treatment evaluations. Evaluation Review, 5(5), 602-619.

Jussim, L., \& Osgood, D. W. (1989). Influence and similarity among friends: An integrative model applied to incarcerated adolescents. Social Psychology Quarterly, 98-112.

Kandel, D. B. (1978). Homophily, selection, and socialization in adolescent friendships. American journal of Sociology, 84(2), 427-436.

Kang, H. (2013). The prevention and handling of the missing data. Korean journal of anesthesiology, 64(5), 402.

Kandel, D. B., Kessler, R. C., \& Margulies, R. Z. (1978). Antecedents of adolescent initiation into stages of drug use: A developmental analysis. Journal of Youth and Adolescence, 7(1), 13-40.

Kenny, D. A. (2015). Measuring model fit.

Kearney, M. W. (2017). Cross Lagged Panel Analysis. In M. R. Allen (Ed.). The Sage Encyclopedia of Communication Research Methods. Thousand Oaks, CA: Sage

Kennedy, L. W., \& Forde, D. R. (1990). Routine activities and crime: An analysis of victimization in Canada. Criminology, 28(1), 137-152.

Kenny, D. A. Kashy, D. A., Bolger, N. (1998). Data analysis in social psychology. In D. Gilbert, S. T. Fiskc, \& G. Lindzcy (Eds.), Handbook of social psychology $\left(4^{\text {th }}\right.$ ed., Vol. 1, pp. 233-265). New York: McGraw-Hill.

Kerr, M., \& Stattin, H. (2000). What parents know, how they know it, and several forms of adolescent adjustment: further support for a reinterpretation of monitoring. Developmental psychology, 36(3), 366-380.

Krull, J. L., \& MacKinnon, D. P. (1999). Multilevel mediation modeling in group-based intervention studies. Evaluation review, 23(4), 418-444.

Krull, J. L., \& MacKinnon, D. P. (2001). Multilevel modeling of individual and group level mediated effects. Multivariate behavioral research, 36(2), 249-277. 
Lenhart, A., Ling, R., Campbell, S., \& Purcell, K. (2010). Teens and mobile phones: Text messaging explodes as teens embrace it as the centerpiece of their communication strategies with friends. Pew Internet \& American Life Project.

Lippold, M. A., Greenberg, M. T., Graham, J. W., \& Feinberg, M. E. (2014). Unpacking the effect of parental monitoring on early adolescent problem behavior: Mediation by parental knowledge and moderation by parent-youth warmth. Journal of Family Issues, 35(13), 1800-1823.

Little, R. J. (1988). A test of missing completely at random for multivariate data with missing values. Journal of the American Statistical Association, 83(404), 11981202.

Little, R. J., \& Rubin, D. B. (2014). Statistical analysis with missing data. $2^{\text {nd }}$ ed. Hoboken, NJ: Wiley.

Long, S. J. \& Freese, J. (2006). Regression models for categorical dependent variables using Stata. Stata press.

MacKinnon, D. P. (1994). Analysis of mediating variables in prevention and intervention research. NIDA Research Monograph, 139, 127-127.

MacKinnon, D. P. (2000). Contrasts in multiple mediator models. In J. Rose, L. Chassin, C. C. Presson, \& S. J. Sherman (Eds.), Multivariate applications in substance use research: New Methods for new questions (pp. 141-160). Mahwah, NJ: Erlbaum.

MacKinnon, D. P., Krull, J. L., \& Lockwood, C. M. (2000). Equivalence of the mediation, confounding and suppression effect. Prevention Science, 1(4), 173181.

Maimon, D., \& Browning, C. R. (2010). Unstructured socializing, collective efficacy, and violent behavior among urban youth. Criminology, 48(2), 443-474.

Margulies, R. Z., Kessler, R. C., \& Kandel, D. B. (1977). A longitudinal study of onset of drinking among high-school students. Journal of Studies on Alcohol, 38(5), 897912.

Matsuda, K. N., Melde, C., Taylor, T. J., Freng, A., \& Esbensen, F. A. (2013). Gang membership and adherence to the "code of the street." Justice Quarterly, 30(3), 440-468.

Matza, D. (1964). Delinquency and drift. New York: John Wiley and Sons. 
McBroom, J. R. (1994). Correlates of alcohol and marijuana use among junior high school students: Family, peers, school problems, and psychosocial concerns. Youth \& Society, 26(1), 54-68.

McHale, S. M., Crouter, A. C., \& Tucker, C. J. (2001). Free-time activities in middle childhood: Links with adjustment in early adolescence. Child Development, 72(6), 1764-1778.

Melde, C., \& Esbensen, F. A. (2011). Gang membership as a turning point in the life course. Criminology, 49(2), 513-552.

Meldrum, R. C., \& Clark, J. (2015). Adolescent virtual time spent socializing with peers, substance use, and delinquency. Crime \& Delinquency, 61(8), 1104-1126.

Meldrum, R. C. \& Leimberg, A. (2018). Unstructured socializing with peers and risk of substance use: Where does the risk begin? Journal of Drug Issues.

Meldrum, R. C., Young, J. T., \& Weerman, F. M. (2009). Reconsidering the effect of self-control and delinquent peers: Implications of measurement for theoretical significance. Journal of Research in Crime and Delinquency, 46(3), 353-376.

Merton, R. K. (1938). Social structure and anomie. American Sociological Review, 3(5), 672-682.

Messner, S. F., \& Tardiff, K. (1985). The social ecology of urban homicide: An application of the "routine activities" approach. Criminology, 23(2), 241-267.

Miller, J. (2013). Individual offending, routine activities, and activity settings: Revisiting the routine activity theory of general deviance. Journal of Research in Crime and Delinquency, 50(3), 390-416.

Mulvey, E. (2017). Research on Pathways to Desistance [Maricopa County, AZ and Philadelphia County, PA]: Subject Measures - Scales, 2000-2010. Ann Arbor, MI: Inter-university Consortium for Political and Social Research [distributor], Retrieved from https://doi.org/10.3886/ICPSR36800.v4

Muthén, L.K. and Muthén, B.O. (1998-2017). Mplus User’s Guide. Eighth Edition. Los Angeles, CA: Muthén \& Muthén.

Muthén, B.O. (2018, June 05). Test Indirect Effect Using Bootstrap. Message posted to http://www.statmodel.com/discussion/messages/11/3625.html?1550544811.

Muthén, L.K. (2016, May 05). Test Indirect Effect Using Bootstrap. Message posted to http://www.statmodel.com/discussion/messages/11/3625.html?1550544811. 
Osgood, D. W., \& Anderson, A. L. (2004). Unstructured socializing and rates of delinquency. Criminology, 42(3), 519-550.

Osgood, D. W., Anderson, A. L., \& Shaffer, J. N. (2005). Unstructured leisure in the after-school hours. Organized activities as contexts of development:

Extracurricular activities, after-school and community programs, 45-64.

Osgood, D. W., Wilson, J. K., O'Malley, P. M., Bachman, J. G., \& Johnston, L. D. (1996). Routine activities and individual deviant behavior. American Sociological Review, 61(4), 635-655.

Pervin, L. A. (1978). Definitions, measurements, and classifications of stimuli, situations, and environments. Human Ecology, 6(1), 71-105.

Podsakoff, P. M., MacKenzie, S. B., Lee, J. Y., \& Podsakoff, N. P. (2003). Common method biases in behavioral research: A critical review of the literature and recommended remedies. Journal of applied psychology, 88(5), 879-903.

Poulin, F., Cillessen, A. H., Hubbard, J. A., Coie, J. D., Dodge, K. A., \& Schwartz, D. (1997). Children's friends and behavioral similarity in two social contexts. Social Development, 6(2), 224-236.

Read, A. W. (1995). The New International Webster's Comprehensive Dictionary of the English Language (encyclopedia edition). Chicago: Trident Press International.

Rebellon, C. J. (2006). Do adolescents engage in delinquency to attract the social attention of peers? An extension and longitudinal test of the social reinforcement hypothesis. Journal of Research in Crime and Delinquency, 43(4), 387-411.

Reiss Jr, A. J., \& Rhodes, A. L. (1964). An empirical test of differential association theory. Journal of Research in Crime and Delinquency, 1(1), 5-18.

Reiss Jr, A. J. (1986). Co-offender influences on criminal careers. In A. Blumstein, J. Cohen, J. Roth \& C. Visher (Eds.), Criminal Careers and Career Criminals, Vol. 2. Washington, D.C.: National Academy Press.

Riley, D. (1987). Time and crime: The link between teenager lifestyle and delinquency. Journal of Quantitative Criminology, 3(4), 339-354.

Schafer, J. L., \& Graham, J. W. (2002). Missing data: our view of the state of the art. Psychological Methods, 7(2), 147-177.

Scheuerman, H. L., Grosholz, J. M., \& Thaxton, S. (2018). Reexamining the link between parental knowledge and delinquency: unpacking the influence of adolescents' and their parents' perceptions. Deviant Behavior, 1-19. 
Schlomer, G. L., Bauman, S., \& Card, N. A. (2010). Best practices for missing data management in counseling psychology. Journal of Counseling psychology, 57(1), $1-10$.

Schreiber, J. B., Nora, A., Stage, F. K., Barlow, E. A., \& King, J. (2006). Reporting structural equation modeling and confirmatory factor analysis results: A review. The Journal of Educational Research, 99(6), 323-338.

Shaw, C. R., \& McKay, H. D. (1942). Juvenile delinquency and urban areas.

Shaw, C. R. \& Myers, E. D. (1929). The juvenile delinquent. In J.H. Wigmore (Ed.), The Illinois Crime Survey. Chicago, IL: Illinois Association for Criminal Justice.

Short, J. F., \& Strodtbeck, F. L. (1965). Group process and gang delinquency Chicago: University of Chicago Press.

Shrout, P. E., \& Bolger, N. (2002). Mediation in experimental and nonexperimental studies: new procedures and recommendations. Psychological Methods, 7(4), 422-445.

Smetana, J. G., Campione-Barr, N., \& Metzger, A. (2006). Adolescent development in interpersonal and societal contexts. Annual. Review of Psychology., 57, 255-284.

Staff, J., Osgood, D. W., Schulenberg, J. E., Bachman, J. G., \& Messersmith, E. E. (2010). Explaining the relationship between employment and juvenile delinquency. Criminology, 48(4), 1101-1131.

Stattin, H., \& Kerr, M. (2000). Parental monitoring: A reinterpretation. Child Development, 71(4), 1072-1085.

Steiger, J. H. (1990). Structural model evaluation and modification: An interval estimation approach. Multivariate Behavioral Research, 25(2), 173-180.

Svensson, R., \& Oberwittler, D. (2010). It's not the time they spend, it's what they do: The interaction between delinquent friends and unstructured routine activity on delinquency: Findings from two countries. Journal of Criminal Justice, 38(5), 1006-1014.

Taylor, T. J., Peterson, D., Esbensen, F. A., \& Freng, A. (2007). Gang membership as a risk factor for adolescent violent victimization. Journal of Research in Crime and Delinquency, 44(4), 351-380.

Thorlindsson, T., \& Bernburg, J. G. (2006). Peer groups and substance use: examining the direct and interactive effect of leisure activity. Adolescence, 41, 321-339. 
Thaxton, S., \& Agnew, R. (2018). When criminal coping is likely: An examination of conditioning effects in general strain theory. Journal of Quantitative Criminology, 34(4), 887-920.

Tillyer, M. S., \& Tillyer, R. (2015). Maybe I should do this alone: A comparison of solo and co-offending robbery outcomes. Justice Quarterly, 32(6), 1064-1088.

Turanovic, J. J., \& Pratt, T. C. (2014). “Can't stop, won’t stop”: Self-control, risky lifestyles, and repeat victimization. Journal of Quantitative Criminology, 30(1), 29-56.

Urberg, K. A., Degirmencioglu, S. M., \& Tolson, J. M. (1998). Adolescent friendship selection and termination: The role of similarity. Journal of Social and Personal Relationships, 15(5), 703-710.

Vásquez, B. E., \& Zimmerman, G. M. (2014). An investigation into the empirical relationship between time with peers, friendship, and delinquency. Journal of Criminal Justice, 42(3), 244-256.

Walters, G. D. (2018). Unsupervised routine activities as a mediator of the parental knowledge-delinquency relationship. Justice Quarterly, 1-24.

Walters, G. D. (2019). Are the effects of parental control/support and peer delinquency on future offending cumulative or interactive? A multiple group analysis of 10 longitudinal studies. Journal of Criminal Justice, 60, 13-24.

Ward, J., Forney, M., \& Bennett, J. (2017, November). Investigating the Cross-Lagged Effects of Unstructured Socializing, Peer Delinquency, and Delinquency. Paper presented at the meeting of American Society of Criminology, Philadelphia, PA.

Warr, M. (2002). Companions in crime: The social aspects of criminal conduct. Cambridge University Press.

Weerman, F. M., Bernasco, W., Bruinsma, G. J., \& Pauwels, L. J. (2015). When is spending time with peers related to delinquency? The importance of where, what, and with whom. Crime \& Delinquency, 61(10), 1386-1413.

Weerman, F. M., \& Smeenk, W. H. (2005). Peer similarity in delinquency for different types of friends: A comparison using two measurement methods. Criminology, 43(2), 499-524.

Whittaker, T. A. (2012). Using the modification index and standardized expected parameter change for model modification. The Journal of Experimental Education, 80(1), 26-44. 
Wikstrom, P. \& Butterworth, D. (2006). Adolescent crime: Individual differences and lifestyles. Collumpton, U.K.: Willan.

Wilcox, S., \& Udry, J. R. (1986). Autism and accuracy in adolescent perceptions of friends' sexual attitudes and behavior. Journal of Applied Social Psychology, 16(4), 361-374.

Wolfe, S. E., \& McLean, K. (2017). Procedural injustice, risky lifestyles, and violent victimization. Crime \& Delinquency, 63(11), 1383-1409.

Wong, S. K. (2005). The effects of adolescent activities on delinquency: A differential involvement approach. Journal of Youth and Adolescence, 34(4), 321-333.

Yuan, K. H., \& Bentler, P. M. (1998). Normal theory based test statistics in structural equation modelling. British Journal of Mathematical and Statistical Psychology, 51(2), 289-309.

Young, R., \& Johnson, D. (2013). Methods for handling missing secondary respondent data. Journal of Marriage and Family, 75(1), 221-234. 


\section{APPENDICES}

Appendix A. Weighted Least Squares With Mean and Variance Adjusted Estimates of Correlations for Mediation Measurement Models

\begin{tabular}{|c|c|c|c|c|}
\hline $\begin{array}{l}\text { Model } 1 \\
\text { Property Delinquency }(\mathrm{N}=1,616)\end{array}$ & $\begin{array}{c}\text { Parental } \\
\text { Knowledge (Wave 1) }\end{array}$ & $\begin{array}{l}\text { Unstructured Socializing } \\
\text { With Peers (Wave 2) }\end{array}$ & $\begin{array}{c}\text { Peer Property } \\
\text { Delinquency (Wave 3) }\end{array}$ & $\begin{array}{c}\text { Property } \\
\text { Delinquency (Wave 4) }\end{array}$ \\
\hline Parental Knowledge (Wave 1) & $1.000 * * *$ & --- & --- & --- \\
\hline $\begin{array}{l}\text { Unstructured Socializing With Peers } \\
\text { (Wave 2) }\end{array}$ & $-0.083 * *$ & $1.000 * * *$ & $0.312 * * *$ & $0.246^{* * *}$ \\
\hline Peer Property Delinquency (Wave 3) & -0.029 & --- & $1.000 * * *$ & --- \\
\hline Property Delinquency (Wave 4) & $-0.108^{* *}$ & --- & $0.473 * * *$ & $1.000 * * *$ \\
\hline $\begin{array}{l}\text { Model } 2 \\
\text { Violent Delinquency }(\mathrm{N}=1,610)\end{array}$ & $\begin{array}{c}\text { Parental } \\
\text { Knowledge (Wave 1) }\end{array}$ & $\begin{array}{l}\text { Unstructured Socializing } \\
\text { With Peers (Wave 2) }\end{array}$ & $\begin{array}{c}\text { Peer Violent } \\
\text { Delinquency (Wave 3) }\end{array}$ & $\begin{array}{c}\text { Violent } \\
\text { Delinquency (Wave 4) }\end{array}$ \\
\hline Parental Knowledge (Wave 1) & $1.000 * * *$ & --- & --- & --- \\
\hline $\begin{array}{l}\text { Unstructured Socializing With Peers } \\
\text { (Wave 2) }\end{array}$ & $-0.095^{* * *}$ & $1.000 * * *$ & $0.320 * * *$ & $0.249 * * *$ \\
\hline Peer Violent Delinquency (Wave 3) & -0.041 & --- & $1.000 * * *$ & --- \\
\hline Violent Delinquency (Wave 4) & $-0.110^{* *}$ & --- & $0.418 * * *$ & $1.000 * * *$ \\
\hline $\begin{array}{l}\text { Model } 3 \\
\text { Substance Use }(\mathrm{N}=1,604)\end{array}$ & $\begin{array}{c}\text { Parental } \\
\text { Knowledge (Wave 1) } \\
\end{array}$ & $\begin{array}{l}\text { Unstructured Socializing } \\
\text { With Peers (Wave 2) } \\
\end{array}$ & $\begin{array}{c}\text { Peer Substance Use } \\
\text { (Wave 3) }\end{array}$ & $\begin{array}{c}\text { Substance Use } \\
\text { (Wave 4) }\end{array}$ \\
\hline Parental Knowledge (Wave 1) & $1.000 * * *$ & --- & --- & --- \\
\hline $\begin{array}{l}\text { Unstructured Socializing With Peers } \\
\text { (Wave 2) }\end{array}$ & $-0.081 * *$ & $1.000 * * *$ & $0.380 * * *$ & $0.268 * * *$ \\
\hline Peer Substance Use (Wave 3) & -0.070 & --- & $1.000 * * *$ & --- \\
\hline Substance Use (Wave 4) & -0.056 & --- & $0.548 * * *$ & $1.000 * * *$ \\
\hline
\end{tabular}

Notes: $* \mathrm{p}<.05 . * * \mathrm{p}<.01 . * * * \mathrm{p}<.001$ 
Appendix B. Weighted Least Squares With Mean and Variance Adjusted Estimates of Correlations for Reciprocal Effects Measurement Models

\begin{tabular}{|c|c|c|c|c|c|c|}
\hline $\begin{array}{l}\text { Model } 1 \\
\text { Property Delinquency } \\
(\mathrm{N}=1,671)\end{array}$ & $\begin{array}{l}\text { Unstructured } \\
\text { Socializing With } \\
\text { Peers (Wave 1) }\end{array}$ & $\begin{array}{l}\text { Unstructured } \\
\text { Socializing With } \\
\text { Peers (Wave 2) }\end{array}$ & $\begin{array}{l}\text { Unstructured } \\
\text { Socializing With } \\
\text { Peers (Wave 3) }\end{array}$ & $\begin{array}{l}\text { Property } \\
\text { Delinquency } \\
\text { (Wave 1) }\end{array}$ & $\begin{array}{l}\text { Property } \\
\text { Delinquency } \\
\text { (Wave 2) }\end{array}$ & $\begin{array}{l}\text { Property } \\
\text { Delinquency } \\
\text { (Wave 3) }\end{array}$ \\
\hline $\begin{array}{l}\text { Unstructured Socializing With } \\
\text { Peers (Wave 1) }\end{array}$ & $1.00 * * *$ & $0.434 * * *$ & --- & --- & --- & $0.102 * * *$ \\
\hline $\begin{array}{l}\text { Unstructured Socializing With } \\
\text { Peers (Wave 2) }\end{array}$ & --- & $1.00^{* * * *}$ & --- & --- & --- & $0.235^{* * *}$ \\
\hline $\begin{array}{l}\text { Unstructured Socializing With } \\
\text { Peers (Wave 3) }\end{array}$ & $0.156^{* * *}$ & $0.360 * * *$ & $1.00^{* * *}$ & --- & --- & $0.292 * * *$ \\
\hline Property Delinquency (Wave 1) & $0.135 * * *$ & $0.221 * * *$ & $0.060 * * *$ & $1.00 * * *$ & --- & $0.067 * * *$ \\
\hline Property Delinquency (Wave 2) & $0.077 * *$ & $0.163^{* * *}$ & 0.011 & $0.437 * * *$ & $1.00^{* * * *}$ & $0.074 *$ \\
\hline Property Delinquency (Wave 3) & --- & --- & --- & --- & --- & $1.00 * * *$ \\
\hline $\begin{array}{l}\text { Model } 1 \\
\text { Violent Delinquency } \\
(\mathrm{N}=1,667)\end{array}$ & $\begin{array}{l}\text { Unstructured } \\
\text { Socializing With } \\
\text { Peers (Wave 1) }\end{array}$ & $\begin{array}{l}\text { Unstructured } \\
\text { Socializing With } \\
\text { Peers (Wave 2) }\end{array}$ & $\begin{array}{l}\text { Unstructured } \\
\text { Socializing With } \\
\text { Peers (Wave 3) }\end{array}$ & $\begin{array}{l}\text { Violent } \\
\text { Delinquency } \\
\text { (Wave 1) }\end{array}$ & $\begin{array}{l}\text { Violent } \\
\text { Delinquency } \\
\text { (Wave 2) }\end{array}$ & $\begin{array}{l}\text { Violent } \\
\text { Delinquency } \\
\text { (Wave 3) }\end{array}$ \\
\hline $\begin{array}{l}\text { Unstructured Socializing With } \\
\text { Peers (Wave 1) }\end{array}$ & $1.00^{* * *}$ & --- & --- & --- & --- & --- \\
\hline $\begin{array}{l}\text { Unstructured Socializing With } \\
\text { Peers (Wave 2) }\end{array}$ & $0.435 * * *$ & $1.00 * * *$ & $0.365 * * *$ & --- & --- & --- \\
\hline $\begin{array}{l}\text { Unstructured Socializing With } \\
\text { Peers (Wave 3) }\end{array}$ & $0.158 * * *$ & --- & $1.00^{* * *}$ & --- & --- & --- \\
\hline Violent Delinquency (Wave 1) & $0.155^{* * *}$ & $0.162 * * *$ & $0.043 * * *$ & $1.00 * * *$ & --- & --- \\
\hline Violent Delinquency (Wave 2) & $0.108 * * *$ & $0.199 * * *$ & 0.018 & $0.315 * * *$ & $1.00 * * *$ & --- \\
\hline Violent Delinquency (Wave 3) & $0.115 * * *$ & $0.250 * * *$ & $0.182 * * *$ & $0.121 * * *$ & $0.322 * * *$ & $1.00 * * *$ \\
\hline $\begin{array}{l}\text { Model } 3 \\
\text { Substance Use } \\
(\mathrm{N}=1,665)\end{array}$ & $\begin{array}{l}\text { Unstructured } \\
\text { Socializing With } \\
\text { Peers (Wave 1) }\end{array}$ & $\begin{array}{l}\text { Unstructured } \\
\text { Socializing With } \\
\text { Peers (Wave 2) }\end{array}$ & $\begin{array}{l}\text { Unstructured } \\
\text { Socializing With } \\
\text { Peers (Wave 3) }\end{array}$ & $\begin{array}{l}\text { Substance } \\
\text { Use } \\
\text { (Wave 1) }\end{array}$ & $\begin{array}{l}\text { Substance } \\
\text { Use } \\
\text { (Wave 2) }\end{array}$ & $\begin{array}{l}\text { Substance } \\
\text { Use } \\
\text { (Wave 3) }\end{array}$ \\
\hline $\begin{array}{l}\text { Unstructured Socializing With } \\
\text { Peers (Wave 1) }\end{array}$ & $1.00^{* * *}$ & $0.443 * * *$ & --- & $0.208 * * *$ & --- & $0.126^{* * *}$ \\
\hline $\begin{array}{l}\text { Unstructured Socializing With } \\
\text { Peers (Wave 2) }\end{array}$ & --- & $1.00^{* * * *}$ & --- & $0.187 * * *$ & --- & $0.253^{* * *}$ \\
\hline $\begin{array}{l}\text { Unstructured Socializing With } \\
\text { Peers (Wave 3) }\end{array}$ & $0.159 * * *$ & $0.364 * * *$ & $1.00^{* * *}$ & 0.044 & -- & $0.245^{* * *}$ \\
\hline Substance Use (Wave 1) & --- & --- & --- & $1.00 * * *$ & --- & --- \\
\hline Substance Use (Wave 2) & $0.129 * * *$ & $0.202 * * *$ & 0.037 & $0.665 * * *$ & $1.00 * * *$ & $0.403 * * *$ \\
\hline Substance Use (Wave 3) & --- & --- & --- & $0.277 * * *$ & --- & $1.00 * * *$ \\
\hline
\end{tabular}

Notes: $* \mathrm{p}<.05 . * * \mathrm{p}<.01 . * * * \mathrm{p}<.001$. 
VITA

\section{ROBERT JOSEPH. LEE ARCHER}

$2007-2012$

$2012-2014$

$2015-2020$
Bachelor of Arts, Criminal Justice

Florida Atlantic University

Boca Raton, Florida

Masters of Science, Criminology and Criminal Justice Florida Atlantic University

Boca Raton, Florida

Ph.D., International Crime and Justice

Florida International University

Miami, Florida

\section{SELECTED PUBLICATIONS AND PRESENTATIONS}

Archer, Robert J. L. "Sexual assault victimization, fear of crime, and self-protective behaviors: A test of general strain theory." Victims \& Offenders, 14(4), 387-407

Meldrum, Ryan C., Jackson, Dylan B., Archer, Robert J. L. Ammons-Blanfort, Candice. (2018). "Perceived school safety, perceived neighborhood safety, and insufficient sleep among adolescents." Sleep Health: Journal of the National Sleep Foundation, 4(5), 429435.

Archer, Robert J. L. 2016. "Scared straight programs." [In] C. Schreck; M. J. Leiber, K. Welch, \& H. Ventura Miller (Eds.), Encyclopedia of Juvenile Delinquency and Justice. Wiley Blackwell: Wiley Online Library. DOI: 10.1002/9781118524275.ejdj0201

Archer, Robert J. L. 2016. “Wilderness programs.” [In] C. Schreck; M. J. Leiber, K. Welch, \& H. Ventura Miller (Eds.), Encyclopedia of Juvenile Delinquency and Justice. Wiley Blackwell: Wiley Online Library. DOI: 10.1002/9781118524275.ejdj0184

"Elaborating the Causes and Consequences of Unstructured Socializing with Peers: A Consideration of Mediating, Reciprocal, and Nonlinear Effects," presented at the annual meeting of the American Society of Criminology (Atlanta, 2018).

"Sexual Assault Victimization, Fear of Crime, and Self-Protective Behaviors: A Test of General Strain Theory," presented at the annual meeting of the American Society of Criminology (Philadelphia, 2017). 
"Examining the Relationship Between Fear of Crime, Self-Protective Behaviors, and Situational Crime Prevention among College Students," presented at the annual meeting of the Academy of Criminal Justice Sciences (Orlando, 2014). 